\title{
Effects of gender and gender role on cardiovascular reactivity and anger experience during an interpersonal interaction
}

\author{
Andria Leigh Black \\ West Virginia University
}

Follow this and additional works at: https://researchrepository.wvu.edu/etd

\section{Recommended Citation \\ Black, Andria Leigh, "Effects of gender and gender role on cardiovascular reactivity and anger experience during an interpersonal interaction" (2000). Graduate Theses, Dissertations, and Problem Reports. 692. https://researchrepository.wvu.edu/etd/692}

This Thesis is protected by copyright and/or related rights. It has been brought to you by the The Research Repository @ WVU with permission from the rights-holder(s). You are free to use this Thesis in any way that is permitted by the copyright and related rights legislation that applies to your use. For other uses you must obtain permission from the rights-holder(s) directly, unless additional rights are indicated by a Creative Commons license in the record and/ or on the work itself. This Thesis has been accepted for inclusion in WVU Graduate Theses, Dissertations, and Problem Reports collection by an authorized administrator of The Research Repository @ WVU. For more information, please contact researchrepository@mail.wvu.edu. 
Effects of Gender and Gender Role on Cardiovascular Reactivity and Anger Experience During an Interpersonal Interaction

\author{
Andria L. Black \\ Thesis Submitted to the \\ College of Arts and Sciences \\ at West Virginia University \\ in partial fulfillment of the requirements \\ for the degree of \\ Master of Arts \\ in \\ Psychology
}

Kevin T. Larkin, Ph.D., Chair

JoNell Strough, Ph.D.

B. Kent Parker, Ph.D.

Department of Psychology

Morgantown, West Virginia University

2000

Keywords: Cardiovascular Reactivity, Gender, Gender Role, Anger, Interpersonal Stress, Heart Rate, Blood Pressure

Copyright 2000 Andria L. Black 


\begin{abstract}
Effects of Gender and Gender Role on Cardiovascular Reactivity and Anger Experience

During an Interpersonal Interaction
\end{abstract}

Andria L. Black

The present study was conducted to examine gender and gender role differences in cardiovascular reactivity and anger experience during an interpersonal interaction in the laboratory. Ninety-six participants were selected to complete an interpersonal interaction in two-person dyads, with traditional masculine men paired with traditional feminine women, and androgynous men paired with androgynous women. Two aspects of the interpersonal interaction were manipulated: Agency (degree of challenge; High versus Low) and Communion (degree of agreement; Agree versus Disagree). Heart rate (HR) and systolic and diastolic blood pressure (SBP and DBP) were measured during all experimental conditions. Participants completed questionnaires assessing trait anger, state anger, and thoughts related to anger. Results indicated that traditional feminine women exhibited significantly higher HR during speaking and listening intervals than other gender/gender role groups. Higher levels of state anger were reported for individuals in Disagree conditions than for individuals in Agree conditions. Traditional masculine men reported significantly higher levels of trait anger than traditional feminine women. Men reported more angry thoughts related to victimization than women. Based on these findings, it is evident that gender role is an important construct for understanding differences in cardiovascular reactivity and experience of anger during interpersonal interactions. As cardiovascular reactivity to stress and experience of anger have been shown to be related to the development of cardiovascular disease, the implications of this work are substantial. 


\section{Acknowledgments}

I wish to thank my advisor and thesis chairperson, Kevin Larkin, for his guidance and encouragement on this project. Thank you to JoNell Strough and Kent Parker for their contributions as members of my thesis committee. Thanks also to the other members of the Larkin laboratory for their support and humor. Special thanks to Nicole Siegwarth, my undergraduate research assistant, for her dedication to this project and all her hard work. I am most grateful for the support of my parents, Edd and Kathy, and siblings, Monica and Jason. Thank you to friends in the Department of Psychology and abroad for all your kindness. Financial assistance for this project was provided by the West Virginia University Department of Psychology Alumni Fund. Thank you to Charles Speilberger, Ph.D. for allowing me to reproduce the STAXI. 


\section{Table of Contents}

Title Page

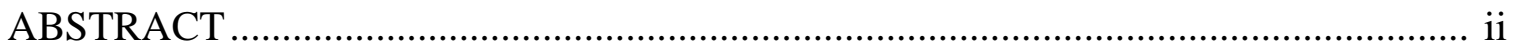

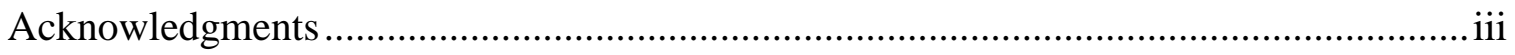

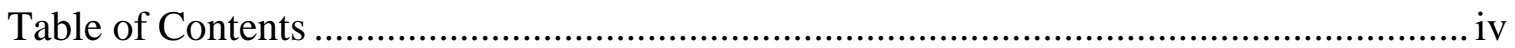

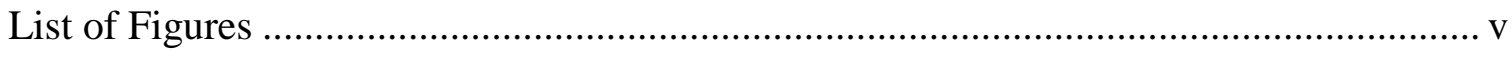

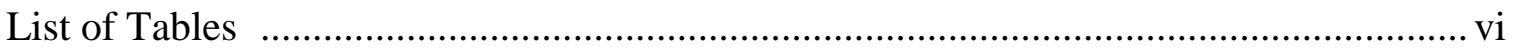

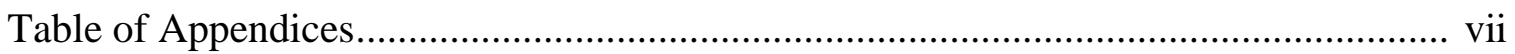

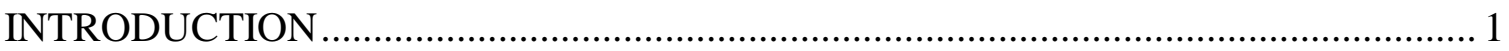

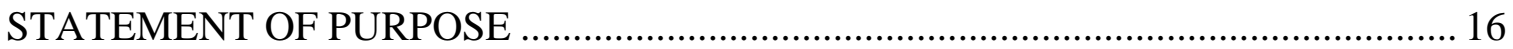

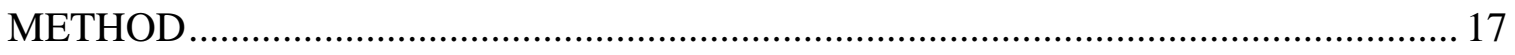

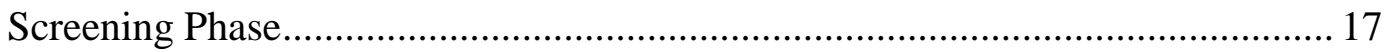

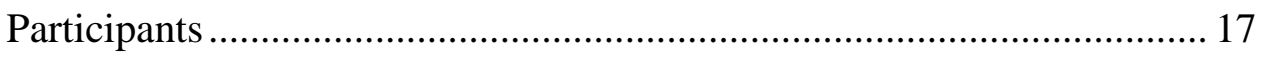

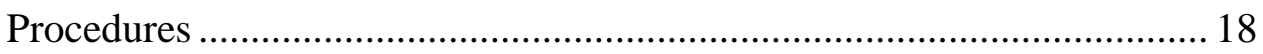

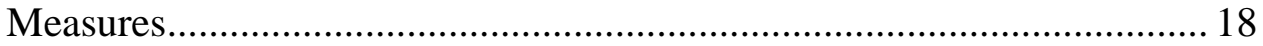

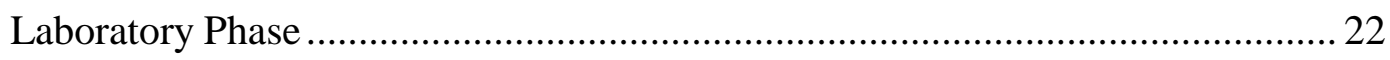

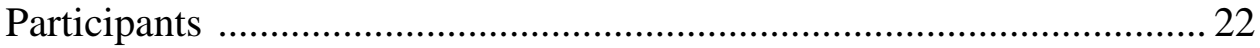

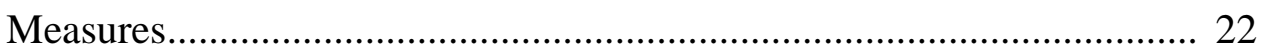

Physiological Measures and Apparatus ............................................... 29

Experimental Condition ............................................................... 30

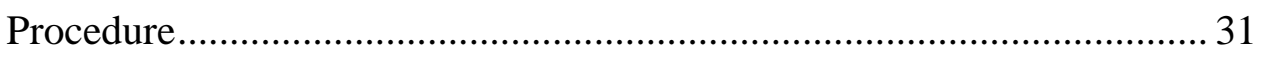

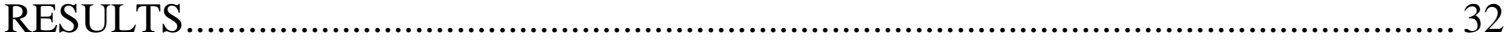

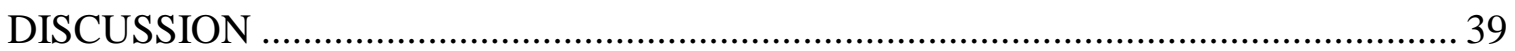

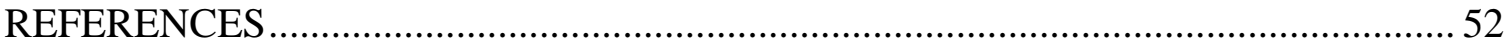

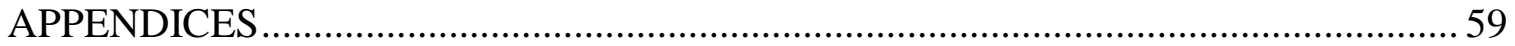




\section{List of Figures}

Figure 1. Gender X Gender Role interaction for HR during all experimental periods.

Figure 2. Gender X Agency interaction for preparation period SBP.

Figure 3. Gender Role X Agency X Communion interaction for Perceived Challenge

Figure 4. Gender X Agency X Communion interaction for Perceived Stress

Figure 5. Gender X Agency X Communion interaction for Perceived Threat

Figure 6. Gender Role X Communion for Perceived Support

Figure 7. Agency X Communion for Perceived Support 


\section{List of Tables}

Table 1. Tasks Used to Assess Gender Differences in Cardiovascular Reactivity to

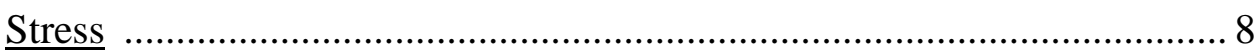

Table 2. Demographic Characteristics as a Function of Gender and Gender Role 24

Table 3. Health Behaviors as a Function of Gender and Gender Role .................. 27 
Table of Appendices

Appendix A

Demographics Questionnaire...... 59

Appendix B

Anger Cognitions Inventory .

Appendix C

Post-experimental Self-report Measure

Appendix D

Text of Instructions

64

Appendix E

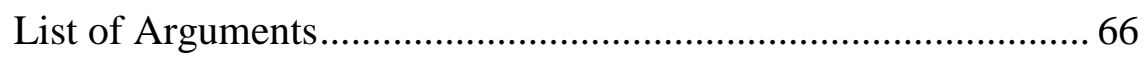

Appendix F

Statistical Analyses...

69 
There is evidence that men and women differ in their response to interpersonal stress, including behavioral measures, as well as physiological parameters, like heart rate or blood pressure (Allen, Stoney, Owens, \& Matthews, 1993; Girdler, Turner, Sherwood, \& Light, 1990; Shapiro, Goldstein, \& Jamner, 1995; Spielberger, 1988; Thomas \& Williams, 1991). Gender differences in physiological parameters have been found in many previous studies (Girdler, Turner, Sherwood, \& Light, 1990; Matthews \& Stoney, 1988; Shapiro, Goldstein, \& Jamner, 1995; Stoney, Matthews, \& Davis, 1987). There is general agreement among researchers that men exhibit greater responses in blood pressure during times of stress, and women exhibit greater responses in heart rate during stress (Allen, Stoney, Owens, \& Matthews, 1993; Stone, Dembroski, Costa, \& McDougall, 1990; Vogele, Jarvis, \& Cheeseman, 1997).

Characteristics of interpersonal interactions, such as the degree of challenge and disagreement that occurs during the interaction, have also been found to affect behavioral or physiological responses differentially depending upon the gender of participants (Smith, Gallo, Goble, Ngu, \& Stark, 1999). For instance, Smith and his colleagues found that women show a greater physiological response than men to disagreement during interpersonal interactions. In contrast, men in their study exhibited a greater physiological response to aspects of challenge inherent in the interpersonal interaction than women.

Additional research has shown that participants' gender roles influence these gender differences in behavioral measures during interpersonal interactions, such as self-report of anger experience (Kopper \& Epperson, 1991; Kogut, Langley, \& O’Neal, 1992). Although, both gender and gender role have been found to affect the experience of anger, there is evidence for a stronger relation between gender role and experience of anger. Individuals characterized as "masculine" have been shown to exhibit more intense experiences of anger than those characterized as "feminine" (Kopper \& Epperson, 1991; Kogut, Langley, \& O'Neal, 1992). The present study was conducted to examine the effects of gender and gender role on cardiovascular reactivity and anger experience during an interpersonal interaction that involved varying levels of challenge and disagreement. 


\section{$\underline{\text { Relation Between Cardiovascular Reactivity and Cardiovascular Disease }}$}

The development of pathological cardiovascular conditions, such as hypertension, atherosclerosis, acute myocardial infarction, and coronary heart disease, has been associated with pronounced cardiovascular reactivity to various stressor conditions (Manuck, 1994). Cardiovascular reactivity has been defined as individual variability in either heart rate or blood pressure that occurs in response to exposure to behavioral stimuli (Manuck, Kamarck, Kasprowicz, \& Waldstein, 1995). This reactivity cannot be predicted from variability in the same cardiovascular parameter during resting conditions when no stimulus is present. The most common index of cardiovascular reactivity is derived by computing a simple difference score between the individual's baseline cardiovascular values (recorded during an initial rest period) and the individual's cardiovascular values obtained during exposure to the behavioral stimuli. This index of cardiovascular reactivity to stress is generally thought to be a trait, much like an individual's personality characteristics. A compilation of studies examining test-retest reliabilities of cardiovascular reactivity indices have demonstrated that heart rate reactivity is the most stable parameter over time, with correlation coefficients ranging from 0.32 to 0.91 . Test-retest reliabilities for systolic blood pressure reactivity range from roughly 0.17 to 0.78 . Diastolic blood pressure represents the parameter with the weakest test-retest correlations, ranging from approximately 0.11 to 0.63 (Manuck et al., 1995). Although these reliability characteristics are not as strong as most personality measures, these authors assert that properly designed studies using multiple stressors may lend more support for the trait conceptualization of cardiovascular reactivity to stress.

The observation that cardiovascular reactivity to stress is an inherent trait that an individual displays consistently across conditions of psychological stress has important implications when considered in terms of the cardiovascular reactivity hypothesis. This hypothesis states that characteristic exaggerated cardiovascular reactivity to psychological stress is associated with increased risk for cardiovascular disease (Blascovich \& Katkin, 1993). Individuals who continually respond to psychological stress with excessive cardiovascular reactivity are then at greatly increased risk for developing cardiovascular 
disorders in comparison to low reactive counterpars. Although some investigators have conceded that cardiovascular reactivity to stress cannot yet be considered a proven risk factor for cardiovascular disease, they recognize that there is enough evidence to support continued research determining the involvement of cardiovascular reactivity to stress in the development of cardiovascular disease (Krantz \& Manuck, 1984).

Numerous studies have been conducted to examine the relation between cardiovascular reactivity to stress and cardiovascular disease. For example, in their research with cynomolgus monkeys, Manuck, Kaplan, and Clarkson (1983) found that coronary artery atherosclerotic lesions were present two times as much in heart rate reactive animals than in low-reactive animals. All animals had experienced 22 months in a stressful environment (i.e., frequent change of social constellation, introduction of a female into the all-male group, etc.) while being fed an atherogenic diet. This led the authors to conclude that environmental stressors and high blood cholesterol, coupled with high cardiovascular reactivity to stress, contributed greatly to coronary artery atherosclerosis.

Another type of research performed to study the influence of cardiovascular reactivity to stress on cardiovascular disease is the case/control study. For example, Manuck and Proietti (1982) compared the cardiovascular reactivity to stress of males with hypertensive parents to that of males without family history of hypertension during a stressful mental arithmetic task in the presence of the experimenter. Findings indicated that sons of hypertensives experienced greater cardiovascular reactivity to the stressor compared to sons of normotensive parents. These findings indicated that persons at risk for developing cardiovascular disease (in this case, hypertension) experienced greater cardiovascular reactivity to a cognitive laboratory stressor than persons at lesser risk for developing cardiovascular disease.

Case control studies have also contrasted patients with and without heart disease and have found similar results (Corse, Manuck, Cantwell, Giordani, \& Matthews, 1982). In this study, patients with and without coronary heart disease were administered two measures of Type A behavior pattern and participated in a series of frustrating cognitive tasks while measures of heart rate and blood pressure were obtained. Regardless of whether individuals 
were labeled Type A, patients with coronary heart disease exhibited significant increases in diastolic blood pressure in response to the tasks over their non-patient counterparts. Investigators concluded that cardiovascular reactivity to stress was a possible mediator between Type A behavior and development of cardiovascular disease (Corse et al., 1982).

Manuck, Morrison, Bellack, and Polefrone (1985) cited a number of studies that have compared the cardiovascular reactivity to stress of normotensives to that of hypertensives. These studies have found that hypertensives generally exhibit greater reactivity than normotensives to a wide variety of stressors, including interviews encompassing personal conflict, demanding cognitive tasks, in preparation for aversive stimulation, and during experimentally-induced emotions of fear and anger (Manuck et al., 1985).

Several prospective studies have been conducted to determine the relation between cardiovascular reactivity to stress and development of cardiovascular disease (Barnett, Spence, Manuck, \& Jennings, 1997; Kasagi, Akahoshi, \& Shimaoka, 1995; Manolio, Burke, Savage, Sidney, Gardin, \& Oberman, 1994; Matthews, Pate, Jackson, Ward, Macera, Kohl, \& Blair, 1998; Wood, Sheldon, Sheps, Elveback, \& Schirger, 1984). Several of these studies have examined cardiovascular reactivity to cold pressor tests as a predictor of hypertension. For example, Kasagi and colleagues (1995) found a relation between blood pressure reactivity to a cold stimulus and subsequent development of hypertension. During a 28-year follow-up period, and while controlling for several confounding variables (e.g., age, body mass index at entry, resting blood pressure), systolic blood pressure during a cold pressor test was found to be a significant predictor of subsequent hypertension (Kasagi et al., 1995).

Cardiovascular reactivity to exercise has also been studied in relation to development of a major risk factor for cardiovascular disease, essential hypertension. For example, Manolio and coworkers (1994) determined that risk of elevated blood pressure was higher at a 5-year follow-up for individuals who demonstrated hyperreactivity to an exercise stressor at entry into the study than low-reactive counterparts. Participants were 3,741 normotensive black and white young adults who underwent a treadmill test during the course of a larger longitudinal study. Findings indicated that individuals who had experienced exaggerated systolic blood pressure during exercise were more likely to have developed hypertension five 
years later than participants with average cardiovascular responses to exercise. This finding was upheld when analyses controlled for sex, race, age, and resting blood pressure (Manolio et al., 1994).

Finally, psychological stress has been prospectively linked to the development of cardiovascular disease through cardiovascular reactivity (Barnett et al., 1997). Carotid artery disease was found to progress over a 2-year period in individuals with smaller heart rate reactions to mental stress (Stroop color-word task) but larger systolic blood pressure changes to the same stressor. These results lend support to the hypothesis that cardiovascular reactivity to stress, particularly blood pressure change, is linked to the progression of cardiovascular disease in the carotid artery.

In sum, the link between cardiovascular reactivity to stress and cardiovascular disease has been studied using numerous experimental strategies. Across these research domains, exaggerated cardiovascular reactivity to stress has been widely shown to be related to the onset and development of cardiovascular disease.

Relation Between Experience of Anger and Cardiovascular Disease

In addition to the relation between cardiovascular reactivity to stress and cardiovascular disease, affective experience has been linked with the development of cardiovascular disorders. Specifically, the experience of anger has been shown to be related to cardiovascular disease (Contrada, 1994; Dembroski, MacDougall, \& Lushene, 1979; Johnson, 1990; Manuck \& Proietti, 1982; Matthews, 1982; Siegel, 1984, 1985; Shapiro, 1996). One pathway through which anger has been related to cardiovascular disease is through what is termed the Type A behavior pattern (Siegel, 1985). This behavior pattern is evidenced by the individual's chronic sense of time urgency, readily expressed anger and hostility, and a competitive nature. Other characteristics that have been associated with the Type A behavior pattern include aggression, impatience, and achievement-orientation (Kaplan \& Saddock, 1998). Importantly, Type A behavior pattern is more than simply one trait; it is a constellation of overt behaviors that are exhibited exclusively during instances of stress, challenge, or threat. Individuals who exhibit behaviors related to the Type A behavior pattern have also been shown to be at greater risk of developing coronary heart disease and 
have a higher propensity for having fatal myocardial infarctions than Type B counterparts (Siegel, 1985). Type A behavior has been associated with essential hypertension and coronary artery disease as well (Kaplan \& Saddock, 1998).

Because anger is an integral component of the Type A behavior pattern, its effect on cardiovascular disease has been studied in numerous investigations. For instance, Type A individuals have been found to differ from Type B individuals on a number of characteristics. With respect to cardiovascular reactivity to stress, Type A persons did not differ from Type B persons during resting baseline conditions; however, during conditions of stress, Type As demonstrated significantly larger blood pressure increases than Type Bs (Matthews, 1982). This finding supports the hypothesis that both anger and cardiovascular reactivity to stress may jointly be associated with increased risk for cardiovascular disease.

In a study of cardiac cases and controls, Dembroski, MacDougall, and Lushene (1979) found that patients with cardiovascular disorders were more likely than controls to be classified as expressing the Type A behavior pattern using a structured interview. In Manuck's and Proietti's (1982) previously described study of the differences in cardiovascular reactivity between the sons of hypertensive parents and the sons of normotensive parents, experience of state anger was also examined. Findings indicated that sons of hypertensives who exhibited high levels of state anger differed in cardiovascular reactivity to mental stress from sons of normotensives who exhibited similarly high levels of state anger. This finding was not determined for participants reporting low levels of state anger, indicating that cardiovascular reactivity to stress was a function of the interaction between parental history of cardiovascular disease and anger experience (Manuck \& Proietti, 1982).

Findings regarding the experience of anger have not always been consistent. For example, in another study, the offspring of hypertensive parents reported lower anger experience, but exhibited increased systolic blood pressure reactions to stress in comparison with children of normotensives (Lawler, Kline, Seabrook, Krishnamoorthy, Anderson, Wilcox, Craig, Adlin, \& Thomas, 1998). 
Other studies have provided evidence that anger is linked to cardiovascular disease independent of the Type A behavior pattern. Representative research by Siegel (1984) provides evidence that anger is related to a number of physical and psychological risk factors for coronary heart disease (e.g., smoking, lack of exercise, anxiety, and accumulation of life events). In a study of adolescents, it was determined that those most at risk for cardiovascular disease acknowledged experiencing more anger on self-report measures, and also endorsed more behaviors linked to cardiovascular disease (Siegel, 1984). Additionally, in a longitudinal study of 200 healthy post-menopausal women, high trait anger at entry was associated with greater carotid atherosclerosis ten years later (Matthews, Owens, Kuller, Sutton-Tyrrell, \& Jansen-McWilliams, 1998).

Similar to the relation between cardiovascular reactivity to stress and cardiovascular disease, the relation between experience of anger and cardiovascular disease has been studied using several experimental approaches. These studies generally concur that, among all emotions, the experience of anger is most closely linked to the development of cardiovascular disease.

\section{Gender Differences in Cardiovascular Reactivity}

Differences in cardiovascular reactivity to a variety of stressors have been observed between men and women (see Table 1). Men have typically been shown to react with larger increases in systolic blood pressure than women, whereas women have been shown to exhibit more pronounced increases in heart rate than men (Allen, Stoney, Owens, \& Matthews, 1993; Girdler, Turner, Sherwood, \& Light, 1990; Matthews \& Stoney, 1988; Stoney, Davis, \& Matthews, 1987; Shapiro, Goldstein, \& Jamner, 1995; Stone, Dembroski, Costa, \& McDougall, 1990). Several studies have found a relation between male gender and patterns of increased cardiovascular reactivity in various stressor conditions (e.g., cold pressor, isometric hand grip, math task). In these studies, men responded with greater cardiovascular reactivity to stress than women, particularly for blood pressure responses (Shapiro, Goldstein, \& Jamner, 1995).

Stoney, Davis, and Matthews (1987) reported that a number of studies have found gender differences in cardiovascular reactivity during baseline resting conditions and during 
completion of stressful tasks. Specifically, women generally exhibit higher resting heart rate and greater heart rate reactivity to stress than do men. Men generally exhibit higher resting systolic blood pressure and greater systolic blood pressure reactivity to stress than do women. Soon after this meta-analysis, Matthews and Stoney (1988) reported that men exhibited greater systolic and diastolic blood pressures than women during a variety of stressors in one investigation with children and adults.

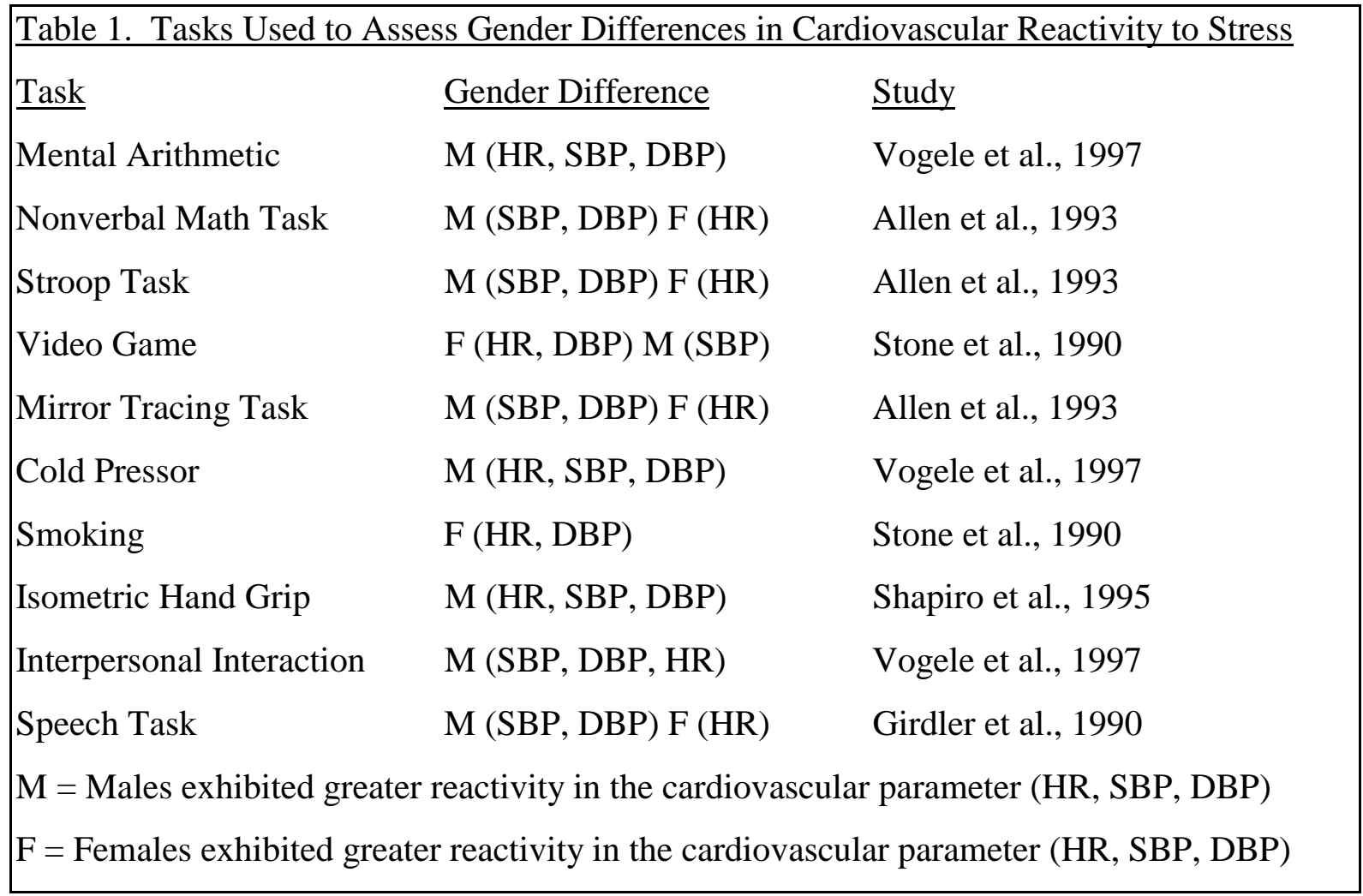

A recent study examined gender differences in cardiovascular reactivity during a number of stressful tasks, including a mental arithmetic task, an interpersonal challenge, a frustrating psychomotor task, and a cold pressor test (Vogele, Jarvis, \& Cheeseman, 1997). Findings coincided with those of the previous literature in that men exhibited higher cardiovascular reactivity to stress than women throughout task presentations. Further, additional variables assessed in this study were found to affect male and female cardiovascular reactivity to stress differentially. Specifically, hypertension risk and anger 
suppression were the strongest predictors of cardiovascular reactivity for men, whereas no differences in health status or anger experience were found to predict cardiovascular reactivity to stress in women (Vogele et al., 1997).

\section{Gender Role Differences in Cardiovascular Reactivity}

Eisler (1998) suggested that gender role socialization may also play a role in differential cardiovascular reactivity to stress observed between men and women. Masculine gender role stress has been defined as perceived threat to masculinity, and has been linked to dysfunctional health consequences for men (Eisler, 1998). One study (Lash, Eisler, \& Schulman, 1990) found that males who scored high on a measure of masculine gender role stress responded with greater cardiovascular reactivity than men who scored low on this measure during several task conditions. Task conditions perceived as threatening to masculinity, particularly those that involved competition or challenge, resulted in increased cardiovascular reactivity, but only among men with high masculine gender role stress. Differences in cardiovascular reactivity between low and high masculine-gender role stress participants were attributed to how individuals appraised situations as stressful. Tasks that were appraised to threaten an individual's gender role were proposed to be more stressful for that individual, and to elicit greater cardiovascular reactivity than non-threatening tasks. This was purportedly due to the individual's perception that he or she was "supposed" to perform better at these particular tasks. The authors concluded that high masculine gender role stress participants, in contrast to their low masculine gender role stress counterparts, exhibited increased cardiovascular reactivity because they appraised experimental tasks as inherently masculine, and thus, more stressful (Eisler, 1998; Lash, Eisler, \& Schulman, 1990; Lash, Gillespie, Eisler, \& Southard, 1991).

In contrast to the work of Eisler and colleagues, Davis and Matthews (1996) reported results from a study of the influences of gender and gender role on gender-oriented task performance. Participant self-ratings on gender-linked characteristics were derived in this case using the Personality Attributes Questionnaire (PAQ; Spence, Helmreich, \& Stapp, 1975). Individuals were labeled Expressive (expressing more feminine-linked traits) or Instrumental (expressing more masculine-linked traits) based on their endorsement of items 
on the two subscales of this measure. In response to speaking tasks that required either persuasion (masculine-oriented) or empathy/understanding (feminine-oriented) on the part of the participant, both gender and gender role differences were found to influence cardiovascular reactivity to the tasks. Contrary to the initial hypotheses of this study and the findings of previous research, Expressive individuals tended to experience greater cardiovascular reactivity during the masculine-oriented task, whereas Instrumental individuals exhibited greater cardiovascular reactivity during the feminine-oriented task. This finding contradicts the belief that a match between gender role orientation of the experimental condition and gender role of the participant necessarily elicited greater physiological responding. Rather, a mismatch between task condition and gender role elicited greater increases in cardiovascular reactivity to stress. Additionally, the findings of this study supported the hypothesis that gender role was a stronger influence than gender of the individual upon the magnitude of cardiovascular reactivity to stress, as no significant differences in cardiovascular response were found between males and females.

Although research on the relation between gender, gender role, and cardiovascular reactivity to stress has at times resulted in conflicting findings, it seems that the majority of investigations have found gender role to elucidate the observed gender differences in cardiovascular response to stress. Additionally, the importance of considering the match or mismatch between experimental conditions and gender role has been affirmed. Whether gender or gender role should be regarded as the primary factor determining observed differences in cardiovascular reactivity to stress is an important consideration for future research and a specific aim of the proposed study.

\section{Gender Differences in Experience of Anger}

Several tasks have been used to assess the experience of anger in laboratory settings. These have included, an anger recall interview (Lawler et al., 1998), interpersonal interactions like discussions and debates (Brown \& Smith, 1992; Newton, Bane, Flores, \& Greenfield, 1999; Rejeski, Gagne, Parker, \& Koritnich, 1989; Smith, Gallo, Goble, Ngu, \& Stark, 1998), and independent tasks completed under frustrating conditions (Thomas \& Williams, 1991). Deffenbacher (1992) highlights the importance of assessing anger through 
multiple methods including interviews, roleplays, self-monitoring, and imagery recall. Studies of gender differences in anger have tended to focus on anger expression, although several valuable investigations of anger experience have been conducted as well. One such study examined self-report of anger experience in men and women, and found no significant gender differences in trait or state anger (Bartz, Blume, \& Rose, 1996). Another study by Averill (1983) found no significant differences in male and female participants' self-reports of anger episodes. Men and women in this college student sample were similar regarding variables surrounding perceived experience of anger (e.g., intensity, frequency, and causes of anger).

Thomas and Williams (1991) compared 218 male college students and 502 female college students on measures of trait anger (propensity to experience anger), anger expression, discussion of anger, and somatic experience of anger during a stressful task. Although significant differences were not found for men and women in terms of trait anger or anger expression, women scored significantly higher on measures of anger discussion and the somatic experience of anger (Thomas \& Williams, 1991).

Spielberger (1988) has provided separate norm tables for males and females for the State-Trait Anger Expression Inventory (STAXI), which includes several scales and subscales assessing anger experience (e.g., trait anger scale, anger temperament subscale, anger reaction subscale, and state anger scale). The author reported minimal gender differences in the normative sample, except for a portion of the sample enrolled as first year military cadets. In this group, men reported significantly higher levels of state anger than women. A portion of the normative sample comparable in age and gender distribution to the military cadet group, a college student group, exhibited essentially no differences in stateanger between men and women. Nonetheless, separate norm tables for men and women have been provided for this widely used measure of anger experience (Spielberger, 1988).

In sum, previous studies have found few significant differences in self-reported experience of anger between men and women. Specific populations of men and women may present with differences in state anger, an element of anger experience that investigators have attempted to account for in devising assessment instruments. 


\section{Gender Role Differences in Experience of Anger}

In one study, experience of anger was shown to vary as a function of gender role rather than gender for both male and female participants. Female $(\mathrm{N}=242)$ and male $(\mathrm{N}=$ 213) college students were asked to complete the T-Anger subscale (a measure of anger temperament) of the Trait Anger Scale (TAS; Spielberger, 1980), the Bem Sex Role Inventory - Short Form (a measure of gender role), and several other measures. Significant differences in trait anger were found for gender role, but not for gender. Individuals with masculine gender roles reported more trait anger (disposition or proneness to experience anger) than individuals with feminine or androgynous gender roles. Individuals with androgynous gender roles exhibited a pattern of what was thought to be "healthy" anger management, including less perception of situations as anger-provoking and greater likelihood of controlling their experience of anger (Kopper \& Epperson, 1991).

Another study by Kogut, Langley, and O’Neal (1992) examined gender role masculinity in women. Participants first completed the Personality Attributes Questionnaire (PAQ; Spence, Helmreich, \& Stapp, 1975). Based on their responses to this measure, participants were then divided using a median split into high-masculine and low-masculine groups. All participants were then provided with either ambiguous information regarding a placebo pill given them, or told that the pill was either a vitamin or a stimulant. Half of the participants were provoked and half were not before allowing participants an opportunity to retaliate. Only after receiving ambiguous information about the pill's effects and having been provoked were high-masculine women found to behave more aggressively in retaliation than low-masculine women. Although high-masculine and low-masculine women in this condition differed behaviorally and in self-report of arousal-related sensations, they did not differ in self-reported experience of anger (Kogut et al., 1992).

Research has resulted in mixed findings concerning the influence of gender and gender role on the experience of anger. However, more evidence exists for a stronger relation between gender role and anger experience than between gender and anger experience. 


\section{Task Influences on Cardiovascular Reactivity}

Various tasks have been used to elicit cardiovascular reactivity and anger in experimental settings. Krantz, Manuck, and Wing (1986) identified three major categories of tasks researchers have used to study these variables: mental challenge, passive participation tasks, and interpersonal interactions. Mental challenge stressors consist of tasks such as mental arithmetic (serial subtraction), reaction time tests (shock avoidance), and cognitive problems (the Stroop color-word task). Passive participation stressors include the cold pressor task and viewing stressful films. Interpersonal stressors have included the structured interview (SI) to assess Type A behavior pattern, public speaking exercises, and games involving cooperation or competition. The latter group of stressors has been identified as particularly useful because interpersonal situations most reflect real-life situations, and responses elicited under such circumstances would be presumably most generalizable to responses elicited from conditions outside the laboratory (Krantz, Manuck, \& Wing, 1986).

Although several schemes exist for classifying laboratory stressors, the most widely recognized distinctions are "active coping" versus "passive coping" (Light \& Obrist, 1980; Obrist, 1981), "sensory intake" versus "mental work" (Lacey, Kagan, \& Lacey, 1963), tasks varying in emotional quality (Ekman, Levenson, \& Friesen, 1983), and tasks varying in controllability (Seligman, 1975). Characteristic cardiovascular response patterns have been reported for each type of the aforementioned task distinctions. Stressors that elicit increased sympathetic nervous system responding, which in turn affects increases in heart rate and systolic blood pressure responding, tend to involve attending to the environment, cognitive integration of external stimuli, and active behavioral responding to accomplish a controllable task. Stressors that elicit decreased heart rate and systolic blood pressure (but increases in diastolic blood pressure) require more passive exposure to an aversive stimuli, sensory intake tasks, or tasks that are generally perceived by participants as being uncontrollable.

In addition to the task influences above, literature from social psychophysiological research suggests that cardiovascular reactivity to stress also is influenced by the interpersonal nature of the task. Interpersonal interactions between participants and confederates have often demonstrated interesting findings. For example, gender differences 
have been observed in a series of studies involving a debate with a female confederate as the primary experimental task (Rejeski, Gagne, Parker, \& Koritnich, 1989; Rejeski, Parker, Gagne, \& Koritnich, 1990). Men exposed to debate conditions tended to respond with increased cardiovascular reactivity only when they reported lower levels of trait dominance. Women in the same condition, in contrast, experienced greater cardiovascular reactivity increases when they reported higher levels of trait dominance. These findings attest to not only the importance of assessing gender-linked characteristics of the participant, but also the nature of the interpersonal task conditions employed when measuring cardiovascular reactivity.

In a recent investigation, Newton, Bane, Flores, and Greenfield (1999) studied the relation between cardiovascular reactivity and gender during dyadic discussions. Men experienced greater increases in systolic blood pressure than women throughout the experiment, and women reacted with greater increases heart rate than men in all conditions. In addition to the observed gender differences, gender attributes played a significant role in magnitude of cardiovascular reactivity to stress. For women, high trait dominance was associated with less change in systolic blood pressure, whereas low trait dominance was related to greater change in systolic blood pressure. Men with high trait dominance experienced significantly greater systolic blood pressure changes than men with low trait dominance. The authors proposed that these differences in cardiovascular reactivity were the result of interpersonal dynamics functioning in mixed-gender dyads, whereby traditional gender role norms were activated, influencing the suppression of dominance in women (and decreases in blood pressure) and the exertion of dominance in men (and subsequent increases in blood pressure) (Newton et al., 1999).

Brown and Smith (1992) examined cardiovascular reactivity and anger experience in response to an interpersonal task between married couples. Husbands asked to persuade their wives during the interaction exhibited greater increases in systolic blood pressure and reported greater anger than husbands asked to simply discuss a problem with their wives. Wives in persuasion or discussion conditions did not differ with respect to systolic blood pressure or anger experience (Brown \& Smith, 1992). These findings demonstrated that, for 
men, competitive interpersonal situations (situations in which they are expected to persuade or influence another person) elicited greater cardiovascular reactivity and experience of anger than neutral interpersonal situations. For women, levels of cardiovascular reactivity and anger experience did not differ with respect to the competitive nature of the interaction.

Another study of interactions in married couples reported that cardiovascular reactivity differed for men and women depending on the type of interpersonal task condition employed (Smith, Gallo, Goble, Ngu, \& Stark, 1998). A four-minute preparation period followed by an eight-minute discussion task was the basis for interpersonal interactions. Husband and wife pairs were randomly assigned to agree or disagree on two topics (imposition of rent controls in the Salt Lake City area and the adoption of stricter admission standards at the University of Utah). Each person was provided with reasons and arguments for their particular position. Two aspects of the interpersonal interaction were manipulated. Namely, conditions were either labeled as high or low achievement challenge (levels of "agency"), and required participants either to agree or disagree (levels of "communion"). This methodology was based on the premise that men would react with greater cardiovascular reactivity than women when the interpersonal condition required performance of an "agency" task (a task encompassing achievement, mastery, status, and power). The authors hypothesized that women would react with greater cardiovascular reactivity than men when the task presented was based on "communion" (a task involving interpersonal relatedness, caring, friendship, and love). In correspondence with the hypotheses of this experiment, men reacted with greater cardiovascular reactivity than women during the achievement challenge condition in which they were in direct competition with their spouses, whereas women experienced greater cardiovascular reactivity than men to a disagreement enacted with their husbands. Specifically, men exhibited significantly greater increases in systolic blood pressure and heart rate during high challenge conditions than during low challenge conditions, with no significant differences in either physiological measure with respect to the level of agreement. Women experienced significantly greater increases in systolic blood pressure and heart rate during disagreement discussions than during agreement discussions, with no significant differences in either physiological measure with respect to the level of 
challenge. These findings implicated a gender-oriented style of physiological responding related to the degree of challenge and perceived discord intrinsic to the interpersonal situation. For women, the level of communion was the determining factor in eliciting cardiovascular reactivity, whereas men responded to the level of agency inherent to the interaction. Although this study provided additional information regarding gender differences in cardiovascular responding during specific types of interpersonal tasks, it did not address the effect of gender role on cardiovascular or emotional response to the discussion task.

\section{$\underline{\text { Statement of Purpose }}$}

Previous research has examined gender differences in cardiovascular responding and experience of anger in various stressful conditions. Few studies have examined the interaction of gender roles and gender in producing differential affective and cardiovascular responses to these stressors. Further, the literature investigating these variables during interpersonal interactions is limited. The purpose of this study was to examine the independent and interactive effects of gender role, gender, and the context of interpersonal interaction on cardiovascular and affective reactivity to stress.

This study examined gender and gender role as determinants of cardiovascular responding and experience of anger during an interpersonal interaction. Comparable to the study by Smith and his colleagues (1998), interactions varied on two dimensions: (a) instructions to participants specifying their dyad as a high challenge or low challenge condition (i.e., agency), and (b) instructions specifying agreement or disagreement between participants (i.e., communion). It was hypothesized that variation in cardiovascular reactivity to the interaction would result as a function of a match between the participant's gender, gender role, and the context of the interpersonal interaction. Specifically, it was hypothesized that men would experience greater increases in systolic blood pressure during high-challenge interpersonal interaction conditions in contrast to women. In these high-challenge conditions, it was hypothesized that men with androgynous gender roles would have lower systolic blood pressure during the interaction than men with traditional gender roles. It was further hypothesized that women would experience greater increases in heart rate during 
interpersonal interaction conditions that involved disagreement between participants. It was hypothesized that women with androgynous gender roles would have lower heart rate responses than women with traditional gender roles.

A second hypothesis was made regarding the experience of anger as a function of gender role. Although previous research has shown no differences in anger experience between men and women, gender role has been found to predict anger experience. It was hypothesized that individuals with traditional masculine gender roles would experience more anger in all conditions than individuals with traditional feminine and androgynous gender roles. Individuals with androgynous gender roles were expected to exhibit the lowest anger experience of any group. It was hypothesized that men and women would be similar in anger experience (that there would be no significant differences in anger experience between men and women). Hypotheses for cardiovascular reactivity and anger experience differed because previous research has demonstrated that gender affects cardiovascular reactivity more so than gender role, whereas gender role affects anger experience more so than gender. Thus, the present hypotheses indicate that cardiovascular reactivity and anger experience have been found to be independent responses, which may be affected differentially by gender and gender role. Because the purpose of this study was to examine the differential effects of gender and gender role, the individual was used as the unit of statistical analysis rather than the dyad. Previous investigations of dyadic interactions (Leaper, 1991; Leaper, Tenenbaum, \& Shaffer, 1999) have relied upon statistical analyses of dyads to effectively evaluate the dependency of dyad partners' scores. This method of analysis was not undertaken in the present study as it was of more interest to determine whether gender and gender role independently affected the variables of interest.

\section{Method}

\section{$\underline{\text { Screening Phase }}$}

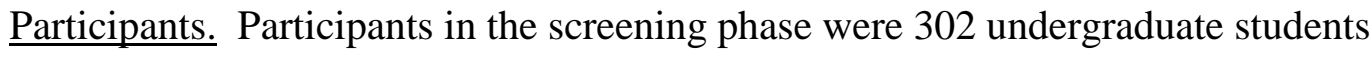
enrolled in entry-level psychology courses at West Virginia University. Each student received extra credit points in his or her psychology class for completing a packet of screening questionnaires. 
Procedure. After giving informed consent, participants were asked to complete four assessment instruments: the Bem Sex-Role Inventory (Bem, 1974), the Trait Anger Scale (Spielberger, 1988), the Anger Expression Scale (AX; Spielberger, 1988), and a demographic questionnaire. Participants were asked to indicate their willingness to participate in the second phase of the study.

Measures.

Demographic questionnaire. This instrument elicited information regarding the participant's age, sex, race, marital status, educational background, medical history, current medications, parental history of cardiovascular disease, exercise habits, and tobacco use (see Appendix A). Participants reporting medical conditions or use of prescription drugs that might interfere with physiological recording were not invited to participate in the laboratory phase of the study.

Bem Sex-Role Inventory. This instrument was designed by Bem (1974) to measure gender role based on the extent to which an individual endorses mostly masculine, mostly feminine, or both masculine and feminine characteristics. The measure was constructed by compiling a list of roughly 200 personality characteristics that were either masculine or feminine in quality. A sample of undergraduate students at a California university then rated each trait according to a 7-point scale as either desirable or undesirable for a man or a woman in American society. From this sample data, 20 items were selected for the Masculinity scale and 20 items were selected for the Femininity scale. Twenty additional items, 10 positive and 10 negative, formed a Neutral, Social Desirability scale.

In 1973, a normative sample of 561 male and 356 female undergraduates was employed to determine the psychometric characteristics of the Bem Sex Role Inventory. Data from this sample reflected adequate internal consistency, with coefficient alphas of .86 for the Masculinity scale and .82 for the Femininity scale. The Androgyny scale, as determined by the difference between Femininity and Masculinity scales, produced a coefficient alpha of .86. The test-retest reliability for the Bem Sex Role Inventory over a four-week period is reportedly good, with correlations of .90 for both Masculinity and Femininity scores, and a correlation of .93 for the Androgyny scores. Correlations between the Masculinity and 
Femininity scales were appropriately low, ranging from $r=.02$ to $r=.14$. This reflects one of the primary strengths of the Bem Sex Role Inventory as an instrument useful in determining gender role without forcing a dichotomy between masculinity and femininity. Masculinity, thus, reflects an endorsement of masculine characteristics, and Femininity reflects an endorsement of feminine characteristics. Androgyny is indicated when both feminine and masculine characteristics are endorsed to a high degree. Convergent validity has been determined by the correlation of the Bem Sex Role Inventory with two other gender role measures. Comparison of the Bem Sex Role Inventory with the California Psychological Inventory and Guilford-Zimmerman Temperament Survey resulted in correlations ranging from $r=.04$ to $r=.50$. Bem (1974) recognized that these other assessment instruments might be measuring different aspects of gender roles than those tapped by the Bem Sex Role Inventory.

Several additional studies have examined the construct validity of the Bem Sex Role Inventory (Carlsson \& Magnusson, 1980; Sassenrath \& Yonge, 1979; Swim, 1994). Findings have been generally supportive of the ability of the Bem Sex Role Inventory to measure femininity and masculinity. Sassenrath and Yonge (1979) found evidence of six factors that accounted for $51 \%$ of the variance in both the masculinity and femininity scales. Multiple correlation coefficients indicated that ample internal validity existed for both the Masculine scale, $\mathrm{R}=.75$, and the Feminine scale, $\mathrm{R}=.86$. Additionally, the total sample coefficient alpha was .96 for masculinity and .88 for femininity. Carlsson and Magnusson (1980) reported acceptable construct validity findings for the Bem Sex Role Inventory in a sample of Swedish men and women from different professions. These authors concluded that the Femininity and Masculinity scales reflected separate individual dimensions, as correlations between the two scales were quite low, ranging from $r=-.15$ to $r=.17$. This study illustrated the ability of the Bem Sex Role Inventory to detect masculinity and femininity as separate entities. In a more recent investigation of self-report of gender roles, Swim (1994) found that participants tended to underestimate gender role differences. This finding contradicted previous claims that individuals based their self-reports on gender stereotypes and therefore tended to overestimate gender role differences. In light of this evidence, it was anticipated 
that participants in the present study accurately reported their gender role characteristics without relying exclusively on gender role stereotypes.

In the present study, participants were asked to rate themselves on each of the 20 feminine, 20 masculine, and 20 neutral items using a 7-point scale. Scores on Masculinity and Femininity scales were then calculated by averaging the ratings for items on each scale. Androgyny scores were derived by obtaining a simple difference score between the Masculinity and Femininity scales. According to criteria established by Bem (1974) this difference score was multiplied by 2.322 to derive an Androgyny score for each participant. Using the Androgyny score, each participant was classified into one of eight categories: Traditional masculine men, traditional feminine women, androgynous men, androgynous women, masculine women, feminine men, undifferentiated men, and undifferentiated women. As specified by Bem's (1974) criteria, traditional men and women obtained a score of 2.0 or greater on the Androgyny scale, with traditional masculine men scoring higher on the masculinity scale and traditional feminine women scoring higher on the femininity scale. Androgynous men and women obtained a score of 1.0 or less on the Androgyny scale. Masculine women had Androgyny scores above 2.0 but scored higher on the masculinity scale than on the femininity scale. Feminine men had Androgyny scores above 2.0 but scored higher on the femininity scale than on the masculinity scale. Undifferentiated men and women had Androgyny scores that fell between 1.0 and 2.0. Masculine women, feminine men, and undifferentiated men and women were not contacted to participate in the laboratory phase of this study.

Trait Anger Scale. The Trait Anger Scale (TAS; Spielberger, 1988) is a 10-item Likert-type questionnaire designed to assess individual differences in frequency and intensity of the experience of anger. The Trait Anger Scale is concerned with measuring the anger proneness of an individual. Two subscales comprise the Trait Anger Scale: TraitAnger/Temperament (disposition toward anger without provocation), and TraitAnger/Reaction (disposition toward anger in frustrating or negatively evaluative situations). Test-retest reliabilities for the Trait Anger Scale range from .70 for males to .77 for females in a college sample (Speilberger \& Sydeman, 1994). The Trait Anger Scale is a reliable 
measure in discriminating individuals with high trait anger from individuals with low trait anger (Deffenbacher, Oetting, Thwaites, Lynch, Baker, Stark, Thacker, \& Eiswerth-Cox, 1996). The measure exhibits internal consistency reliabilities ranging from .81 to .91 (Spielberger, 1988). Several studies have indicated general support for the concept of trait anger, and have tested a number of hypotheses regarding the relation of Trait Anger Scale scores to physiological and cognitive responses in various situations (Deffenbacher et al., 1996). For instance, Trait Anger Scale scores are correlated with frequency of anger experienced in the preceding month $(\mathrm{r}=.56)$ for men and $(\mathrm{r}=.48)$ for women (Deffenbacher et al., 1996). Finally, the Trait Anger Scale shows adequate convergent validity, demonstrating significant correlations with the Symptom Checklist-90 (SCL-90; Derogatis, 1977), ranging from .17 to .55 for specific disorders. The Trait Anger Scale is correlated .33 with the Beck Depression Inventory (BDI; Beck, Steer, \& Brown, 1987), reflecting adequate discriminant validity (Deffenbacher et al., 1996). The Trait Anger Scale was initially combined with the State Anger Scale to form the State-Trait Anger Scale (STAS; Spielberger, Jacobs, Russell, \& Crane, 1983). Later, the State-Trait Anger Scale was combined with the Anger Expression scales to form the State-Trait Anger Expression Inventory (STAXI; Spielberger, 1988). The State-Trait Anger Scale was used in the present study during both screening (Trait Anger Scale) and laboratory (State Anger Scale) phases. Although there have been no studies examining overlap in item content between the Bem Sex Role Inventory and the State-Trait Anger Scale, this is a consideration of the present study. For instance, Bem Sex Role Inventory items such as "does not use harsh language" identify similar characteristics as those on the Trait Anger Scale (e.g., "When I get mad, I say nasty things," and "I feel like swearing."). Other Bem Sex Role Inventory items (e.g., "forceful," "eager to sooth hurt feelings," "willing to take a stand," "aggressive") compare similarly to items on the State-Trait Anger Scale.

In this study, participants rated how they generally feel on the 10 Trait Anger Scale items, using a 4 -point scale $(1=$ not at all to $4=$ very much so). Data were used to calculate a mean score for all items, resulting in a composite score for each participant on the Trait Anger Scale. One Trait Anger/ Temperament score and one Trait Anger/ Reaction score was 
calculated for each participant, as well, by averaging the specified items of the Trait Anger Scale for each subscale.

Laboratory Phase

Participants. From the initial group of participants, 96 individuals, 48 men and 48 women, were selected to participate in the second phase of this study. These participants were chosen on the basis of gender role, as determined by the Bem Sex-Role Inventory completed during the screening phase. For each gender group, 24 participants from the group of screening participants were characterized as having a "traditional gender role" and 24 participants were characterized as having an "androgynous gender role." Screening participants with chronic medical problems or medication use that affected cardiovascular functioning were excluded. Smokers were not excluded, but an equal number were included in each group. All participants were instructed to refrain from eating, drinking alcoholic beverages, ingesting caffeine, or smoking for two hours prior to the laboratory session. Participants completed the experiment in dyads, such that two individuals (one male and one female) were scheduled for the same laboratory session. In addition to gender, a second selection criteria for experimental dyads was each participant's gender role. An equal number of traditional man/traditional woman and androgynous man/androgynous woman dyads were placed in each of the experimental conditions. Table 2 shows frequencies for various participant demographic variables (e.g., race, age, height, education, trait anger scores) for each gender/gender role group. The results of chi square analyses and univariate analyses of variance, which were performed to test for group differences, are provided (see table 2). Table 3 shows frequencies for health behavior variables (e.g., exercise, tobacco use) for each gender/gender role group. The results of chi square analyses performed to test for group differences are provided (see table 3). Participants had not met one another prior to the experimental session. No significant differences in demographic variables were observed across Agency and Communion conditions.

Measures.

State Anger Scale. The 10-item State Anger Scale was initially devised using dictionary definitions of anger to select items for inclusion on the measure (Spielberger et al., 
1983). State anger was defined as subjective feelings of anger that vary in intensity over time. Thus, on the State Anger Scale, individuals were asked to rate the intensity of their feelings "right now" using a 4-point scale $(1=$ Not at all to $4=$ Very much so $)$. This measure has reportedly low test-retest reliability correlations ranging from .21 for females to .27 for males in a college sample (Spielberger \& Sydeman, 1994). This is not surprising, given that the intent of this measure was to assess anger states, which fluctuate over time. The State Anger Scale has high internal consistency reliabilities, ranging from .88 to .95 (Spielberger, 1988). Additionally, the State Anger Scale is correlated with the Trait Anger Scale during anger-eliciting situations ( $\mathrm{r}=.55$; Deffenbacher, Demm, \& Brandon, 1986). It has been shown to correlate with other measures of anger, such as the Anger Inventory (AI; Novaco, 1975) ( $\mathrm{r}=.60$; Deffenbacher et al., 1986). The State Anger Scale was originally combined with the Trait Anger Scale to form the State-Trait Anger Scale (Spielberger et al., 1983). The State-Trait Anger Scale exhibited moderate correlations with the Buss-Durkee Hostility Inventory (BDHI; Buss \& Durkee, 1957) and the Hostility scale of the Minnesota Multiphasic Personality Inventory (MMPI; Cook \& Medley, 1954), suggesting adequate concurrent validity (Spielberger \& Sydeman, 1994). The State Anger Scale of the combined State-Trait Anger Scale and the Anger Expression scales (STAXI; Speilberger, 1988) was used in the present study during the laboratory phase. Each participant completed this measure following the interpersonal interaction (experimental condition). 
Table 2. Demographic characteristics as a function of gender and gender role

\begin{tabular}{|c|c|c|c|c|c|}
\hline & Traditional Men & $\begin{array}{l}\text { Traditional } \\
\text { Women }\end{array}$ & $\begin{array}{l}\text { Androgynous } \\
\text { Men }\end{array}$ & $\begin{array}{l}\text { Androgynous } \\
\text { Women }\end{array}$ & $x^{2}$ \\
\hline $\begin{array}{l}\text { Race } \\
\text { Caucasian } \\
\text { African American } \\
\text { Asian } \\
\text { Hispanic } \\
\text { Other }\end{array}$ & $\begin{array}{l}24 \\
0 \\
0 \\
0 \\
0\end{array}$ & $\begin{array}{l}21 \\
0 \\
2 \\
0 \\
0\end{array}$ & $\begin{array}{l}18 \\
2 \\
1 \\
2 \\
1\end{array}$ & $\begin{array}{l}23 \\
\mathbf{0} \\
\mathbf{0} \\
\mathbf{1} \\
\mathbf{0}\end{array}$ & 16.310 \\
\hline $\begin{array}{l}\text { Marital Status } \\
\text { Single } \\
\text { Cohabiting } \\
\text { Married } \\
\text { Divorced }\end{array}$ & $\begin{array}{l}23 \\
0 \\
1 \\
0\end{array}$ & $\begin{array}{l}23 \\
0 \\
1 \\
0\end{array}$ & $\begin{array}{l}23 \\
0 \\
1 \\
0\end{array}$ & $\begin{array}{l}23 \\
1 \\
0 \\
0\end{array}$ & 4.000 \\
\hline $\begin{array}{l}\text { Education (years) } \\
\text { High school } \\
1 \text { Year College } \\
2 \text { Years College } \\
3 \text { Years College } \\
4 \text { + Years College }\end{array}$ & $\begin{array}{l}11 \\
8 \\
3 \\
0 \\
2\end{array}$ & $\begin{array}{l}16 \\
3 \\
4 \\
1 \\
0\end{array}$ & $\begin{array}{l}14 \\
6 \\
2 \\
1 \\
1\end{array}$ & $\begin{array}{l}20 \\
2 \\
1 \\
1 \\
0\end{array}$ & 14.259 \\
\hline
\end{tabular}




\begin{tabular}{|c|c|c|c|c|c|}
\hline $\begin{array}{l}\text { Medical Problems } \\
\text { None } \\
\text { Migraine } \\
\text { Asthma } \\
\text { Allergies } \\
\text { Stomach / GI } \\
\text { Sinus } \\
\text { Injury } \\
\text { Depression }\end{array}$ & $\begin{array}{l}23 \\
\mathbf{0} \\
\mathbf{0} \\
\mathbf{1} \\
\mathbf{0} \\
\mathbf{0} \\
\mathbf{0} \\
\mathbf{0}\end{array}$ & $\begin{array}{l}19 \\
1 \\
2 \\
0 \\
1 \\
0 \\
0 \\
1\end{array}$ & $\begin{array}{l}18 \\
1 \\
1 \\
3 \\
0 \\
0 \\
1 \\
0\end{array}$ & $\begin{array}{l}17 \\
0 \\
2 \\
2 \\
1 \\
1 \\
1 \\
0\end{array}$ & 18.611 \\
\hline $\begin{array}{l}\text { Medications } \\
\text { None } \\
\text { Allergy } \\
\text { Birth control } \\
\text { Anti-depressant } \\
\text { Asthma } \\
\text { Prilosec } \\
\text { Acne }\end{array}$ & $\begin{array}{l}\mathbf{2 3} \\
\mathbf{1} \\
\mathbf{0} \\
\mathbf{0} \\
\mathbf{0} \\
\mathbf{0} \\
\mathbf{0}\end{array}$ & $\begin{array}{l}15 \\
2 \\
3 \\
2 \\
0 \\
0 \\
2\end{array}$ & $\begin{array}{l}22 \\
\mathbf{2} \\
\mathbf{0} \\
\mathbf{0} \\
\mathbf{0} \\
\mathbf{0} \\
\mathbf{0}\end{array}$ & $\begin{array}{l}17 \\
0 \\
5 \\
0 \\
1 \\
1 \\
0\end{array}$ & $\begin{array}{l}31.525 \\
*\end{array}$ \\
\hline $\begin{array}{l}\text { Parental CV Illness } \\
\text { Yes } \\
\text { No }\end{array}$ & $\begin{array}{l}5 \\
19\end{array}$ & $\begin{array}{l}5 \\
19\end{array}$ & $\begin{array}{l}5 \\
19\end{array}$ & $\begin{array}{l}10 \\
14\end{array}$ & 4.056 \\
\hline
\end{tabular}

$*$ Indicates significance at the .05 level of confidence. $* *$ Indicates significance at the .01 level. *** Indicates significance at the .001 level 
Table 2. (Continued) Demographic characteristics as a function of gender and gender role

\begin{tabular}{|c|c|c|c|c|c|c|c|}
\hline & Traditional Men & $\begin{array}{l}\text { Traditional } \\
\text { Women }\end{array}$ & $\begin{array}{l}\text { Androgynous } \\
\text { Men }\end{array}$ & $\begin{array}{l}\text { Androgynous } \\
\text { Women }\end{array}$ & G & GR & G X GR \\
\hline $\begin{array}{l}\text { Age (years) } \\
\text { Mean (SD) }\end{array}$ & $19.917(3.51)$ & $18.583(0.78)$ & $19.083(1.28)$ & $18.292(0.55)$ & $7.279 * *$ & 2.040 & .473 \\
\hline $\begin{array}{l}\text { Height (in.) } \\
\text { Mean } \\
\text { (SD) }\end{array}$ & $69.5208(2.6105)$ & $63.8958(2.1668)$ & 69.8333 (1.8572) & $65.0417(2.1964)$ & $\begin{array}{l}131.633 * \\
* *\end{array}$ & 2.580 & .8421 \\
\hline $\begin{array}{l}\text { Weight } \\
\text { (lbs.) }\end{array}$ & $167.79(26.38)$ & $135.29(26.96)$ & $178.33(30.64)$ & $141.29(19.70)$ & $42.21 * * *$ & 2.388 & .180 \\
\hline $\begin{array}{l}\text { TAS- Total } \\
\text { Mean } \\
\text { (SD) }\end{array}$ & $21.417(4.49)^{\mathrm{a}}$ & $17.50(5.78)^{b}$ & $20.042(3.54)$ & $20.333(6.75)$ & 2.822 & .457 & $\begin{array}{l}3.804 \\
(p=.054)\end{array}$ \\
\hline $\begin{array}{l}\text { TAS-R } \\
\text { Mean } \\
\text { (SD) }\end{array}$ & $9.67(2.30)$ & $8.42(2.45)$ & $9.00(2.27)$ & $9.33(2.93)$ & .807 & .060 & 2.409 \\
\hline $\begin{array}{l}\text { TAS-T } \\
\text { Mean } \\
\text { (SD) }\end{array}$ & $7.625(2.98)$ & $6.042(2.97)^{\mathrm{c}}$ & $7.292(1.92)$ & $7.875(2.68)^{d}$ & .841 & 1.893 & $3.949 *$ \\
\hline
\end{tabular}

* Indicates significance at the .05 level of confidence. ** Indicates significance at the .01 level. *** Indicates significance at the .001 level. $\mathrm{a}$ and $\mathrm{b}$ indicate groups that are significantly different.

$\mathrm{c}$ and $\mathrm{d}$ indicate groups that are significantly different. 
Table 3. Health behaviors as a function of sex and gender role

\begin{tabular}{|c|c|c|c|c|c|}
\hline & Traditional Men & Traditional Women & Androgynous Men & $\begin{array}{l}\text { Androgynous } \\
\text { Women }\end{array}$ & $x^{2}$ \\
\hline $\begin{array}{l}\text { Exercise } \\
\text { Frequency } \\
\text { (per week) } \\
\text { Never } \\
\text { 1-3 times } \\
\text { 4-6 times } \\
7 \text { + times }\end{array}$ & $\begin{array}{l}3 \\
12 \\
8 \\
1\end{array}$ & $\begin{array}{l}3 \\
15 \\
6 \\
0\end{array}$ & $\begin{array}{l}3 \\
16 \\
5 \\
0\end{array}$ & $\begin{array}{l}6 \\
14 \\
3 \\
1\end{array}$ & 6.778 \\
\hline $\begin{array}{l}\text { Minutes } \\
\text { Exercise } \\
\text { (per } \\
\text { occasion) } \\
\text { 5-10 mins } \\
\text { 10-15 mins } \\
\text { 15-30 mins } \\
\text { 30-60 mins } \\
\text { 60+ mins }\end{array}$ & $\begin{array}{l}4 \\
2 \\
6 \\
5 \\
7\end{array}$ & $\begin{array}{l}5 \\
4 \\
6 \\
7 \\
2\end{array}$ & $\begin{array}{l}5 \\
1 \\
6 \\
8 \\
4\end{array}$ & $\begin{array}{l}6 \\
4 \\
8 \\
6 \\
0\end{array}$ & 12.316 \\
\hline $\begin{array}{l}\text { Tobacco Use } \\
\text { Y } \\
\mathbf{N}\end{array}$ & $\begin{array}{l}8 \\
16\end{array}$ & $\begin{array}{l}4 \\
20\end{array}$ & $\begin{array}{l}4 \\
20\end{array}$ & $\begin{array}{l}8 \\
16\end{array}$ & 3.556 \\
\hline
\end{tabular}




\begin{tabular}{|c|c|c|c|c|c|}
\hline $\begin{array}{l}\text { Type of } \\
\text { Tobacco } \\
\text { Used } \\
\text { Cigarettes } \\
\text { Smokeless }\end{array}$ & $\begin{array}{l}6 \\
2\end{array}$ & $\begin{array}{l}4 \\
0\end{array}$ & $\begin{array}{l}4 \\
0\end{array}$ & $\begin{array}{l}8 \\
0\end{array}$ & 8.889 \\
\hline $\begin{array}{l}\text { Frequency } \\
\text { of Tobacco } \\
\text { Use (per } \\
\text { week) } \\
1-3 \text { times } \\
\text { 4-6 times } \\
\text { 7-10 times } \\
10 \text { + times }\end{array}$ & $\begin{array}{l}3 \\
2 \\
1 \\
2\end{array}$ & $\begin{array}{l}\mathbf{0} \\
1 \\
2 \\
1\end{array}$ & $\begin{array}{l}\mathbf{0} \\
\mathbf{1} \\
\mathbf{0} \\
\mathbf{3}\end{array}$ & $\begin{array}{l}3 \\
2 \\
0 \\
3\end{array}$ & 12.444 \\
\hline $\begin{array}{l}\text { Number } \\
\text { Tobacco } \\
\text { Products } \\
\text { Used (per } \\
\text { occasion) } \\
1 \\
2 \\
3 \\
4\end{array}$ & $\begin{array}{l}8 \\
0 \\
\text { 0 } \\
\text { 0 }\end{array}$ & $\begin{array}{l}3 \\
\mathbf{0} \\
\mathbf{1} \\
\mathbf{0}\end{array}$ & $\begin{array}{l}4 \\
\text { 0 } \\
\text { 0 } \\
\text { 0 }\end{array}$ & $\begin{array}{l}7 \\
\mathbf{0} \\
\mathbf{0} \\
\mathbf{1}\end{array}$ & 9.980 \\
\hline
\end{tabular}

$*$ Indicates significance at the .05 level of confidence. ** Indicates significance at the .01 level. *** Indicates significance at the .001 level. 
Anger Cognitions Inventory. The Anger Cognitions Inventory (ACI; Suchday \& Larkin, 1991) is a list of 27 statements regarding thoughts experienced during anger (see Appendix B). Four factors comprise this instrument: Victimization, Self-Righteousness, Rational Coping, and Repression/Distancing. The former two factors (Victimization and Self-Righteousness) represent the individual's endorsement of items related to reactions to anger. High scores on Victimization reflect feelings of unfair treatment or victimization, whereas high scores on Self-Righteousness reflect an attempt to justify angry feelings. The latter two factors (Rational Coping and Repression/Distancing) represent the individual's endorsement of items related to coping with anger. High scores on Rational Coping indicate an attempt at rational justification of anger, whereas high scores on Repression/Distancing indicate an effort to stop thinking about anger. Internal consistency estimates for all factors range from coefficient alphas .66 to .74. The Anger Cognitions Inventory presents adequate convergent and divergent validity when compared with other measures such as the Ways of Coping Checklist and the CookMedley Hostility scale (Cook \& Medley, 1954). In present study, participants were asked to rate each statement once using a 4-point scale (Not at all, A lot, Somewhat, and Extremely). Each participant completed this measure once during the laboratory session, following the interpersonal interaction (experimental condition).

Post-experimental Self-Report Measure. The Post-experimental Self-report measure was devised for the purpose of this study to determine the effectiveness of experimental manipulations, and to gauge participants' cognitive and affective experience during the experiment. Five scores (in $\mathrm{mm}$ ) were calculated by measuring with a ruler the distance from the left end of a horizontal line to the participant's mark through a $13 \mathrm{~mm}$ line, which indicated his or her response to each item. The scores derived from this measure were: perceived support, perceived threat, perceived effort to convince one's dyad partner, perceived stress, and perceived challenge (see Appendix C).

Physiological Measures and Apparatus. The Polar Heart Rate Monitor (model Polar Vantage XL) is a heart rate sampling instrument designed to record heart rate (HR) continuously and store information digitally in beats per minute (bpm) through a watch 
placed on the participant's wrist. The monitor has been demonstrated to measure HR reliably (Goodie, Schauss, Larkin, \& Aragona, 1997). In this study, a Polar heart rate monitor was used to record and store HR information for each participant. Systolic blood pressure (SBP) and diastolic blood pressure (DBP) were monitored at specified intervals throughout the experiment. An occluding cuff was placed around the participant's nondominant upper arm over the brachial artery. Each cuff was connected to an IBS Model 700-SD automated sphygmomanometer, a device that detected SBP and DBP using a small microphone embedded in the cuff.

A tape player was used to provide instructions to participants throughout the experiment. Instructions were recorded prior to the experiment and played for participants at the beginning of each experimental condition and during each condition. All instructions were recorded by the (female) experimenter. A stopwatch was used by the experimenter to ensure proper starting and stopping times for each condition, and to monitor BP at proper intervals.

Experimental Condition. The experimental condition entailed an interpersonal interaction between the two participants. In this condition, participants engaged in a debate or discussion with one another. The topic of their conversation concerned the construction of a new parking garage at West Virginia University. Each participant was provided with a list of arguments supporting a particular position (either in favor of the parking garage or against it), and was instructed to present his or her position (see Appendix D for text of instructions; Appendix E for lists of arguments). A 2-min. preparation period allowed each participant to review his or her list of arguments and formulate a verbal response.

Participants were instructed to either agree or disagree with one another during the interpersonal interaction, constituting one level of experimental manipulation (i.e., Communion). Additionally, each dyad participated in either a high-challenge condition (in which they were instructed that their responses would be video-taped and coded for articulateness, validity of their argument, and speech competence), or a low-challenge condition (in which they were instructed that their responses would be video-taped and 
should be clear and audible). This high-challenge, low-challenge discrimination constituted a second level of experimental manipulation (i.e., Agency). Although instructions for the high challenge condition specified that the participants' arguments would be coded for "validity," participants were actually unable to influence the validity of the arguments with which they were provided.

During the interaction, each participant was advised via audio-taped instructions to present his or her arguments in two 1.5-min. speaking intervals, and then to listen as the other participant presented his or her arguments during two 1.5-min. intervals. Participants alternated speaking and listening roles for a total of 6 min. After a 2-min. preparation period, instructions were provided specifying which participant should speak first. Experimental sessions were counterbalanced so that an equal number of male and female participants spoke first in the dyads. Participants were instructed that they may refer to the list of arguments provided, but may not read verbatim from the list. Additional audio-taped instructions specified the points at which participants should switch speaking and listening roles.

Procedure. Upon arriving at the laboratory, participants were directed to a room containing a table, a tape recorder, and two chairs in which they were seated back to back to prevent communication. Each participant was instructed to place a Polar Heart Rate Monitor around his or her lower chest at the level of the sternum. Each participant was then seated and a Polar heart rate watch was positioned on his or her wrist. An automated blood pressure cuff was placed on each participant's non-dominant upper arm. After attachment to physiological monitoring equipment, participants were asked to remain as still as possible and refrain from speaking during a ten min. initial rest phase. Heart rate (HR) was measured continuously throughout the initial rest period while systolic blood pressure (SBP) and diastolic blood pressure (DBP) were monitored three times in the last five minutes of the resting phase.

Following the initial rest period, audio-taped instructions were given regarding the interpersonal interaction condition, and participants were provided with their respective lists of arguments. After the 2-min. preparation period, additional audio-taped 
instructions were provided indicating which participant should speak first. Further audiotaped instructions advised the second participant to speak, and the participants to alternate speaking and listening roles. HR in beats per minute was sampled throughout the 2-min. preparation period, while SBP and DBP were monitored at the onset of minutes 0 and 1. Additionally, HR in beats per minute was sampled for each participant's two 1.5-min. speaking intervals, while SBP and DBP were monitored at the onset of minutes 0 and 1 of each speaking interval. Following the interpersonal interaction condition, each participant completed the 10-item State Anger Scale and the 27-item Anger Cognitions Inventory. After completing the experiment, participants were given extra credit forms, recording equipment was removed, and participants were debriefed as to the purposes of the study.

\section{Results}

Reduction procedures for cardiovascular data are first described, followed by results of analyses performed for cardiovascular variables (SBP, DBP, and HR). Results of analyses performed for measures of anger experience (Anger Cognitions Inventory, Trait Anger Scale, and State Anger Scale) are then presented. Finally, results of analyses performed for the five scales of the Post-experimental Self-report Questionnaire are presented in the following order: Perceived Challenge, Perceived Stress, Perceived Effort to Convince, Perceived Threat, and Perceived Support. Regarding the presentation of statistical results, eta ${ }^{2}$ is provided as a measure of strength of the experimental effect. It should be interpreted as the percent of variance in the dependent variable that is explained by the independent variable.

\section{Data reduction}

HR data (sampled every five seconds) were reduced initially by averaging the 12 readings obtained for each minute of: (a) the initial rest period, (b) the preparation period, and (c) the task period. Prior to obtaining averages of HR for each period, repeated measures ANOVAs were performed to ensure that the HRs measured during each minute of the period did not differ significantly. No significant differences were observed across minutes for both the initial rest and preparation periods. HR data (in beats per minute) 
were then reduced by averaging the last five minutes of the initial rest period to obtain a mean resting $\mathrm{HR}$ for each participant. HR data were averaged across the 2-min preparation period to obtain a mean preparation period HR for each participant. For speaking and listening intervals, HR data were not further reduced, but recorded in two intervals: speaking periods 1 and 2 combined, and listening periods 1 and 2 combined.

Prior to averaging SBP and DBP data for each period (initial rest, preparation, speaking, and listening), repeated measures ANOVAs were performed to ensure no significant differences between blood pressure measures during each minute of the respective experimental conditions. Like HR, no significant differences were observed. SBP and DBP data (in $\mathrm{mm} / \mathrm{Hg}$ ) were reduced by averaging measures obtained from the last five minutes of the initial rest period to obtain a mean resting SBP and a mean resting DBP for each participant. SBP and DBP data were each averaged across the 2-min preparation period to obtain a mean preparation period SBP and DBP for each participant. For speaking and listening intervals, SBP and DBP data were not reduced, but recorded in two intervals: speaking periods 1 and 2 combined, and listening periods 1 and 2 combined.

\section{$\underline{\text { Cardiovascular Measures }}$}

A series of 2 X 2 X 2 X 2 ([Gender (Male, Female) X Gender Role (Traditional, Androgynous) X Agency (Low Challenge, High Challenge) X Communion (Agree, Disagree)] Univariate Analyses of Variance (ANOVAs) were performed on dependent variables. Significant interactions were followed by simple effect analyses. All analyses were conducted using a .05 level of confidence. For summary tables of results of all statistical analyses, see Appendix F.

Heart Rate. For the initial rest period, the ANOVA on HR yielded a significant main effect for Gender, $\underline{\mathrm{F}}(1,80)=5.38, \underline{\mathrm{p}}=.023$, eta $^{2}=.063$, with significant differences between HR of men $(\underline{\mathrm{M}}=83.2 \mathrm{bpm}, \underline{\mathrm{SD}}=13.45)$ and women $(\underline{\mathrm{M}}=89.4 \mathrm{bpm}, \underline{\mathrm{SD}}=$ 11.67) (see Figure 1). No other main effects or interaction terms were significant. In analyses on HR as the dependent variable during the preparation and task periods, HR obtained from the initial rest period was included as a covariate. For the preparation 
period, the ANCOVA showed no significant main effects or interactions for HR. The ANCOVA analysis on HR during speaking periods resulted in a significant Gender X Gender Role interaction, $\underline{F}(1,79)=4.63, \underline{p}=.035$, eta $^{2}=.055$. Simple effects analyses revealed that adjusted mean HRs of traditional men were lower during speaking than HRs of traditional women, $\underline{F}(1,45)=5.18, \underline{p}=.028$, eta $^{2}=.103$. Simple effects analyses of HR comparing traditional men and androgynous men were not significant. Simple effects analyses of HR comparing traditional women and androgynous women and comparing androgynous men and androgynous women also were not significant. No other main effects or interactions were significant. The ANCOVA analysis on HR during listening periods also resulted in a significant Gender X Gender Role interaction, $\underline{F}(1,79)=6.75$, $\underline{p}=.011$, eta $^{2}=.079$. Although simple main effects analyses resulted in no significant mean differences, contrast analyses revealed a significant difference between the mean adjusted HR of traditional women and the combined mean adjusted HR of traditional men and androgynous women, $\underline{\mathrm{F}}(1,69)=5.56, \underline{\mathrm{p}}=.021$, eta $^{2}=.075$. No other main effects or interactions were significant.

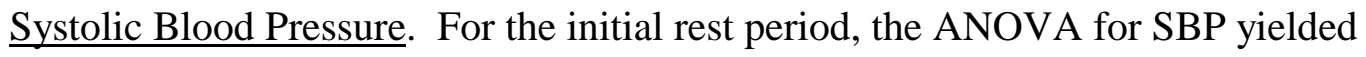
a significant main effect for Gender, $\underline{\mathrm{F}}(1,80)=8.95, \underline{\mathrm{p}}=.004$, eta $^{2}=.101$, with significant differences between the resting SBP of men $(\underline{\mathrm{M}}=122.7 \mathrm{~mm} \mathrm{Hg}, \underline{\mathrm{SD}}=11.95)$ and women $(\underline{\mathrm{M}}=116.0 \mathrm{~mm} \mathrm{Hg}, \underline{\mathrm{SD}}=9.26)$. No other main effects or interactions were significant. In subsequent analyses on SBP during the preparation and task periods, SBP obtained from the initial rest period was included as a covariate. For the preparation period, a near significant interaction was found for Gender X Agency, $\underline{F}(1,79)=3.93, \underline{p}$ $=.051$ eta $\left.^{2}=.047\right)($ see Figure 2$)$. Simple effects analyses of this interaction revealed a significant difference between men and women in the Low Challenge condition, $\underline{F}(1,45)$ $=8.04, \underline{p}=.007$, eta $^{2}=.152$, with men having significantly higher adjusted SBP than women. Simple effects analyses of men and women in the High Challenge condition did not indicate significant differences between these groups. No other main effects or interactions were significant. The ANCOVA for SBP during speaking periods resulted in no significant main effects or interactions. For SBP during listening periods, the 
ANCOVA analysis resulted in a main effect for Gender Role that approached significance, $\underline{\mathrm{F}}(1,79)=3.79, \underline{\mathrm{p}}=.055$, eta ${ }^{2}=.046$, with traditional participants $(\underline{\mathrm{M}}=$ $130.2 \mathrm{mmHg}, \underline{\mathrm{SD}}=14.74)$ exhibiting higher adjusted mean SBPs than androgynous participants $(\underline{\mathrm{M}}=126.6 \mathrm{mmHg}, \underline{\mathrm{SD}}=12.24)$. No other main effects or interactions were significant.

Diastolic Blood Pressure. The ANOVA on the initial rest period DBP resulted in no significant main effects or interactions. However, to maintain consistency with other analyses of cardiovascular parameters, further analyses performed with DBP as the dependent variable included initial rest period DBP as a covariate. The ANCOVA for DBP in the preparation period resulted in no significant main effects or interactions. The ANCOVAs for DBP in speaking periods and listening periods also yielded no significant main effects or interactions.

Self Report Measures of Cognitive and Affective Response

A series of 2 X 2 X 2 X 2 ([Gender (Male, Female) X Gender Role (Traditional, Androgynous) X Agency (Low Challenge, High Challenge) X Communion (Agree, Disagree)] Univariate Analyses of Variance (ANOVAs) were performed on self-report measures of cognitive and affective responses. Like cardiovascular measures, significant interactions were followed by tests for simple effects.

Anger Cognitions Inventory. Scores for each of the four scales of the Anger Cognitions Inventory were computed for each participant (i.e., Victimization, Rational Coping, Repression, Self-righteousness). A significant main effect for Gender was found for the Anger Cognitions Inventory Victimization scale, $\underline{F}(1,80)=8.60, \underline{p}=.004$, eta ${ }^{2}=$ .097 , with men $(\underline{\mathrm{M}}=1.2, \underline{\mathrm{SD}}=2.20)$ scoring higher than women $(\underline{\mathrm{M}}=0.2, \underline{\mathrm{SD}}=.39)$. No other main effects or interactions were significant. For the Anger Cognitions Inventory Rational Coping and Repression/Distancing scales, there were no significant main effects or interactions. The ANOVA for the Anger Cognitions Inventory Self-Righteousness scale resulted in a significant main effect for Communion, $\underline{\mathrm{F}}(1,80)=5.02, \underline{\mathrm{p}}=.028$, eta ${ }^{2}$ $=.059$, with dyads in the Disagreement condition $(\underline{\mathrm{M}}=1.6, \underline{\mathrm{SD}}=1.73)$ obtaining 
significantly higher Self-Righteousness scores that dyads in the Agreement condition (ㅆ $=.9, \underline{\mathrm{SD}}=1.30)$. No other significant main effects or interactions were found.

Trait Anger Scale. The ANOVA on Trait Anger Scale total scores resulted in a significant Gender X Gender Role interaction, $\underline{F}(1,80)=4.24, \underline{p}=.043$, eta ${ }^{2}=.05$. Simple effects analyses yielded significant differences for participants with traditional gender roles, $\underline{\mathrm{F}}(1,46)=6.87, \underline{\mathrm{p}}=.012, \mathrm{eta}^{2}=.13$, with traditional men $(\underline{\mathrm{M}}=21.4, \underline{\mathrm{SD}}=$ 4.49) reporting more trait anger than traditional women $(\underline{M}=17.5, \underline{S D}=5.78)$. Simple effects analyses did not reveal significant differences between androgynous men and androgynous women. Simple effects analyses also did not result in significant differences between androgynous men and traditional men, and between androgynous women and traditional women. The ANOVA for Trait Anger Scale total scores also resulted in a significant main effect for Communion, $\underline{\mathrm{F}}(1,80)=6.29, \underline{\mathrm{p}}=.014$. Participants in the Disagree condition $(\underline{\mathrm{M}}=21.1, \underline{\mathrm{SD}}=5.14)$ obtained significantly higher total trait anger scores than participants in the Agree condition $(\underline{\mathrm{M}}=18.5, \underline{\mathrm{SD}}=5.39)$. For the Reaction subscale of the Trait Anger Scale no significant findings were observed. For the Temperament subscale of the Trait Anger Scale, the ANOVA resulted in a Gender X Gender Role interaction, $\underline{\mathrm{F}}(1,80)=3.89, \underline{\mathrm{p}}=.052$, $\mathrm{eta}^{2}=.046$ that approached significance. Simple effects analyses resulted in a significant difference, $\underline{F}(1,46)=5.05$, $\underline{p}=.03$, eta $^{2}=.099$, between traditional women $(\underline{\mathrm{M}}=6.0, \underline{\mathrm{SD}}=2.97)$ and androgynous women $(\underline{\mathrm{M}}=7.9, \underline{\mathrm{SD}}=2.68)$. No significant differences resulted for simple effects analyses on traditional men and androgynous women. There were no significant differences between traditional men and traditional women. There were no significant differences between androgynous men and androgynous women.

State Anger Scale. Because there was a statistically significant difference between Communion conditions on trait anger, Trait Anger Scale total score was used as a covariate in subsequent analyses of State Anger Scale total scores. The ANCOVA for participants' scores on the State Anger Scale revealed a significant main effect for Communion, $\underline{\mathrm{F}}(1,80)=4.21, \underline{\mathrm{p}}=.043$ eta $^{2}=.051$. Participants in the Disagree condition $(\underline{\mathrm{M}}=11.2, \underline{\mathrm{SD}}=2.53)$ reported significantly higher total scores on the State 
Anger Scale than participants in the Agree condition $(\underline{\mathrm{M}}=10.3, \underline{\mathrm{SD}}=0.82)$. No other main effects or interactions were significant.

Post-experimental Self-report Measure. A series of 2 X 2 X 2 X 2 ANOVAs were performed on the five items from the Post-experimental Self-report Measure. The ANOVA on Perceived Challenge resulted in a significant Gender Role X Agency X Communion interaction, $\underline{\mathrm{F}}(1,80)=6.52, \underline{\mathrm{p}}=.013$, eta $^{2}=.075$ (see Figure 3 ). Simple effects analyses of this interaction revealed that traditional participants in the Low Challenge Agree condition exhibited higher perceived challenge ratings than androgynous participants in the Low Challenge Agree condition. Similarly, traditional participants in the High Challenge Disagree condition exhibited higher Perceived Challenge ratings than androgynous participants in the High Challenge Disagree condition. Simple effects analyses of the High Challenge Agree condition and the Low Challenge Disagree condition did not result in significant differences between androgynous and traditional participants. For the ANOVA on Perceived Challenge, no other main effects or interactions were significant.

The ANOVA on Perceived Stress resulted in a significant main effect for Gender, $\underline{\mathrm{F}}(1,80)=4.92, \underline{\mathrm{p}}=.029, \mathrm{eta}^{2}=.058$, with women $(\underline{\mathrm{M}}=3.6, \underline{\mathrm{SD}}=2.93)$ reporting significantly more stress than men $(\underline{\mathrm{M}}=2.4, \underline{\mathrm{SD}}=2.28)$. This main effect for Gender was qualified by a Gender X Agency X Communion interaction. The ANOVA on Perceived Stress also resulted in a significant Gender X Agency X Communion interaction, $\underline{\mathrm{F}}(1,80)=3.99, \underline{\mathrm{p}}=.049$, $\mathrm{eta}^{2}=.047$ (see Figure 4 ). Follow-up analyses revealed a significant gender difference for participants in the High Challenge Agree condition, $\underline{\mathrm{F}}(1,22)=5.26, \underline{\mathrm{p}}=.032$ eta $^{2}=.193$. Women in the High Challenge Agree condition reported higher perceived stress ratings than men in the High Challenge Agree condition. No significant gender differences were observed in any of the other conditions. For the ANOVA on Perceived Stress, no other main effects or interactions were significant.

The ANOVA on Perceived Effort to Convince their partner resulted in a significant main effect for Gender Role, $\underline{F}(1,80)=4.64, \underline{p}=.034$, eta ${ }^{2}=.055$, with 
participants in androgynous dyads $(\underline{\mathrm{M}}=7.4, \underline{\mathrm{SD}}=4.01)$ reporting significantly higher effort to convince scores than participants in traditional dyads $(\underline{\mathrm{M}}=5.6, \underline{\mathrm{SD}}=3.90)$. The ANOVA on Perceived Effort to Convince also resulted in a significant main effect for Communion, $\underline{\mathrm{F}}(1,80)=5.76, \underline{\mathrm{p}}=.019$, eta ${ }^{2}=.067$. Participants in Disagree dyads reported significantly higher scores on effort to convince their partners $(\underline{\mathrm{M}}=7.5, \underline{\mathrm{SD}}=$ 4.27) than those in Agree dyads $(\underline{\mathrm{M}}=5.5, \underline{\mathrm{SD}}=3.55)$. No other main effects or interactions were significant for the ANOVA on Perceived Effort to Convince.

The ANOVA on Perceived Threat resulted in a significant main effect for Communion, $\underline{\mathrm{F}}(1,80)=3.99, \underline{\mathrm{p}}=.049$, eta ${ }^{2}=.048$. Participants in Disagree dyads $(\underline{\mathrm{M}}=$ $1.7, \underline{\mathrm{SD}}=1.79)$ reported significantly higher Perceived Threat scores than participants in Agree dyads $(\underline{\mathrm{M}}=1.1, \underline{\mathrm{SD}}=1.17)$. The main effect for Communion was qualified by a Gender X Agency X Communion interaction. The ANOVA on Perceived Threat also resulted in a significant Gender X Agency X Communion interaction, $\underline{F}(1,80)=4.22$, $\underline{p}$ $=.043$ eta $^{2}=.05$ (see Figure 5). Simple effects analyses of this interaction revealed that men in the Low Challenge Agree condition reported higher perceived threat ratings than men in the High Challenge Agree condition. Simple effects analyses did not result in significant differences between women in the Agree conditions. Simple effects analyses also did not result in significant differences between participants in the Disagree conditions. No other main effects or interactions were significant for the ANOVA on Perceived Threat.

The ANOVA on Perceived Support resulted in a significant main effect for Communion, $\underline{\mathrm{F}}(1,80)=6.51, \underline{\mathrm{p}}=.013, \mathrm{eta}^{2}=.075$. Participants in Agree dyads $(\underline{\mathrm{M}}=$ 9.2, $\underline{\mathrm{SD}}=3.13$ ) reported significantly higher Perceived Support scores than those in Disagree dyads $(\underline{\mathrm{M}}=7.4, \underline{\mathrm{SD}}=4.01)$. The main effect for Communion was qualified by both a Gender Role X Communion interaction and an Agency X Communion interaction. The ANOVA on Perceived Support also resulted in a significant Gender Role X Communion interaction, $\underline{F}(1,80)=4.63, \underline{p}=.034$, eta $^{2}=.055$ (see Figure 6$)$. Simple effects analyses of this interaction revealed significant differences between participants in androgynous dyads in the Agree condition and Disagree condition. There was no 
significant difference between Agree and Disagree conditions for participants in traditional gender role dyads. The ANOVA on Perceived Support also resulted in a significant Agency X Communion interaction, F $(1,80)=13.46, \mathrm{p}<.0001$, eta $^{2}=.144$ (see Figure 7). Simple effects analyses of the Agency X Communion interaction resulted in a significant difference in Perceived Support between participants in Agree dyads and Disagree dyads in the Low Challenge condition, $\underline{\mathrm{F}}(1,46)=27.71, \underline{\mathrm{p}}<.0001$, eta $^{2}=.376$. Simple effects analyses of High Challenge dyads indicated no significant differences between Agree and Disagree dyads. No other main effects or interactions were significant for the ANOVA on Perceived Support.

\section{Discussion}

A substantial amount of literature exists supporting the link between cardiovascular reactivity to stress and the development and progression of cardiovascular disease (Barnett et al., 1997; Blascovich \& Katkin, 1993; Kasagi et al., 1995; Manolio et al., 1994; Manuck, 1994). The present study offers an important addition to this research, as it establishes the importance of the interactive effects of gender and gender role influences on cardiovascular reactivity to stress. The present findings suggest that gender and gender role interact to modify the effects of an interpersonal interaction stressor on cardiovascular reactivity and the experience of anger.

\section{Gender Differences in Cardiovascular Reactivity}

Consistent with previous research (Allen, Stoney, Owens, \& Matthews, 1993;

Girdler, Turner, Sherwood, \& Light, 1990; Shapiro, Goldstein, \& Jamner, 1995; Stone, Dembroski, Costa, \& McDougall, 1990) men had significantly higher resting SBP than women and women had significantly higher resting HR than men. Also, similar to the findings of previous research (Matthews \& Stoney, 1988; Stoney, Davis, \& Matthews, 1987; Vogele, Jarvis, \& Cheeseman, 1997), men in this study exhibited a higher mean SBP response than women during the experimental condition. However, this gender difference occurred only when the interpersonal interaction involved a Low Challenge component and only during the preparation period. This gender difference in SBP response during Low Challenge interaction preparation periods may be attributed to 
increased uncertainty experienced by men prior to interacting with their female dyad partner in a minimally challenging situation. Under High Challenge instructions, men may have more clearly understood their goal and were not apt to display differential SBP responding during the preparation period than women.

Congruent with the findings of Stone and colleagues (1990), traditional women exhibited significantly higher mean HR responses than traditional men during the stressor condition. This finding, however, was not observed among androgynous participants. The finding of higher HR responses among traditional women than men may be related to the interpersonal nature of the stressor used in the present study. It is possible that women with traditional feminine gender roles are more reactive to interpersonal interactions with traditional masculine men than androgynous women interacting with androgynous men. Because previous investigations (Allen et al, 1993; Girdler et al., 1990; Stone et al., 1990) have examined cardiovascular reactivity to non-interpersonal challenges, like video game or a smoking challenge, it is unclear whether this gender difference for only traditional gender role dyads would generalize to stressors like these. It is also possible that samples used in these previous studies were predominantly traditional gender-typed volunteers. Because gender role was not measured in these studies, this is only speculation. More research is necessary to confirm the finding that HR differences between genders is limited to persons with traditional gender roles.

The present study found no gender differences in DBP or DBP response. This is discrepant from previous studies, which have found men to exhibit greater DBP responses to stress than women (Allen et al., 1993; Girdler et al., 1990, Shapiro et al., 1995; Vogele, 1997), or women to have greater DBP responses than men (Stone et al., 1990). In this regard, the current study corroborates the lack of any consistent gender differences in DBP reactivity. It is possible that this lack of gender differences in DBP response was due to the interpersonal nature of the stressor used in the present study. In previous research, the use of more non-interpersonal laboratory stressors produced cardiovascular reactivity dissimilar from that produced by the interpersonal interaction stressor used in the present study. Additionally, many studies have confirmed greater 
heart rate reactivity for women and greater systolic blood pressure reactivity for men. There is only limited evidence that men and women differ in diastolic blood pressure reactivity.

\section{Gender Role Differences in Cardiovascular Reactivity}

Some of the findings on cardiovascular reactivity in the present study demonstrated that gender role also influenced magnitude of responding to the interpersonal task. As described above, gender role influenced the effect of gender on HR response to the stressor. HR reactions of traditional feminine women were significantly greater than those of traditionally masculine men during both speaking and listening intervals. Participants with traditional gender roles had slightly higher mean SBP reactivity than participants with androgynous gender roles. For DBP, there was no indication that traditional and androgynous participants differed from one another. Although the pattern of findings is of interest, they are not consistent with findings of previous studies.

For example, Lash and colleagues (1990) found that, in a sample of men, those with traditional masculine gender roles exhibited greater cardiovascular reactivity to a high challenge task than those with androgynous gender roles. Although near significant differences in SBP reactivity between traditional and androgynous participants were observed, this difference in cardiovascular reactivity occurred only during listening intervals. This finding lends very limited support to the hypothesis that individuals with traditional gender roles have higher SBP responses than individuals with androgynous gender roles. Also in contrast to the work of Lash and colleagues (1990), traditional feminine women did not exhibit greater cardiovascular reactivity than androgynous women during Disagreement conditions. These findings contradicted the theory proposed by Eisler (1998), which stated that tasks that were appraised to threaten an individual's gender role were more stressful for that individual, and therefore elicited greater cardiovascular reactivity than tasks not threatening to the gender role. Also contradicting Eisler's (1998) theory is the present study's finding that during the High Challenge condition in which participants agreed, men reported significantly less stress than women. 
Men reported approximately the same amount of stress as women during the High Challenge condition in which participants disagreed. Thus, perhaps the individual's perception that he or she is "supposed" to perform better at a particular task is not related to the amount of stress the individual experiences while performing the task, and does not affect the individual's cardiovascular reactivity to the task. Or, it is possible that men did not report more stress or experience greater cardiovascular reactivity because the Agency manipulation in the present study was not effective.

The findings of the present study did not indicate that participants with more feminine-oriented gender roles (traditional feminine women) exhibited greater cardiovascular reactivity during "masculine-oriented tasks" (Agency) than during "feminine-oriented tasks" (Communion). Neither did traditional masculine men exhibit greater cardiovascular reactivity to "feminine-oriented tasks" than to "masculine-oriented tasks." Thus, the findings of the present study failed to support the idea proposed by Davis and Matthews (1996) that individuals reacted with greater cardiovascular reactivity to task conditions that were "mismatched" to their gender roles.

The findings of the present study indicated that the interaction between gender and gender role may be an important factor in determining observed differences in cardiovascular reactivity to stress. Neither gender nor gender role alone accounted for the differences in HR responding to the interpersonal interaction. HR differences between traditional masculine men and traditional feminine women during speaking intervals, as well as HR differences between traditional women and the combined mean HR of traditional men and androgynous women, indicated that men (and possibly androgynous women) with more traditional masculine gender roles experienced less dramatic increases in HR during the interpersonal interaction than traditionally feminine women. While little research has been undertaken thus far to understand the relation between gender and gender role in influencing cardiovascular reactivity, the results of the present study indicate that this should be a topic of future investigation. 


\section{Cardiovascular Reactivity in Relation to Agency and Communion}

In the present study, the High Challenge condition did not produce greater cardiovascular reactivity for men than for women; nor did participation in the High Challenge condition result in greater cardiovascular reactivity for men than participation in the Low Challenge condition. These findings differ from those of Brown and Smith (1992), which demonstrated that, for men, competitive interpersonal situations (situations in which they were expected to persuade or influence another person) elicited greater cardiovascular reactivity than neutral interpersonal situations. Brown and Smith (1992) found also that, for women, levels of cardiovascular reactivity did not differ with respect to the competitive nature of the interaction. The present study confirmed this finding, as women in High Challenge conditions did not differ from women in Low Challenge conditions with regard to cardiovascular reactivity. Additionally, women did not differ from men in their reaction to High Challenge conditions. One hypothesis of the present study was that women would experience significantly greater cardiovascular reactivity than men in experimental conditions that involved Disagreement. This was not confirmed, although during Agreement conditions that also involved a High Challenge component, women reported significantly more stress than men.

The present study found no gender differences in cardiovascular reactivity. Men did not have greater cardiovascular reactivity than women to interpersonal interaction conditions involving High Challenge (Agency). Women did not have greater cardiovascular reactivity than men to interpersonal interaction conditions involving Disagreement (Communion). In contrast to the findings of Smith and his colleagues (1998), no gender-oriented style of physiological responding was replicated by the present findings. This may be due in part to the use of participants who were not familiar with one another in the present study, in contrast to the use of married couples in the Smith study. It is possible that married couples with a history of interaction have different cardiovascular reactivity when interacting with one another in the laboratory than do unfamiliar individuals. Additionally, the use of only participants who met specific gender role criteria may have influenced the present non-significant findings with regard to 
Agency and Communion. Smith and his co-investigators obtained physiological data from a random sample of individuals whose Bem Sex Role Inventory scores probably fell across the androgyny continuum.

\section{Gender Differences in Self-Report of Anger Experience}

Findings of the present study indicated that men and women differed in the amount of trait anger they reported, but these gender differences were influenced by gender role. Men and women differed in the degree to which they reported trait anger (men reported significantly more trait anger than women) but only for individuals with traditional gender roles. When androgynous gender role individuals were considered, no gender differences in trait anger were observed. These findings can be contrasted with previous reports of no gender differences in self-report of state or trait anger (Averill, 1983; Bartz et al., 1996; Spielberger, 1988; Thomas \& Williams, 1991).

Although no hypotheses were made with regard to individuals' anger-related cognitions during the interpersonal interaction, it is interesting to observe that men reported significantly more Victimization anger-related thoughts than women. Thus, men endorsed significantly more statements reflecting feelings of unfair treatment in reaction to anger than women. Perhaps the gender of the experimenter (i.e., female) influenced the greater self-report of feelings of unfair treatment by men than by women. There was no significant difference between genders in reported Self-Righteousness (attempt to justify angry feelings), Rational Coping, or Repression/Distancing. Although men and women did differ in their self-reported reactions to anger (Victimization), it is interesting to note that men and women did not differ in their self-report of the ways in which they coped with anger (Rational Coping or Repression/Distancing). Thus, there were no gender differences in use of rational justification to cope with anger, or effort to stop thinking about anger as a coping tactic during the interpersonal interaction.

\section{Gender Role Differences in Self-Report of Anger Experience}

Men and women with traditional gender roles differed in the amount of trait anger they reported during the screening phase of this study. As described earlier, men with traditional masculine gender roles had significantly higher self-reported trait anger than 
women with traditional feminine gender roles. Following the interpersonal interaction, there were no significant gender role differences observed in state anger. Similar to the findings of Kopper and Epperson (1991), the present study found that individuals differed on the Trait Anger-Temperament scale of the Trait Anger Scale (Spielberger, 1980) with regard to gender role. Specifically, findings indicated that women with traditional gender roles had significantly lower Trait Anger-Temperament scores than women with androgynous gender roles. However, traditional men did not differ from androgynous men in this respect. This finding is consistent with the findings of Kopper and Epperson (1991) that suggested gender role is a powerful predictor of Trait Anger-Temperament. The present findings are also quite similar to those of Kogut and colleagues' (1992) study that showed women differed in anger experience depending upon their gender role. Both studies found that women with more traditional feminine gender roles reported less experience of anger than women with less traditional feminine gender roles (androgynous women). However, the Kogut study found differences in state anger after provocation, whereas the present findings showed only significant differences in Trait Anger-Temperament (prior to provocation) among traditional feminine and androgynous women. In all, findings of the present study suggest that gender and gender role interact to influence self-report if trait anger, whereas neither gender nor gender role appeared to affect self-reported state anger during the interpersonal interaction.

Self-Report of Anger Experience in Relation to Agency and Communion

The present study found that all participants (both men and women) reported more state anger following interactions that involved differing levels of disagreement (Communion), but not differing levels of challenge (Agency). Specifically, participants in Disagree dyads reported significantly more state anger following the interpersonal interaction than did Agree dyads. Similarly, the level of disagreement (Communion), but not the level of challenge (Agency) influenced participant report of Self-Righteousness thoughts related to anger on the Anger Cognitions Inventory. Participants in Disagree conditions had higher Self-Righteousness scores than participants in Agree conditions. These findings suggest that self-report of anger experience (state anger and cognitive 
reaction to anger) may have been influenced more by characteristics of Communion in the experimental condition employed in this investigation than by level of Agency. Thus, in the present study, whether there was disagreement between participants appeared to predict the experience of anger more than whether there was challenge. This findings can be contrasted to that of Brown and Smith (1992), who found that competitive interpersonal interactions elicited a greater experience of anger than neutral interpersonal situations for men.

Limitations of the Study

There are several factors that limit direct comparisons with previous research. First, instructions to participants regarding the Agency aspect of the experimental condition may not have distinguished between High Challenge and Low Challenge conditions. Although instructions to participants regarding videotaping differed for High Challenge and Low Challenge conditions, perhaps the presence of a video camera itself resulted in the perception of an equally-challenging condition for participants in either Agency condition. Ratings of challenge on the post-experimental self-report questionnaire did not differ significantly between High Challenge and Low Challenge conditions. In fact, participants only rated High Challenge conditions as more challenging than Low Challenge conditions when the dyads participating were androgynous and their positions on the issue agreed. No differences in Challenge ratings were observed for all remaining dyad groups. Participant ratings of threat in High Challenge conditions did not differ from ratings of threat for participants in Low Challenge conditions, as well. An exception to this occurred for men in Agree conditions, who, paradoxically, rated Low Challenge conditions as more threatening than High Challenge conditions. For ratings of stress, there was no difference between High and Low Challenge conditions. Thus, it appears that instructions to participants regarding the Agency component of the interpersonal interaction may have been too similar to distinguish High Challenge from Low Challenge conditions.

A related concern is that Disagree conditions may have contained an element of challenge, resulting in a combination of Agency and Communion rather than simply a 
level of Communion. This possibility is supported from the present findings because participant-reported "effort to convince one's dyad partner" (on the Post-experimental self-report questionnaire) received higher ratings for Disagree dyads than for Agree dyads. However, further analyses on the Post-experimental self-report questionnaire indicated that participants reported similar (e.g., not significantly different) amounts of "challenge" in both Disagree and Agree conditions. Additionally, participants in Agree conditions reported more challenge than participants in Disagree conditions for androgynous dyads when the level of Agency was High Challenge. Thus, when taking into account participants' self-report of challenge, Disagree conditions did not appear to involve inherent elements of challenge.

In the present study, experimental groups differed at the outset of the experiment (prior to the interpersonal interaction) on Trait Anger Scale total scores. Participants randomly assigned to Disagree conditions scored higher on the Trait Anger Scale than participants assigned to Agree conditions. This may be perceived as a possible shortcoming of the present study, as initial Trait Anger Scale scores may have influenced self-report of state anger following the interpersonal interaction. However, to remedy this potential confound, total Trait Anger Scale scores were used as a covariate in the analyses of State Anger Scale total scores. Thus, pre-existing group effect differences in Trait Anger Scale scores may have affected self-report of state anger, but were controlled for in statistical analyses.

The findings of the present study are generalizable only to a population of individuals whose Bem Sex Role Inventory scores fall at either extreme of the Androgyny continuum. As individuals with Bem Sex Role Inventory scores that fall between 1.0 and 2.0 on this continuum (undifferentiated men and women) were not included in the laboratory phase of this study, results may not be applicable to this population. Additionally, masculine women and feminine men were not included in the laboratory investigation, and therefore results cannot be generalized to this population. Future research should include laboratory investigations of cardiovascular reactivity and anger 
experience with participants whose scores fall across the entire Bem Sex Role Inventory continuum.

One further limitation of the present study is that traditional participants were only paired with one another, and androgynous participants were only paired with one another. Future research might include mixed traditional/androgynous dyads in investigations of cardiovascular reactivity and experience of anger. Newton and colleagues (1999) have attributed differences in cardiovascular reactivity to interpersonal dynamics in mixedgender dyads. In light of these findings and the findings of the present study, it would be interesting to include same-gender dyads in future research.

In the present study, data have been analyzed for each individual participant. Thus, results of the present study may differ from those of studies in which data is analyzed using the dyad as the unit of analysis. For the purposes of the present study, analyzing individual data was more appropriate than analyses involving each dyad, as the objective was to examine gender differences and each experimental dyad was composed of one man and one woman. By averaging data across both participants in the dyad, gender differences could not be examined and the Gender X Gender Role interactions would have been obscured. However, in analyzing data for each participant, it has not been possible to compare dyads with one another, or to evaluate collaborative aspects of the discussion/debate in which the participants engaged. In these respects, the present method of data analysis is a limitation of the present study.

A related concern is the large number of statistical analyses that have been performed in the present study. A statistical correction procedure, such as the Bonferoni correction, might have been performed to compensate for the number of analyses that were conducted. Alternatively, a multivariate analysis of variance (MANOVA) statistical analysis procedure might have been used instead of the multiple univariate analyses of variance (ANOVA/ANCOVA) that were performed.

Another limitation pertains to the measure of anger cognitions used in this study. Although the Anger Cognitions Inventory is an unpublished measure, it has been validated in one study (Suchday \& Larkin, 1991). As there are no other valid assessment 
instruments for measuring anger cognitions, the Anger Cognitions Inventory was selected for this purpose. The Anger Cognitions Inventory was initially created to assess anger cognitions in a trait-like manner (what one "usually" thinks following an anger experience). In the present study, the Anger Cognitions Inventory was used to assess anger cognitions in a state-like manner. Thus, instructions were changed to elicit selfreport of thoughts during the interpersonal interaction. This modification of the Anger Cognitions Inventory should be noted in interpreting the results from this assessment instrument in the present study.

Laboratory assessment of anger experience was limited to self-report data in the present study. This possible shortcoming results from a lack of available assessment instruments useful in examining the experience of anger. To a limited extent, otherreport data was collected following the interpersonal interaction, as participants were asked to indicate how supportive they believed their dyad partner to be. Analysis of direct observational data is advisable for future investigations of anger experience in future studies of this type.

A final consideration is that the state anger data collected following the interpersonal interaction varied little across conditions. Participants did not indicate high levels of state anger in any Agency/Communion condition. As participants' State Anger Scale scores were generally low, mean differences in State Anger Scale scores across Communion conditions should be interpreted with caution. Future investigations should include aspects of the experimental condition besides disagreement to study the experience of anger. The effects of experimental manipulations that are more likely to elicit anger in participants should be examined. For example, experiments that involve direct confrontation or harassment may elicit higher State Anger Scale scores than those found in the present experiment. Likewise, providing a model (e.g., live model, video recording) of angry behavior prior to the experimental investigation may elicit more anger in participants. For all practical purposes, in this investigation, levels of elicited anger were minimal. 


\section{Directions for Future Research}

This study provoked many questions that should be addressed in future research. Future investigations should recognize the importance of accounting for both gender and gender role differences when measuring cardiovascular reactivity to stress. In light of the present findings, longitudinal research should be conducted to determine the effects of gender and gender role differences in cardiovascular reactivity on the development of cardiovascular disease. Of particular concern is the finding that traditional women have greater HR increases during interpersonal stress than do other gender/gender role groups. It is interesting to note, however, that traditional women report significantly less trait anger than do other gender/gender role groups. Further research is necessary to confirm whether cardiovascular health is compromised for traditional women over time. Future investigations of gender and gender role would benefit from examining the long-term health consequences of excessive cardiovascular reactivity to interpersonal stress among persons with varying gender role characteristics.

Additional research is required also to study the differences in cardiovascular reactivity elicited by interpersonal interactions as opposed to more conventional laboratory stressors. Investigations are needed to examine whether exaggerated cardiovascular reactivity to the stress of interpersonal interactions is more closely linked with the development of cardiovascular disease than reactivity to isometric handgrips or math tasks, for instance. The use of an interpersonal interaction as a stressor in the laboratory possibly makes the present findings more generalizable, as daily stress is often related to interpersonal interactions rather than completion of isolated stressful tasks. Further, the use of an interpersonal interaction allows for obtainment of self-report and cardiovascular measures from two participants during a single experimental session. This procedure is both timesaving and cost-effective.

In addition to implications for cardiovascular reactivity research, the findings of the present study may impact current investigations of anger experience during interpersonal interactions. These findings indicate that gender and gender role differences exist in trait anger and may affect the experience of anger during interpersonal 
interactions. Of particular interest are the differences between men and women in their self-reported anger-related cognitions (e.g., victimization thoughts) during interpersonal interaction. More research is necessary to confirm these differences and to validate the existing assessments for measuring anger cognitions. In light of the numerous studies showing that experience of anger is linked to the development of cardiovascular disease (Contrada, 1994; Dembroski et al., 1979; Johnson, 1990; Manuck \& Proietti, 1982; Matthews, 1982; Siegel, 1984, 1985; Shapiro, 1996), the present findings are especially significant. Further investigations are needed to determine the impact of gender and gender role on anger experience in relation to long term cardiovascular health. For instance, it is important to examine whether higher trait anger predisposes men to increased risk for cardiovascular disease in a longitudinal design. Also to be further investigated is the finding that women with traditional gender roles report higher levels of Trait Anger-Temperament than women with androgynous gender roles. This finding may relate to previous studies such as that of Matthews and her colleagues (1998), which determined that for women, higher trait anger was associated with the development of more cardiovascular related problems in later life. In combination, these findings suggest that, particularly for traditional women, high trait anger may be related to development of cardiovascular disease. Future research should target this hypothesis.

The present study manipulated aspects of the interpersonal interaction (Agency, Communion) to which men and women were expected to respond physiologically and affectively. Future investigations should consider not only these aspects, but also particular experimental conditions that may elicit differences in cardiovascular reactivity and anger experience for different gender/gender role groups. In an experimental design similar to that developed by Davis and Matthews (1996), future experiments might involve gender/gender role-specific tasks such as a social support task or a competition task. Based upon this body of important research, specific behavioral risk factors for cardiovascular disease might be identified, understood, and used to develop preventive strategies for future generations. 


\section{References}

Allen, M.T., Stoney, C. M., Owens, J. F., \& Matthews, K. A. (1993).

Hemodynamic adjustments to laboratory stress: The influence of gender and personality. Psychosomatic Medicine, 55, 505-517.

Barnett, P. A., Spence, D., Manuck, S. B., \& Jennings, J. R. (1997).

Psychological stress and the progression of carotid artery disease. Journal of Hypertension, 15, 49-55.

Bartz, A. E., Blume, N. E., \& Rose, J. (1996). Gender differences in self-report measures of anger: The role of social desirability and negative affect. Handbook of gender research (Special issue) Journal of Social Behavior and Personality, 11, 241-253.

Beck, A. T., Steer, R.A., \& Brown, G.K. (1987). Beck Depression Inventory. San Antonio: The Psychological Corporation.

Bem, S. L. (1974). The measurement of psychological androgyny. Journal of Consulting and Clinical Psychology, 42, 155-162.

Blascovich, J., \& Katkin, E. S. (1995). Cardiovascular reactivity to psychological

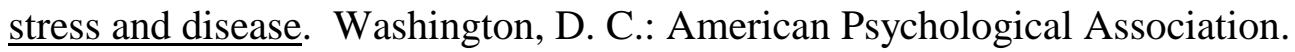

Brown, P. C., \& Smith, T. W. (1992). Social influence, marriage, and the heart: Cardiovascular consequences of interpersonal control in husbands and wives. Health Psychology, 11, 88-96.

Buss, A.H., Durkee, A., \& Baer, M.B. (1957). The measurement of hostility in clinical situations. Journal of Abnormal and Social Psychology, 52, 84-86.

Carlsson, M., \& Magnusson, E. (1980). Construct validation of the Bem Sex Role Inventory. Scandinavian Journal of Psychology, 21, 27-31.

Chesney, M., \& Roseman, R. H. (Eds.). (1985). Anger and hostility in cardiovascular and behavioral disorders. Washington D.C.: Hemisphere Publishing Corporation.

Contrada, R. J. (1994). Personality and anger in cardiovascular disease: Toward a psychological model. In A. W. Siegman \& T. W. Smith (Eds.). Anger, hostility, and the heart. Hillsdale, NJ: Lawrence Erlbaum Associates, pp. 149-171. 
Cook, W.W., \& Medley, D.M. (1954). Proposed hostility and pharisaic-virtue scales for the MMPI. The Journal of Applied Psychology, 38, 414-418.

Corse, C. D., Manuck, S. B., Cantwell, J. D., Giordani, B., Matthews, K. A. (1982). Coronary-prone behavior pattern and cardiovascular response in persons with and without coronary heart disease. Psychosomatic Medicine, 44, 449-459.

Davis, M. C., \& Matthews, K. A. (1996). Do gender-relevant characteristics determine cardiovascular reactivity? Match versus mismatch of traits and situation. Journal of Personality and Social Psychology, 71, 527-535.

Deffenbacher, J., Demm, P., \& Brandon, A. (1986). High general anger: Correlates and treatment. Behavioral Research and Therapy, 24, 481-489.

Deffenbacher, J. L., Oetting, E. R., Thwaites, G. A., Lynch, R. S., Baker, D. A., Stark, R. S., Thacker, S., \& Eiswerth-Cox, L. (1996). State-trait anger theory and the utility of the Trait Anger Scale. Journal of Counseling Psychology, 43, 131-148.

Dembroski, T., MacDougall, J., \& Lushene, R. (1979). Interpersonal interaction and cardiovascular response in Type A subjects and coronary patients. Journal of Human Stress, 5, 28-36.

Derogatis, L. (1977). Symptom Checklist-90-R (SCL-90-R). Minneapolis: Leonard R. Derogatis.

Eisler, R. M. (1999). The relationship between masculine gender role stress and men's health risk: The validation of a construct. In D.L. Anselmi \& A.L. Law (Eds.). Questions of gender: Perspectives and paradoxes (pp. ) New York: McGraw-Hill.

Ekman, P., Levenson, R. W., \& Friesen, W. V. (1983). Autonomic nervous system activity distinguishes among emotions. Science, 221, 1208-1210.

Girdler, S. S., Turner, J. R., Sherwood, A., Light, K. C. (1990). Gender differences in blood pressure control during a variety of behavioral stressors. Psychosomatic Medicine, 52, 571-591. 
Goodie, J., Schauss, S. L., Larkin, K.T., \& Aragona, B. (1997). Validation of the Polar heart rate monitor for measuring heart rate responses to mental stress.

Psychophysiology, 34, S38. Paper presented at the $37^{\text {th }}$ Annual Meeting of the Society for Psychophysiological Research, Cape Cod, MA.

Johnson, E. H. (1990). The deadly emotions: The role of anger, hostility, and aggression in health and emotional well-being. New York: Praeger Publishers.

Jorgensen, R. S., \& Houston, B. K. (1981). Family history of hypertension, gender, and cardiovascular reactivity and stereotypy during stress. Journal of Behavioral Medicine, 4, 175-189.

Kaplan, H., \& Saddock, B. (1998). Synopsis of Psychiatry: Behavioral Sciences/Clinical Psychiatry $\left(8^{\text {th }}\right.$ ed.), Baltimore: Williams \& Wilkins.

Kasagi, F., Akahoshi, M., \& Shimaoka, K. (1995). Relation between cold pressor test and development of hypertension based on 28-year follow-up. Hypertension, 25, 7176.

Kogut, D., Langley, T., \& O’Neal, E. (1992). Gender role masculinity and angry aggression in women. Sex-Roles, 26, 355-368.

Kopper, B. A. (1993). Role of gender, sex role identity, and Type A behavior in anger expression and mental health functioning. Journal of Counseling Psychology, 40, 232-237.

Kopper, B. A., \& Epperson, D. L. (1991). Women and anger: Sex and sex-role comparisons in the expression of anger. Psychology of Women Quarterly, 15, 7-14.

Krantz, D. S., \& Manuck, S. B. (1984). Acute psychophysiologic reactivity and risk of cardiovascular disease: A review and methodological critique. Psychological Bulletin, 96, 435-464.

Krantz, D. S., Manuck, S. B., \& Wing, R. R. (1986). Psychological stressors and task variables as elicitors of reactivity. In K. Matthews, S. Weiss, T. Detre, T. Dembrowski, B. Falkner, S. Manuck, \& R. Williams (Eds.). Handbook of stress, reactivity, and cardiovascular disease. New York: John Wiley \& Sons. 
Lacey, J. I., Kagan, J., \& Lacey, B. C. (1963). The visceral level: Situational determinants and behavioral correlates of autonomic response patterns. In P. Knapp (Ed.). Expression of the emotions in man. (pp.161-196). New York: International Universities Press.

Lash, S. J., Eisler, R. M., \& Schulman, R. S. (1990). Cardiovascular reactivity to stress in men. Effects of masculine gender role stress appraisal and masculine performance challenge. Behavior Modification, 14, 3-20.

Lash, S. J., Gillespie, B. L., Eisler, R. M., \& Southard, D. R. (1991). Sex differences in cardiovascular reactivity: Effects of the gender relevance of the stressor. Health Psychology, 10, 392-398.

Lawler, K. A., Kline, K., Seabrook, E., Krishnamoorthy, J., Anderson, S., Wilcox, Z., Craig, F., Adlin, R, \& Thomas, S. (1998). Family history of hypertension: A pschophysiological analysis. International Journal of Psychophysiology, 28, 207-222.

Leper, C. (1991). Influence and involvement in children's discourse: Age, gender, and partner effects. Child Development, 62, 797-811.

Leper, C., Tenenbaum, H.R., \& Shaffer, T.G. (1999). Communication patterns of African American girls and boys from low-income, urban backgrounds. Child Development, 70, 1489-1503.

Light, K., \& Obrist, P. A. (1980). Cardiovascular response to stress: Effects of opportunity to avoid, shock experience, and performance feedback. Psychophysiology, 17, 234-252.

Manolio, T. A., Burke, G. L., Savage, P. J., Sidney, S., Gardin, J. M., \& Oberman, A. (1994). Exercise blood pressure response and 5-year risk of elevated blood pressure in a cohort of young adults: The CARDIA study. American Journal of Hypertension, 7 , 234-241.

Manuck, S., Kamarck, T., Kasprowicz, A., \& Waldstein, S. (1995). Stability and patterning of behaviorally evoked cardiovascular reactivity. In J. Blascovich \& E. S. Katkin (Eds.). Cardiovascular reactivity to psychological stress and disease. (pp. 111134). Washington, D.C.: American Psychological Association. 
Manuck, S. B., Kaplan, J. R., \& Clarkson, T. B. (1983). Behaviorally induced heart rate reactivity and atherosclerosis in cynomolgus monkeys. Psychosomatic Medicine, 45, 95-108.

Manuck, S. B., Morrison, R. L., Bellack, \& Polefrone, (1985). Behavioral factors in hypertension: Cardiovascular responsivity, anger, and social competence. In M. A. Chesney \& R. H. Rosenman (Eds.). Anger and Hostility in Cardiovascular and Behavioral Disorders. (pp. 149-172). New York: Hemisphere/McGraw-Hill.

Manuck, S., \& Proietti, J. (1982). Parental hypertension and cardiovascular response to cognitive isometric challenge. Psychophysiology, 19, 481-489.

Matthews, C. E., Pate, R. R., Jackson, K. L., Ward, D. S., Macera, C. A., Kohl, H. W., \& Blair, S. N. (1998). Exaggerated blood pressure response to dynamic exercise and risk for future hypertension. Journal of Clinical Epidemiology, 51, 29-35.

Matthews, K. (1982). Psychological perspectives on the Type A behavior pattern. Psychological Bulletin, 91, 292-323.

Matthews, K. A. \& Stoney, C.M. (1988). Influences of sex and age on cardiovascular responses during stress. Psychosomatic Medicine, 50, 46-56.

Matthews, K., Owens, J., Kuller, L., Sutton-Tyrrell, K., \& Jansen-McWilliams, L. (1998). Are hostility and anxiety associated with carotid atherosclerosis in healthy postmenopausal women? Psychosomatic Medicine, 60, 633-638.

Newton, T. L., Bane, C. M., Flores, A., \& Greenfield, J. (1999). Dominance, gender, and cardiovascular reactivity during social interaction. Psychophysiology, 36, 245-252.

Novaco, R. (1975). Anger control: The development and evaluation of an experimental treatment. Lexington, MA: D.C. Heath.

Obrist, P. A. (1981). Cardiovascular Psychophysiology: A Perspective. New York: Plenum. 
Rejeski, W.J., Gagne, M., Parker, P. E., \& Koritnich, D. R. (1989). Acute stress reactivity from contested dominance in dominant and submissive males. Behavioral Medicine, 15, 118-124.

Rejeski, W. J., Parker, P. E., Gagne, M., \& Koritnich, D.R. (1990)

Cardiovascular and testosterone responses to contested dominance in women. Health Psychology, 9, 35-47.

Sassenrath, J. M., \& Yonge, G. D. (1979). The Bem Sex Role Inventory reexamined. Psychological Reports, 45, 935-941.

Seligman, M. E. (1975). Helplessness: On Depression, Development, and Death. San Francisco: Freeman.

Shapiro, P. A. (1996). Psychiatric aspects of cardiovascular disease. Psychiatric Clinics of North America, 19, 613-629.

Shapiro, D., Goldstein, I. B., \& Jamner, L. D. (1995). Effects of anger/hostility, defensiveness, gender, and family history of hypertension on cardiovascular reactivity. Psychophysiology, 32, 425-435.

Siegel, J. (1984). Anger and cardiovascular risk in adolescents. Health Psychology, 3, 293-313.

Siegel, J. (1985). The measurement of anger as a multidimensional construct. In M. Chesney \& R. Rosenman (Eds.). Anger and hostility in cardiovascular and behavioral disorders. (pp. ) Washington, D.C.: Hemisphere Publishing Corporation.

Smith, T., Gallo, L., Goble, L., Ngu, L., \& Stark, K. (1998). Agency, communion, and cardiovascular reactivity during marital interaction. Health Psychology, 17, 537-545.

Spence, J. T., Helmreich, R., \& Stapp, J. (1975). Ratings of self and peers on sex role attributes and their relation to self-esteem and conceptions of masculinity and femininity. Journal of Personality and Social Psychology, 32, 29-39.

Spielberger, C.D. (1988). Manual for the State-Trait Anger Expression Inventory (STAXI). Odessa, FL: Psychological Assessment Resources. 
Spielberger, C.D., Jacobs, G., Russell, S., \& Crane, R. (1983). Assessment of anger: The State-Trait Anger Scale. In J.N. Butcher \& C.D. Spielberger (Eds.). Advances in Personality Assessment (Vol. 2, pp. 159-187). Hillsdale, NJ: Lawrence Erlbaum Associates.

Spielberger, C., \& Sydeman, S. (1994). State-Trait Anxiety Inventory and Statetrait Anger Expression Inventory. In M. Maruish (Ed.). The use of psychological testing for treatment planning and outcome assessment. (pp.292-321). Hillsdale, NJ: Lawrence Erlbaum.

Stone, S. V., Dembroski, T. M., Costa, P. T., \& MacDougall, J. M. (1990). Gender differences in cardiovascular reactivity. Journal of Behavioral Medicine, 13, 137156.

Stoney, C.M., Davis, M.C., \& Matthews, K.A. (1987). Sex differences in physiological responses to stress and in coronary heart disease: A causal link? Psychophysiology, 24, 393-402.

Suchday, S., \& Larkin, K. (1991). Anger Cognitions Inventory. Unpublished manuscript, West Virginia University at Morgantown.

Swim, J.K. (1994). Perceived versus meta-analytic effect sizes: An assessment of the accuracy of gender stereotypes. Journal of Personality and Social Psychology, 66, 21-36.

Thomas, S., \& Williams, R. L. (1991). Perceived stress, trait anger, modes of anger expression, and health status of college men and women. Nursing Research, 40, 303-307.

Vogele, C., Jarvis, A., \& Cheeseman, K. (1997). Anger suppression, reactivity, and hypertension risk: Gender makes a difference. Annals of Behavioral Medicine, 19 , 61-69.

Wood, D. L., Sheldon, M. D., Sheps, S. G., Elveback, L. R., \& Schirger, A. (1984). Cold pressor test as a predictor of hypertension. Hypertension, 6, 301-306. 


\section{Appendix A}

Participant Name:

Demographics Questionnaire

Participant \#:

1) Please indicate your sex:

O Male

O Female

2) Please indicate your age:

3) Please indicate your race:

O African American

O Caucasian

O Hispanic

O Asian

O Other

4) Please indicate your marital status:

O Single

O Cohabiting/ Live-in Partner

O Married

O Divorced / Separated

5) Total Number Years of Education Completed:

O High school

O 1 year college

O 2 years college

O 3 years college

O 4 or more years college

6) Please describe any cardiovascular related illnesses, including high blood pressure, that you have:

7) Please list any other medical problems you have:

8) Please list any medications that you are currently taking:

9) Do either of your parents have a cardiovascular related illness, including high blood pressure?

$\mathrm{O} \mathrm{Y}$

$\mathrm{O} \mathrm{N}$

10) If yes, please state which parent and describe the illness: 
11) How many times per week do you engage in aerobic physical activity (do not include weight lifting):
O 0 (Never)
O $1-3$
O $4-6$
O 7 or more

12) For how long do you exercise per occasion?

O 5 - 10 minutes

O 10 - 15 minutes

O 15 - 30 minutes

O 30 - 60 minutes

O More than 60 minutes

13) Do you use tobacco products?

$\mathrm{O}$ Yes

$\mathrm{O}$ No

14) If yes, indicate the type of tobacco product(s) used:

O Cigarettes

O Smokeless

O Other

15) Indicate the frequency of tobacco use per day:
O $1-3$ times per day
O 4-6 times per day
O 7-10 times per day
O More than 10 times per day

16) Provide information on the number / amount of tobacco product used per occasion: ( e.g., 2 cigarettes per occasion)

\section{IMPORTANT!!!}

17) Please indicate your willingness to participate in the second phase of this study for additional extra credit and your name entered in a lottery drawing for a $\$ 25, \$ 50$, or $\$ 75$ cash prize:

O Please contact me at the following number:

O Please do not contact me. 
Appendix B

Anger Cognitions Inventory

\begin{tabular}{|c|c|c|c|c|}
\hline & $\begin{array}{c}\text { Not at } \\
\text { all }\end{array}$ & $\begin{array}{c}\text { Somew } \\
\text { hat }\end{array}$ & A lot & $\begin{array}{c}\text { Extrem } \\
\text { ely }\end{array}$ \\
\hline \multicolumn{5}{|c|}{ 1. I thought. . . "I can't do a thing about what has happened." } \\
\hline \multicolumn{5}{|c|}{ 2. I thought. . . "I want to strike out at something/someone." } \\
\hline \multicolumn{5}{|l|}{ 3. I thought. . . "I don't understand this." } \\
\hline \multicolumn{5}{|l|}{$\begin{array}{l}\text { 4. I thought. . . "This is } \\
\text { unfair." }\end{array}$} \\
\hline \multicolumn{5}{|l|}{ 5. I thought. . . "I should not be treated this way." } \\
\hline \multicolumn{5}{|l|}{$\begin{array}{l}\text { 6. I thought. . . "This should be put into } \\
\text { perspective." }\end{array}$} \\
\hline \multicolumn{5}{|c|}{ 7. I thought. . . "I want to get even or make the other person feel bad." } \\
\hline \multicolumn{5}{|c|}{ 8. I thought. . . "I've got to find a way to change things." } \\
\hline \multicolumn{5}{|l|}{ 9. I thought. . . "It would help to talk to someone." } \\
\hline \multicolumn{5}{|l|}{ 10.I thought. . . "This situation is frustrating." } \\
\hline \multicolumn{5}{|l|}{ 11.I thought. . . "I hate them." } \\
\hline \multicolumn{5}{|l|}{ 12.I thought. . . "Why should this happen to me?" } \\
\hline \multicolumn{5}{|l|}{ 13.I thought. . . "I'm responsible for this." } \\
\hline \multicolumn{5}{|c|}{ 14. I thought. . . "I must have done something to deserve this." } \\
\hline \multicolumn{5}{|l|}{ 15.I thought. . . "I shouldn't be angry about this." } \\
\hline \multicolumn{5}{|l|}{ help." } \\
\hline \multicolumn{5}{|l|}{ 17.I thought. . ."I could hurt myself." } \\
\hline \multicolumn{5}{|l|}{$\begin{array}{l}\text { 18.I thought. . . "I should just stop thinking about } \\
\text { this." }\end{array}$} \\
\hline 19.I thought. . . "My anger should be concealed." & & & & \\
\hline
\end{tabular}




\begin{tabular}{l|l|l|l|l|}
\hline $\begin{array}{l}\text { 20.I thought. . "I'll put it out of my } \\
\text { mind." }\end{array}$ & & & \\
\hline $\begin{array}{l}\text { 21.I thought. . "I need to find other ways to express my } \\
\text { anger." }\end{array}$ & & & & \\
\hline 22.I thought. . "I have the right to be angry." & & & & \\
\hline 23.I thought. . "They should see it my way." & & & & \\
\hline 24.I thought. . "This situation should be rectified." & & & & \\
\hline 25.I thought. . "I'm right." & & & & \\
\hline 26.I thought. . "I need to reason this through." & & & & \\
\hline 27.I thought. . "I have mean thoughts toward the person I'm angry with." & & & & \\
\hline
\end{tabular}




\section{Appendix C}

\section{Post-experimental Self-report Inventory}

Please indicate your response by making a vertical slash across the line provided under each item.

1) How stressful was the discussion?

Not at all stressful

Extremely stressful

2) How challenging was the discussion?

Not at all challenging

Extremely challenging

3) How threatening was the discussion?

Not at all threatening

Extremely threatening

4) How supportive of you was the other participant during the discussion?

Not at all supportive

Extremely supportive

5) To what extent were you attempting to convince the other participant of your point of view during the discussion?

Not at all

Extremely 
Appendix D

Instructions to Participants

\section{Baseline Phase:}

To Both Participants: "Please sit as still as possible for the next 10 minutes. Any movement such as shifting in your seat or shaking your legs will interfere with the heart rate and blood pressure readings we get from you."

\section{Interpersonal Interaction Phase: (High-Challenge, Disagree Condition)}

Two-Minute Preparation Period: "During this portion of the experiment, you will be asked to engage in a debate with the other participant. The issue you will be debating is the construction of a new parking garage on the downtown campus of West Virginia University. You will each present either arguments in support of the issue or against this issue. On the table next to you, you will find a list of arguments for your position. You will have two minutes to prepare to discuss the issue. You may refer to your list while speaking, but do not read from the page. Additionally, your responses will be video-taped and coded for articulateness, the validity of your arguments, and your speaking competence, so please do your very best. The tape recorded instructions will prompt speaking and listening intervals." First Speaking Interval: "Will the person with Sheet A please discuss the issue." Second Speaking Interval: "Will the person with Sheet B please discuss the issue."

\section{Interpersonal Interaction Phase: (High-Challenge, Agree Condition)}

Two-Minute Preparation Period: "During this portion of the experiment, you will be asked to engage in a discussion with the other participant. The issue you will be discussing is the construction of a new parking garage on the downtown campus of West Virginia University. You will each present arguments in support of this issue. On the table next to you, you will find a list of arguments for your position. You will have two minutes to prepare to discuss the issue. You may refer to your list while speaking, but do not read from the page. Additionally, your responses will be video-taped and coded for articulateness, the validity of your stated ideas, and your speaking competence, so please do your very best. The tape recorded instructions will prompt speaking and listening intervals."

First Speaking Interval: "Will the person with Sheet A please discuss the issue." 
Second Speaking Interval: "Will the person with Sheet B please discuss the issue."

\section{Interpersonal Interaction Phase: (Low-Challenge, Disagree Condition)}

Two-Minute Preparation Period: "During this portion of the experiment, you will be asked to engage in a debate with the other participant. The issue you will be debating is the construction of a new parking garage on the downtown campus of West Virginia University. You will each present either arguments in support of this issue or against this issue. On the table next to you, you will find a list of arguments for your position. You will have two minutes to prepare to discuss the issue. You may refer to your list while speaking, but do not read from the page. Additionally, your responses will be videotaped, so please speak in a clear, audible voice. The tape recorded instructions will prompt speaking and listening intervals."

First Speaking Interval: "Will the person with Sheet A please discuss the issue." Second Speaking Interval: " Will the person with Sheet B please discuss the issue."

\section{Interpersonal Interaction Phase: (Low-Challenge, Agree Condition)}

Two-Minute Preparation Period: "During this portion of the experiment, you will be asked to engage in a discussion with the other participant. The issue you will be discussing is the construction of a new parking garage on the downtown campus of West Virginia University. You will each present arguments in support of this issue. On the table next to you, you will find a list of arguments for your position. You will have two minutes to prepare to discuss the issue. You may refer to your list while speaking, but do not read from the page. Additionally, your responses will be videotaped, so please speak in a clear, audible voice. The tape recorded instructions will prompt speaking and listening intervals." First Speaking Interval: "Will the person with Sheet A please discuss the issue." Second Speaking Interval: "Will the person with Sheet B please discuss the issue." 


\section{Appendix E}

Sheet A

\section{(Arguments in Support of Building a New Parking Garage)}

1) More cars would stay protected in instances of bad weather.

2) Driving around campus would be safer because fewer cars would park curbside, making streets wider and there would be less hazardous parallel parking.

3) Better use of the PRT would be made if people parked on the downtown campus and took the PRT to other sites.

4) Students need more places to park because there are never enough spaces.

5) People could park nearer academic buildings and ensure punctual arrival for classes.

6) The new garage could incorporate another open area on the upper level (similar to the current parking garage), so that bigger events (like concerts) could be held on the downtown campus.

7) A larger area for parking would reduce levels of carbon monoxide fumes and other harmful gases that are highly concentrated in the present parking garage.

8) The extra revenue generated by charging to park in the new garage could be used to fund valuable student programs.

9) More parking on the downtown campus would encourage student use of the Mt. Lair facilities and programs there.

10) More parking would attract more commuters to attend classes at WVU (this would provide more money to the university, and fund student programs). 


\section{Sheet B}

(Arguments in Support of Building a New Parking Garage)

1) Enough space might be provided for students who live in dormitories to have vehicles on campus.

2) Many students live quite far from the downtown campus and must drive to school every day (e.g., commuters who don't have the option of walking), so they would benefit from more parking spaces.

3) Repairs could be made to the old parking garage (e.g., it could be shut down temporarily) after the completion of the new parking garage.

4) Students would receive fewer tickets from local parking authorities if they were able to find parking in the new garage instead of parking illegally on the street.

5) Cars would be safer (e.g., protected from theft) during the day and at night.

6) A new garage would make the campus more handicap accessible by providing more parking spaces close to academic buildings.

7) Construction of a new garage would create more jobs for community-dwelling individuals.

8) Better use would be made of the land surrounding the Mt. Lair, which has remained unused for too long.

9) All campuses of WVU would benefit by a new parking garage because people could park on the downtown campus and commute via PRT to other campuses.

10) Visitors to the university would have somewhere to park without having to reserve a section of the current parking garage. 
Sheet B

(Arguments Against Building a New Parking Garage)

1) The cost of construction work might be added to students' tuition bills.

2) Students who work in town or have on-campus jobs would have more taxes taken out of their paychecks in order to pay for the new parking garage.

3) The land behind the Mountain Lair would be destroyed, including several trees that are over 100 years old.

4) On campus parking is too expensive. Even if a new garage were built, no one would park there.

5) The cost of parking in the new garage would be increased in order to pay for the costs of construction.

6) People should walk instead of driving to campus because it is healthier (e.g., they get more exercise).

7) Building a new parking garage would deplete funds that could be used for other valuable university projects and programs.8) The already high rate of traffic accidents in and around campus parking facilities would increase.

9) People should walk instead of driving to campus because it is better for the environment (e.g., fewer toxic vehicle emissions, etc.).

10) Traffic would become more congested around the downtown campus, creating more noise in an area in which many classes are held. 
Appendix $\mathrm{F}$

ANOVA table for initial rest period HR

Source

GEND

GROLE

AGEN

COMM

GEND * GROLE

GEND * AGEN

GROLE * AGEN

GEND * GROLE * AGEN

GEND * COMM

GROLE * COMM

GEND * GROLE * COMM

AGEN * COMM

GEND * AGEN * COMM

GROLE * AGEN * COMM $\quad 1.081$

GEND * GROLE * AGEN * 11.098

COMM

Error

Total

Corrected Total
Sum of Squares Df Mean Square F

$$
931.842
$$

272.116

41.151

307.450

4.392

117.631

51.314

20.240

134.143

7.585E-03

23.259

56.939

2.627

1.081

13858.766

731185.162

15834.057 $\begin{array}{lll}1 & 931.842 & 5.379\end{array}$

$\begin{array}{lll}1 & 272.116 & 1.571\end{array}$

$1 \quad 41.151$

.238

1.775

.025

.679

.296

.117

.774

$1 \quad 134.143$

1

7.585E-03 .000

$\begin{array}{lll}1 & 23.259 & .134\end{array}$

156.939

.329

12.627

.015

$1 \quad 1.081$

.006

$1 \quad 11.098$

.064
Sig. Eta

Squared

$.023 \quad .063$

$.214 \quad 019$

$.627 \quad .003$

$.187 \quad .022$

$.874 \quad .000$

$.412 \quad 008$

$.588 \quad .004$

$.733 \quad .001$

$.382 \quad .010$

$.995 \quad .000$

$.715 \quad .002$

$.568 \quad .004$

$.902 \quad .000$

$.937 \quad 000$

$.801 \quad .001$

a R Squared $=.125$ (Adjusted R Squared $=-.039)$ 
ANCOVA table for preparation period HR

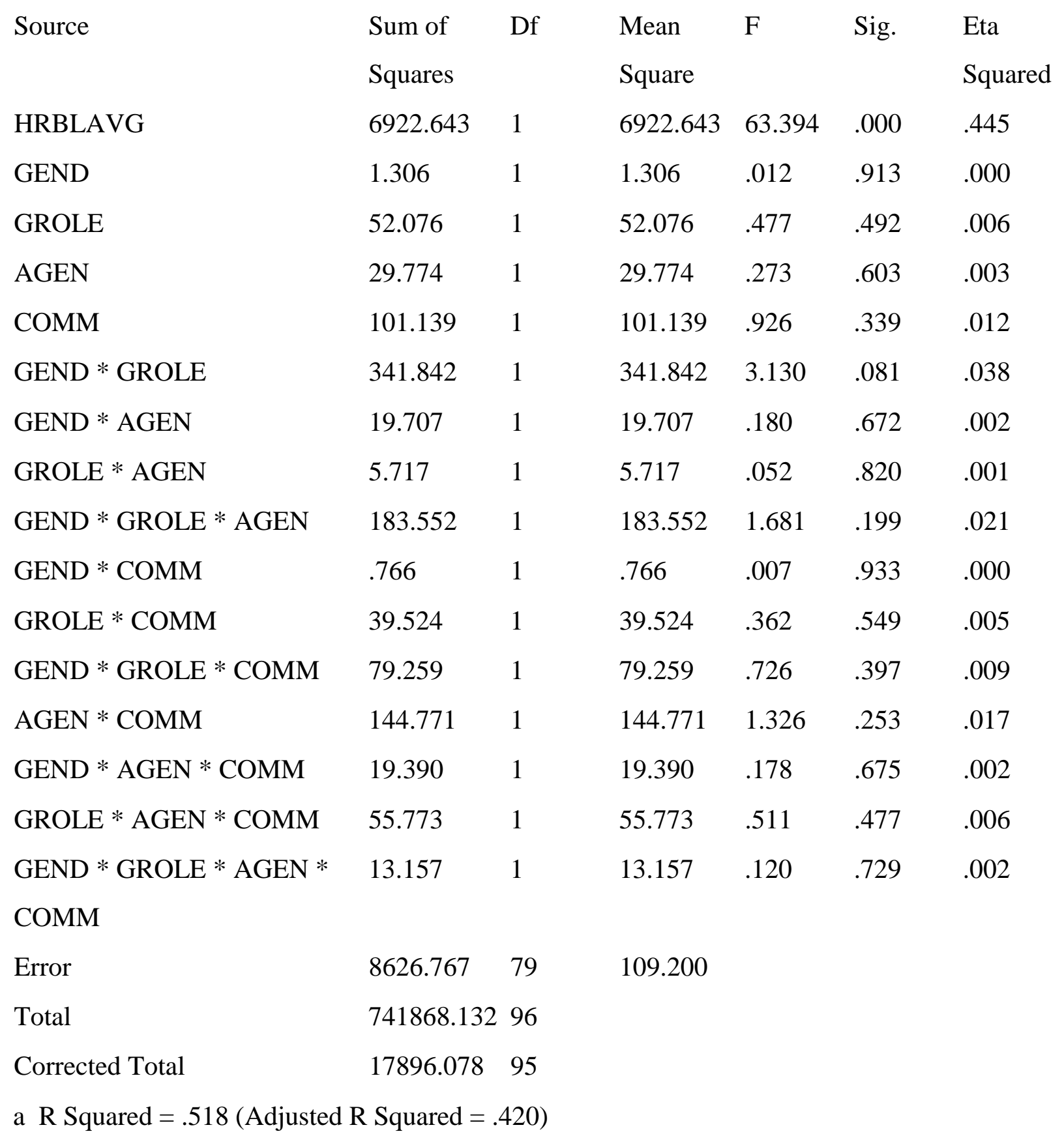


ANCOVA table for speaking intervals HR

\begin{tabular}{|c|c|c|c|c|c|c|}
\hline Source & Sum of & df & Mean & $\mathrm{F}$ & Sig. & Eta \\
\hline & Squares & & Square & & & Squared \\
\hline HRBLAVG & 6223.841 & 1 & 6223.841 & 65.493 & .000 & .453 \\
\hline GEND & 169.910 & 1 & 169.910 & 1.788 & .185 & .022 \\
\hline GROLE & 25.060 & 1 & 25.060 & .264 & .609 & .003 \\
\hline AGEN & 108.958 & 1 & 108.958 & 1.147 & .288 & .014 \\
\hline COMM & 226.711 & 1 & 226.711 & 2.386 & .126 & .029 \\
\hline GEND * GROLE & 439.523 & 1 & 439.523 & 4.625 & .035 & .055 \\
\hline GEND * AGEN & 3.070 & 1 & 3.070 & .032 & .858 & .000 \\
\hline GROLE * AGEN & 141.583 & 1 & 141.583 & 1.490 & .226 & .019 \\
\hline GEND $*$ GROLE $*$ AGEN & 76.563 & 1 & 76.563 & .806 & .372 & .010 \\
\hline GEND * COMM & 2.116 & 1 & 2.116 & .022 & .882 & .000 \\
\hline GROLE * COMM & 76.036 & 1 & 76.036 & .800 & .374 & .010 \\
\hline GEND $*$ GROLE $*$ COMM & 54.723 & 1 & 54.723 & .576 & .450 & .007 \\
\hline $\mathrm{AGEN} * \mathrm{COMM}$ & 94.197 & 1 & 94.197 & .991 & .322 & .012 \\
\hline GEND * AGEN * COMM & 117.455 & 1 & 117.455 & 1.236 & .270 & .015 \\
\hline GROLE * AGEN * COMM & 129.798 & 1 & 129.798 & 1.366 & .246 & .017 \\
\hline GEND $*$ GROLE $*$ AGEN * & 127.637 & 1 & 127.637 & 1.343 & .250 & .017 \\
\hline COMM & & & & & & \\
\hline Error & 7507.410 & 79 & 95.031 & & & \\
\hline Total & 865592.500 & 96 & & & & \\
\hline Corrected Total & 17046.015 & 95 & & & & \\
\hline
\end{tabular}


ANCOVA table for listening intervals HR

\begin{tabular}{|c|c|c|c|c|c|c|}
\hline Source & Sum of & df & Mean & $\mathrm{F}$ & Sig. & Eta \\
\hline & Squares & & Square & & & Squared \\
\hline HRBLAVG & 7653.466 & 1 & 7653.466 & 83.889 & .000 & .515 \\
\hline GEND & 3.157 & 1 & 3.157 & .035 & .853 & .000 \\
\hline GROLE & 52.461 & 1 & 52.461 & .575 & .451 & .007 \\
\hline AGEN & 40.845 & 1 & 40.845 & .448 & .505 & .006 \\
\hline COMM & 1.390 & 1 & 1.390 & .015 & .902 & .000 \\
\hline GEND * GROLE & 616.170 & 1 & 616.170 & 6.754 & .011 & .079 \\
\hline GEND * AGEN & 91.520 & 1 & 91.520 & 1.003 & .320 & .013 \\
\hline GROLE * AGEN & 133.267 & 1 & 133.267 & 1.461 & .230 & .018 \\
\hline GEND * GROLE * AGEN & 72.526 & 1 & 72.526 & .795 & .375 & .010 \\
\hline GEND * COMM & 8.134E-04 & 1 & 8.134E-04 & .000 & .998 & .000 \\
\hline GROLE $*$ COMM & 155.510 & 1 & 155.510 & 1.705 & .195 & .021 \\
\hline GEND * GROLE $*$ COMM & 69.491 & 1 & 69.491 & .762 & .385 & .010 \\
\hline $\mathrm{AGEN} * \mathrm{COMM}$ & 227.779 & 1 & 227.779 & 2.497 & .118 & .031 \\
\hline GEND * AGEN * COMM & 106.790 & 1 & 106.790 & 1.171 & .283 & .015 \\
\hline GROLE * AGEN * COMM & 2.175 & 1 & 2.175 & .024 & .878 & .000 \\
\hline GEND $*$ GROLE $*$ AGEN $*$ & 148.623 & 1 & 148.623 & 1.629 & .206 & .020 \\
\hline COMM & & & & & & \\
\hline Error & 7207.448 & 79 & 91.234 & & & \\
\hline Total & 762769.686 & 96 & & & & \\
\hline Corrected Total & 17554.689 & 95 & & & & \\
\hline
\end{tabular}


ANOVA table for initial rest period SBP

\begin{tabular}{|c|c|c|c|c|c|c|}
\hline Source & Sum of & df & Mean & $\mathrm{F}$ & Sig. & Eta \\
\hline & Squares & & Square & & & Squared \\
\hline GEND & 1046.760 & 1 & 1046.760 & 8.948 & .004 & .101 \\
\hline GROLE & 75.260 & 1 & 75.260 & .643 & .425 & .008 \\
\hline AGEN & 129.890 & 1 & 129.890 & 1.110 & .295 & .014 \\
\hline COMM & 10.446 & 1 & 10.446 & .089 & .766 & .001 \\
\hline GEND * GROLE & 164.501 & 1 & 164.501 & 1.406 & .239 & .017 \\
\hline GEND * AGEN & 23.010 & 1 & 23.010 & .197 & .659 & .002 \\
\hline GROLE * AGEN & 61.760 & 1 & 61.760 & .528 & .470 & .007 \\
\hline GEND * GROLE * AGEN & 39.612 & 1 & 39.612 & .339 & .562 & .004 \\
\hline GEND * COMM & 401.529 & 1 & 401.529 & 3.432 & .068 & .041 \\
\hline GROLE $*$ COMM & 9.168 & 1 & 9.168 & .078 & .780 & .001 \\
\hline GEND $*$ GROLE $*$ COMM & 39.612 & 1 & 39.612 & .339 & .562 & .004 \\
\hline $\mathrm{AGEN} * \mathrm{COMM}$ & $2.894 \mathrm{E}-02$ & 1 & $2.894 \mathrm{E}-02$ & .000 & .987 & .000 \\
\hline GEND * AGEN * COMM & 10.446 & 1 & 10.446 & .089 & .766 & .001 \\
\hline GROLE $*$ AGEN $*$ COMM & 193.612 & 1 & 193.612 & 1.655 & .202 & .020 \\
\hline GEND $*$ GROLE $*$ AGEN * & 223.057 & 1 & 223.057 & 1.907 & .171 & .023 \\
\hline COMM & & & & & & \\
\hline Error & 9358.722 & 80 & 116.984 & & & \\
\hline Total & 1379267.889 & 96 & & & & \\
\hline Corrected Total & 11787.416 & 95 & & & & \\
\hline
\end{tabular}


ANCOVA table for preparation period SBP

\begin{tabular}{|c|c|c|c|c|c|c|}
\hline Source & $\begin{array}{l}\text { Sum of } \\
\text { Squares }\end{array}$ & df & $\begin{array}{l}\text { Mean } \\
\text { Square }\end{array}$ & $\mathrm{F}$ & Sig. & $\begin{array}{l}\text { Eta } \\
\text { Squared }\end{array}$ \\
\hline SBPBLAV & 7925.216 & 1 & 7925.216 & 138.090 & .000 & .636 \\
\hline GEND & 174.016 & 1 & 174.016 & 3.032 & .086 & .037 \\
\hline GROLE & 14.750 & 1 & 14.750 & .257 & .614 & .003 \\
\hline AGEN & 23.435 & 1 & 23.435 & .408 & .525 & .005 \\
\hline COMM & 41.113 & 1 & 41.113 & .716 & .400 & .009 \\
\hline GEND * GROLE & $4.225 \mathrm{E}-03$ & 1 & $4.225 \mathrm{E}-03$ & .000 & .993 & .000 \\
\hline GEND * AGEN & 225.309 & 1 & 225.309 & 3.926 & .051 & .047 \\
\hline GROLE * AGEN & 49.066 & 1 & 49.066 & .855 & .358 & .011 \\
\hline GEND * GROLE * AGEN & 72.751 & 1 & 72.751 & 1.268 & .264 & .016 \\
\hline GEND * COMM & 17.345 & 1 & 17.345 & .302 & .584 & .004 \\
\hline GROLE * COMM & .413 & 1 & .413 & .007 & .933 & .000 \\
\hline GEND $*$ GROLE $*$ COMM & 2.413 & 1 & 2.413 & .042 & .838 & .001 \\
\hline $\mathrm{AGEN} * \mathrm{COMM}$ & 17.057 & 1 & 17.057 & .297 & .587 & .004 \\
\hline GEND * AGEN * COMM & 70.204 & 1 & 70.204 & 1.223 & .272 & .015 \\
\hline GROLE * AGEN * COMM & 42.403 & 1 & 42.403 & .739 & .393 & .009 \\
\hline GEND * GROLE * AGEN * & $1.825 \mathrm{E}-02$ & 1 & $1.825 \mathrm{E}-02$ & .000 & .986 & .000 \\
\hline \multicolumn{7}{|l|}{ COMM } \\
\hline Error & 4533.951 & 79 & 57.392 & & & \\
\hline Total & 1547847.500 & 96 & & & & \\
\hline Corrected Total & 15424.156 & 95 & & & & \\
\hline
\end{tabular}


ANCOVA table for speaking intervals SBP

\begin{tabular}{|c|c|c|c|c|c|c|}
\hline Source & Sum of & df & Mean & $\mathrm{F}$ & Sig. & Eta \\
\hline & Squares & & Square & & & Squared \\
\hline SBPBLAV & 6395.516 & 1 & 6395.516 & 64.392 & .000 & .449 \\
\hline GEND & 36.535 & 1 & 36.535 & .368 & .546 & .005 \\
\hline GROLE & 233.230 & 1 & 233.230 & 2.348 & .129 & .029 \\
\hline AGEN & 173.127 & 1 & 173.127 & 1.743 & .191 & .022 \\
\hline COMM & 4.731 & 1 & 4.731 & .048 & .828 & .001 \\
\hline GEND * GROLE & 23.965 & 1 & 23.965 & .241 & .625 & .003 \\
\hline GEND * AGEN & 244.370 & 1 & 244.370 & 2.460 & .121 & .030 \\
\hline GROLE * AGEN & 97.061 & 1 & 97.061 & .977 & .326 & .012 \\
\hline GEND * GROLE * AGEN & 98.561 & 1 & 98.561 & .992 & .322 & .012 \\
\hline GEND * COMM & 8.871 & 1 & 8.871 & .089 & .766 & .001 \\
\hline GROLE $*$ COMM & .662 & 1 & .662 & .007 & .935 & .000 \\
\hline GEND * GROLE * COMM & 102.739 & 1 & 102.739 & 1.034 & .312 & .013 \\
\hline $\mathrm{AGEN} * \mathrm{COMM}$ & 142.891 & 1 & 142.891 & 1.439 & .234 & .018 \\
\hline GEND * AGEN * COMM & 177.684 & 1 & 177.684 & 1.789 & .185 & .022 \\
\hline GROLE $*$ AGEN $*$ COMM & 11.658 & 1 & 11.658 & .117 & .733 & .001 \\
\hline GEND $*$ GROLE $*$ AGEN $*$ & 15.849 & 1 & 15.849 & .160 & .691 & .002 \\
\hline COMM & & & & & & \\
\hline Error & 7846.442 & 79 & 99.322 & & & \\
\hline Total & 1771653.750 & 96 & & & & \\
\hline Corrected Total & 17325.560 & 95 & & & & \\
\hline
\end{tabular}


ANCOVA table for listening intervals SBP

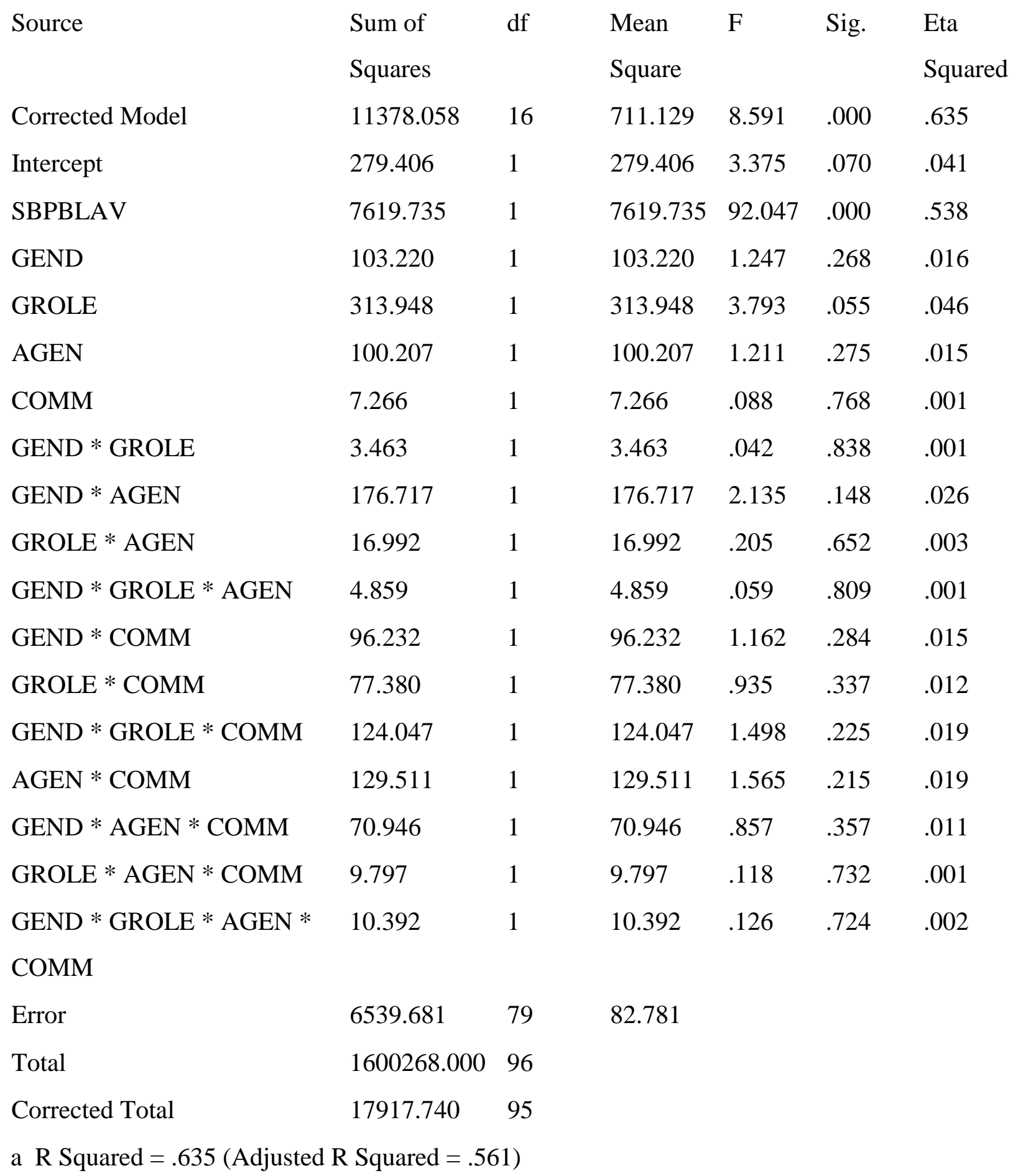


ANOVA table for initial rest period DBP

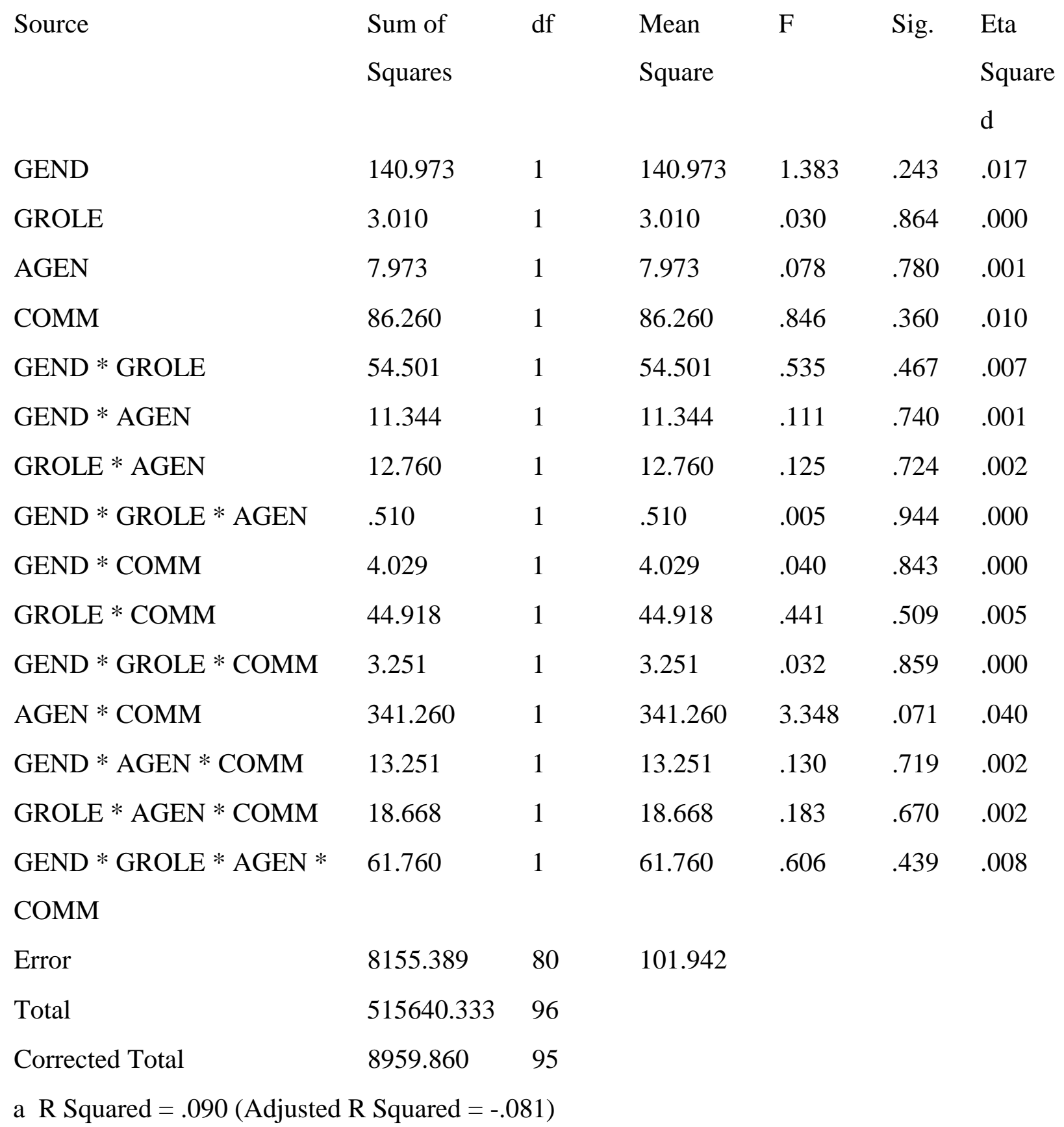


ANCOVA table for preparation period DBP

\begin{tabular}{|c|c|c|c|c|c|c|}
\hline Source & $\begin{array}{l}\text { Sum of } \\
\text { Squares }\end{array}$ & df & $\begin{array}{l}\text { Mean } \\
\text { Square }\end{array}$ & $\mathrm{F}$ & Sig. & $\begin{array}{l}\text { Eta } \\
\text { Squared }\end{array}$ \\
\hline DBPBLAVG & 3386.322 & 1 & 3386.322 & 2.875 & .094 & .035 \\
\hline GEND & 2073.875 & 1 & 2073.875 & 1.761 & .188 & .022 \\
\hline GROLE & 1106.942 & 1 & 1106.942 & .940 & .335 & .012 \\
\hline AGEN & 1913.684 & 1 & 1913.684 & 1.625 & .206 & .020 \\
\hline COMM & 370.691 & 1 & 370.691 & .315 & .576 & .004 \\
\hline GEND * GROLE & 633.286 & 1 & 633.286 & .538 & .466 & .007 \\
\hline GEND * AGEN & 436.025 & 1 & 436.025 & .370 & .545 & .005 \\
\hline GROLE * AGEN & 2195.432 & 1 & 2195.432 & 1.864 & .176 & .023 \\
\hline GEND $*$ GROLE $*$ AGEN & 972.197 & 1 & 972.197 & .825 & .366 & .010 \\
\hline GEND * COMM & 1222.569 & 1 & 1222.569 & 1.038 & .311 & .013 \\
\hline GROLE * COMM & 909.596 & 1 & 909.596 & .772 & .382 & .010 \\
\hline GEND * GROLE * COMM & 1994.077 & 1 & 1994.077 & 1.693 & .197 & .021 \\
\hline $\mathrm{AGEN} * \mathrm{COMM}$ & 618.077 & 1 & 618.077 & .525 & .471 & .007 \\
\hline GEND $*$ AGEN $*$ COMM & 1995.289 & 1 & 1995.289 & 1.694 & .197 & .021 \\
\hline GROLE $*$ AGEN * COMM & 1534.718 & 1 & 1534.718 & 1.303 & .257 & .016 \\
\hline GEND $*$ GROLE $*$ AGEN $*$ & 2229.484 & 1 & 2229.484 & 1.893 & .173 & .023 \\
\hline \multicolumn{7}{|l|}{ COMM } \\
\hline Error & 93049.511 & 79 & 1177.842 & & & \\
\hline Total & 739066.000 & 96 & & & & \\
\hline Corrected Total & 117605.833 & 95 & & & & \\
\hline
\end{tabular}


ANCOVA table for speaking intervals DBP

\begin{tabular}{|c|c|c|c|c|c|c|}
\hline Source & $\begin{array}{l}\text { Sum of } \\
\text { Squares }\end{array}$ & $\mathrm{df}$ & $\begin{array}{l}\text { Mean } \\
\text { Square }\end{array}$ & $\mathrm{F}$ & Sig. & $\begin{array}{l}\text { Eta } \\
\text { Squared }\end{array}$ \\
\hline DBPBLAVG & 4499.973 & 1 & 4499.973 & 31.233 & .000 & .283 \\
\hline GEND & 47.229 & 1 & 47.229 & .328 & .569 & .004 \\
\hline GROLE & 3.326 & 1 & 3.326 & .023 & .880 & .000 \\
\hline AGEN & 4.141 & 1 & 4.141 & .029 & .866 & .000 \\
\hline COMM & 71.175 & 1 & 71.175 & .494 & .484 & .006 \\
\hline GEND * GROLE & 12.843 & 1 & 12.843 & .089 & .766 & .001 \\
\hline GEND * AGEN & 55.453 & 1 & 55.453 & .385 & .537 & .005 \\
\hline GROLE * AGEN & 335.108 & 1 & 335.108 & 2.326 & .131 & .029 \\
\hline GEND * GROLE * AGEN & 24.703 & 1 & 24.703 & .171 & .680 & .002 \\
\hline GEND * COMM & 433.748 & 1 & 433.748 & 3.011 & .087 & .037 \\
\hline GROLE * COMM & 29.898 & 1 & 29.898 & .208 & .650 & .003 \\
\hline GEND $*$ GROLE $*$ COMM & 161.078 & 1 & 161.078 & 1.118 & .294 & .014 \\
\hline $\mathrm{AGEN} * \mathrm{COMM}$ & 524.092 & 1 & 524.092 & 3.638 & .060 & .044 \\
\hline GEND $*$ AGEN $*$ COMM & 95.857 & 1 & 95.857 & .665 & .417 & .008 \\
\hline GROLE $*$ AGEN * COMM & 73.426 & 1 & 73.426 & .510 & .477 & .006 \\
\hline GEND * GROLE * AGEN * & 435.755 & 1 & 435.755 & 3.024 & .086 & .037 \\
\hline \multicolumn{7}{|l|}{ COMM } \\
\hline Error & 11382.152 & 79 & 144.078 & & & \\
\hline Total & 678288.750 & 96 & & & & \\
\hline Corrected Total & 18189.164 & 95 & & & & \\
\hline
\end{tabular}


ANCOVA table for listening intervals DBP

\begin{tabular}{|c|c|c|c|c|c|c|}
\hline Source & Sum of & $\mathrm{df}$ & Mean & $\mathrm{F}$ & Sig. & Eta \\
\hline & Squares & & Square & & & Squared \\
\hline DBPBLAVG & 5852.061 & 1 & 5852.061 & 65.220 & .000 & .452 \\
\hline GEND & 4.936 & 1 & 4.936 & .055 & .815 & .001 \\
\hline GROLE & 1.021 & 1 & 1.021 & .011 & .915 & .000 \\
\hline AGEN & 6.537 & 1 & 6.537 & .073 & .788 & .001 \\
\hline COMM & 139.692 & 1 & 139.692 & 1.557 & .216 & .019 \\
\hline GEND * GROLE & 101.881 & 1 & 101.881 & 1.135 & .290 & .014 \\
\hline GEND * AGEN & 40.574 & 1 & 40.574 & .452 & .503 & .006 \\
\hline GROLE * AGEN & 116.532 & 1 & 116.532 & 1.299 & .258 & .016 \\
\hline GEND $*$ GROLE $*$ AGEN & 23.432 & 1 & 23.432 & .261 & .611 & .003 \\
\hline GEND * COMM & .277 & 1 & .277 & .003 & .956 & .000 \\
\hline GROLE $*$ COMM & 99.238 & 1 & 99.238 & 1.106 & .296 & .014 \\
\hline GEND * GROLE * COMM & 164.090 & 1 & 164.090 & 1.829 & .180 & .023 \\
\hline $\mathrm{AGEN} * \mathrm{COMM}$ & 245.896 & 1 & 245.896 & 2.740 & .102 & .034 \\
\hline GEND * AGEN * COMM & 22.693 & 1 & 22.693 & .253 & .616 & .003 \\
\hline GROLE $*$ AGEN $*$ COMM & 16.101 & 1 & 16.101 & .179 & .673 & .002 \\
\hline GEND $*$ GROLE $*$ AGEN * & 30.453 & 1 & 30.453 & .339 & .562 & .004 \\
\hline COMM & & & & & & \\
\hline Error & 7088.480 & 79 & 89.728 & & & \\
\hline Total & 606255.250 & 96 & & & & \\
\hline Corrected Total & 14600.747 & 95 & & & & \\
\hline
\end{tabular}

a R Squared $=.515$ (Adjusted R Squared $=.416$ ) 
ANOVA table for ACI - V Score

\begin{tabular}{|c|c|c|c|c|c|c|}
\hline Source & $\begin{array}{l}\text { Sum of } \\
\text { Squares }\end{array}$ & df & $\begin{array}{l}\text { Mean } \\
\text { Square }\end{array}$ & $\mathrm{F}$ & Sig. & $\begin{array}{l}\text { Eta } \\
\text { Squared }\end{array}$ \\
\hline GEND & 24.000 & 1 & 24.000 & 8.597 & .004 & .097 \\
\hline GROLE & .167 & 1 & .167 & .060 & .808 & .001 \\
\hline AGEN & .667 & 1 & .667 & .239 & .626 & .003 \\
\hline COMM & .375 & 1 & .375 & .134 & .715 & .002 \\
\hline GEND * GROLE & 1.042 & 1 & 1.042 & .373 & .543 & .005 \\
\hline GEND * AGEN & 3.375 & 1 & 3.375 & 1.209 & .275 & .015 \\
\hline GROLE * AGEN & 2.042 & 1 & 2.042 & .731 & .395 & .009 \\
\hline GEND $*$ GROLE $*$ AGEN & .667 & 1 & .667 & .239 & .626 & .003 \\
\hline GEND * COMM & .167 & 1 & .167 & .060 & .808 & .001 \\
\hline GROLE $*$ COMM & .667 & 1 & .667 & .239 & .626 & .003 \\
\hline GEND $*$ GROLE $*$ COMM & .375 & 1 & .375 & .134 & .715 & .002 \\
\hline $\mathrm{AGEN} * \mathrm{COMM}$ & .667 & 1 & .667 & .239 & .626 & .003 \\
\hline GEND $*$ AGEN $*$ COMM & .375 & 1 & .375 & .134 & .715 & .002 \\
\hline GROLE * AGEN * COMM & $4.167 \mathrm{E}-02$ & 1 & 4.167E-02 & .015 & .903 & .000 \\
\hline GEND $*$ GROLE $*$ AGEN $*$ & .667 & 1 & .667 & .239 & .626 & .003 \\
\hline \multicolumn{7}{|l|}{ COMM } \\
\hline Error & 223.333 & 80 & 2.792 & & & \\
\hline Total & 304.000 & 96 & & & & \\
\hline Corrected Total & 258.625 & 95 & & & & \\
\hline
\end{tabular}


ANOVA table for ACI - RC Score

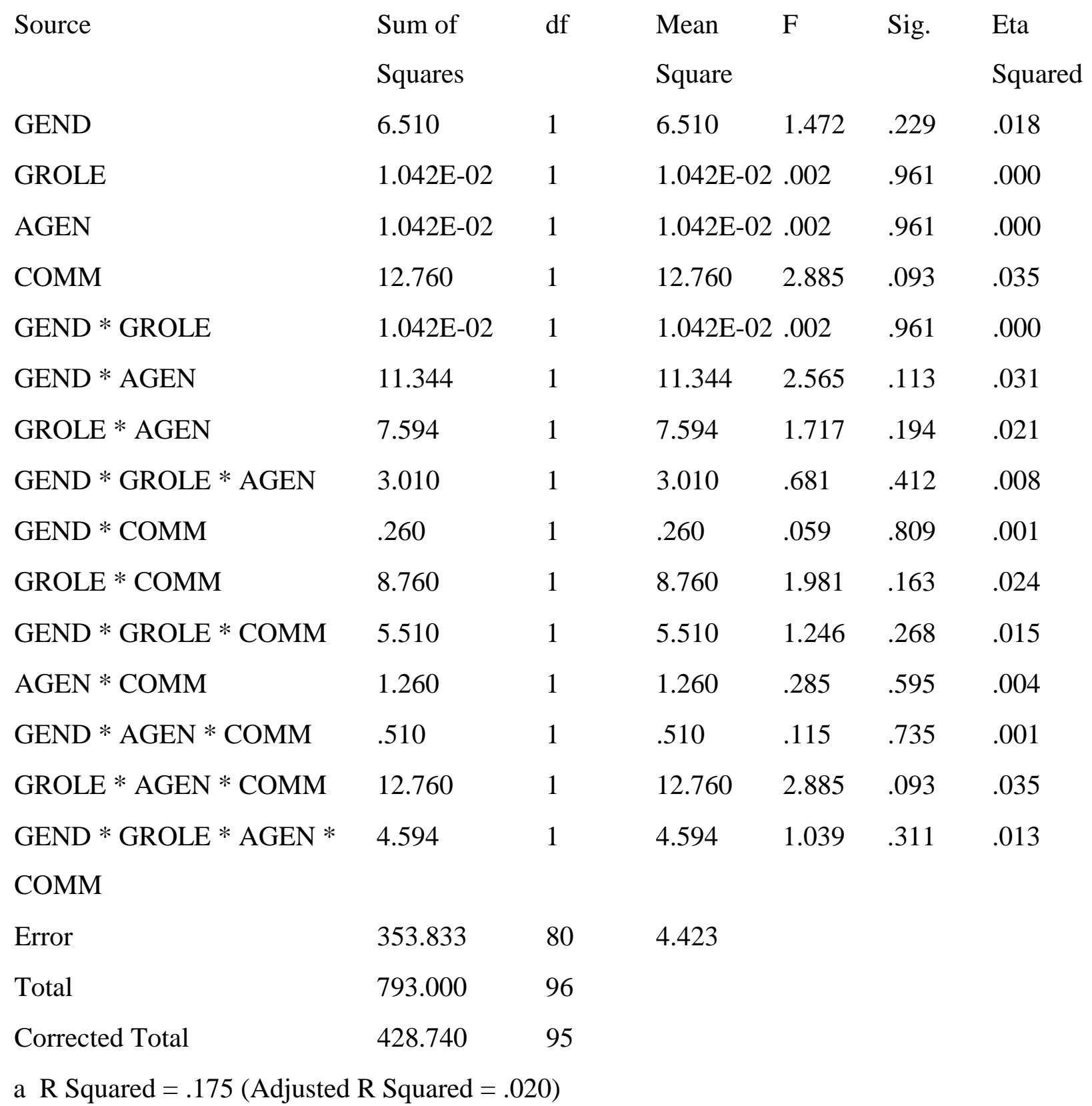


ANOVA table for ACI - R Score

\begin{tabular}{|c|c|c|c|c|c|c|}
\hline Source & $\begin{array}{l}\text { Sum of } \\
\text { Squares }\end{array}$ & df & $\begin{array}{l}\text { Mean } \\
\text { Square }\end{array}$ & $\mathrm{F}$ & Sig. & $\begin{array}{l}\text { Eta } \\
\text { Squared }\end{array}$ \\
\hline GEND & 5.042 & 1 & 5.042 & 1.811 & .182 & .022 \\
\hline GROLE & .375 & 1 & .375 & .135 & .715 & .002 \\
\hline AGEN & 1.042 & 1 & 1.042 & .374 & .542 & .005 \\
\hline COMM & 2.042 & 1 & 2.042 & .734 & .394 & .009 \\
\hline GEND * GROLE & .375 & 1 & .375 & .135 & .715 & .002 \\
\hline GEND * AGEN & 7.042 & 1 & 7.042 & 2.530 & .116 & .031 \\
\hline GROLE * AGEN & 5.042 & 1 & 5.042 & 1.811 & .182 & .022 \\
\hline GEND $*$ GROLE $*$ AGEN & $4.167 \mathrm{E}-02$ & 1 & 4.167E-02 & .015 & .903 & .000 \\
\hline GEND * COMM & 1.042 & 1 & 1.042 & .374 & .542 & .005 \\
\hline GROLE $*$ COMM & 2.042 & 1 & 2.042 & .734 & .394 & .009 \\
\hline GEND $*$ GROLE $*$ COMM & 4.167E-02 & 1 & 4.167E-02 & .015 & .903 & .000 \\
\hline $\mathrm{AGEN} * \mathrm{COMM}$ & 1.042 & 1 & 1.042 & .374 & .542 & .005 \\
\hline GEND $*$ AGEN $*$ COMM & 3.375 & 1 & 3.375 & 1.213 & .274 & .015 \\
\hline GROLE * AGEN * COMM & 3.375 & 1 & 3.375 & 1.213 & .274 & .015 \\
\hline GEND $*$ GROLE $*$ AGEN $*$ & .375 & 1 & .375 & .135 & .715 & .002 \\
\hline \multicolumn{7}{|l|}{ COMM } \\
\hline Error & 222.667 & 80 & 2.783 & & & \\
\hline Total & 400.000 & 96 & & & & \\
\hline Corrected Total & 254.958 & 95 & & & & \\
\hline
\end{tabular}


ANOVA table for ACI - SR Score

\begin{tabular}{|c|c|c|c|c|c|c|}
\hline Source & $\begin{array}{l}\text { Sum of } \\
\text { Squares }\end{array}$ & $\mathrm{df}$ & $\begin{array}{l}\text { Mean } \\
\text { Square }\end{array}$ & F & Sig. & $\begin{array}{l}\text { Eta } \\
\text { Squared }\end{array}$ \\
\hline GEND & 2.344 & 1 & 2.344 & .921 & .340 & .011 \\
\hline GROLE & 1.260 & 1 & 1.260 & .495 & .484 & .006 \\
\hline AGEN & .510 & 1 & .510 & .201 & .655 & .003 \\
\hline COMM & 12.760 & 1 & 12.760 & 5.016 & .028 & .059 \\
\hline GEND * GROLE & 1.260 & 1 & 1.260 & .495 & .484 & .006 \\
\hline GEND * AGEN & 7.594 & 1 & 7.594 & 2.985 & .088 & .036 \\
\hline GROLE * AGEN & .510 & 1 & .510 & .201 & .655 & .003 \\
\hline GEND * GROLE * AGEN & .260 & 1 & .260 & .102 & .750 & .001 \\
\hline GEND * COMM & $9.375 \mathrm{E}-02$ & 1 & $9.375 \mathrm{E}-02$ & .037 & .848 & .000 \\
\hline GROLE * COMM & 1.260 & 1 & 1.260 & .495 & .484 & .006 \\
\hline GEND * GROLE * COMM & 1.260 & 1 & 1.260 & .495 & .484 & .006 \\
\hline $\mathrm{AGEN} * \mathrm{COMM}$ & .260 & 1 & .260 & .102 & .750 & .001 \\
\hline GEND * AGEN * COMM & $1.042 \mathrm{E}-02$ & 1 & $1.042 \mathrm{E}-02$ & .004 & .949 & .000 \\
\hline GROLE * AGEN * COMM & .510 & 1 & .510 & .201 & .655 & .003 \\
\hline GEND * GROLE * AGEN * & $9.375 \mathrm{E}-02$ & 1 & $9.375 \mathrm{E}-02$ & .037 & .848 & .000 \\
\hline \multicolumn{7}{|l|}{ COMM } \\
\hline Error & 203.500 & 80 & 2.544 & & & \\
\hline Total & 381.000 & 96 & & & & \\
\hline Corrected Total & 233.490 & 95 & & & & \\
\hline
\end{tabular}


ANCOVA table for SAS total scores

\begin{tabular}{|c|c|c|c|c|c|c|}
\hline Source & $\begin{array}{l}\text { Sum of } \\
\text { Squares }\end{array}$ & df & $\begin{array}{l}\text { Mean } \\
\text { Square }\end{array}$ & $\mathrm{F}$ & Sig. & $\begin{array}{l}\text { Eta } \\
\text { Squared }\end{array}$ \\
\hline GEND & 1.042 & 1 & 1.042 & .280 & .598 & .003 \\
\hline GROLE & 1.500 & 1 & 1.500 & .403 & .527 & .005 \\
\hline AGEN & .667 & 1 & .667 & .179 & .673 & .002 \\
\hline COMM & 20.167 & 1 & 20.167 & 5.420 & .022 & .063 \\
\hline GEND * GROLE & 5.042 & 1 & 5.042 & 1.355 & .248 & .017 \\
\hline GEND * AGEN & 12.042 & 1 & 12.042 & 3.236 & .076 & .039 \\
\hline GROLE * AGEN & .000 & 1 & .000 & .000 & 1.000 & .000 \\
\hline GEND * GROLE * AGEN & 2.042 & 1 & 2.042 & .549 & .461 & .007 \\
\hline GEND * COMM & 4.167E-02 & 1 & 4.167E-02 & .011 & .916 & .000 \\
\hline GROLE * COMM & 2.667 & 1 & 2.667 & .717 & .400 & .009 \\
\hline GEND * GROLE * COMM & 3.375 & 1 & 3.375 & .907 & .344 & .011 \\
\hline $\mathrm{AGEN} * \mathrm{COMM}$ & 4.167 & 1 & 4.167 & 1.120 & .293 & .014 \\
\hline GEND * AGEN * COMM & .375 & 1 & .375 & .101 & .752 & .001 \\
\hline GROLE * AGEN * COMM & .167 & 1 & .167 & .045 & .833 & .001 \\
\hline GEND $*$ GROLE $*$ AGEN $*$ & 1.042 & 1 & 1.042 & .280 & .598 & .003 \\
\hline \multicolumn{7}{|l|}{ COMM } \\
\hline Error & 297.667 & 80 & 3.721 & & & \\
\hline Total & 11446.000 & 96 & & & & \\
\hline Corrected Total & 352.000 & 95 & & & & \\
\hline
\end{tabular}


ANOVA table for Perceived Challenge

\begin{tabular}{|c|c|c|c|c|c|c|}
\hline Source & $\begin{array}{l}\text { Sum of } \\
\text { Squares }\end{array}$ & $\mathrm{df}$ & $\begin{array}{l}\text { Mean } \\
\text { Square }\end{array}$ & $\mathrm{F}$ & Sig. & $\begin{array}{l}\text { Eta } \\
\text { Squared }\end{array}$ \\
\hline GEND & 17.940 & 1 & 17.940 & 2.014 & .160 & .025 \\
\hline GROLE & 30.488 & 1 & 30.488 & 3.422 & .068 & .041 \\
\hline AGEN & .100 & 1 & .100 & .011 & .916 & .000 \\
\hline COMM & .618 & 1 & .618 & .069 & .793 & .001 \\
\hline GEND * GROLE & 12.688 & 1 & 12.688 & 1.424 & .236 & .017 \\
\hline GEND * AGEN & 4.125 & 1 & 4.125 & .463 & .498 & .006 \\
\hline GROLE * AGEN & 13.878 & 1 & 13.878 & 1.558 & .216 & .019 \\
\hline GEND * GROLE * AGEN & .128 & 1 & .128 & .014 & .905 & .000 \\
\hline GEND * COMM & 1.283 & 1 & 1.283 & .144 & .705 & .002 \\
\hline GROLE * COMM & 24.908 & 1 & 24.908 & 2.796 & .098 & .034 \\
\hline GEND * GROLE * COMM & 22.138 & 1 & 22.138 & 2.485 & .119 & .030 \\
\hline $\mathrm{AGEN} * \mathrm{COMM}$ & 9.563 & 1 & 9.563 & 1.073 & .303 & .013 \\
\hline GEND * AGEN * COMM & 8.461 & 1 & 8.461 & .950 & .333 & .012 \\
\hline GROLE $*$ AGEN $*$ COMM & 58.126 & 1 & 58.126 & 6.524 & .013 & .075 \\
\hline GEND * GROLE * AGEN * & .100 & 1 & .100 & .011 & .916 & .000 \\
\hline \multicolumn{7}{|l|}{ COMM } \\
\hline Error & 712.718 & 80 & 8.909 & & & \\
\hline Total & 2603.150 & 96 & & & & \\
\hline Corrected Total & 917.262 & 95 & & & & \\
\hline
\end{tabular}


ANOVA table for Perceived Stress

\begin{tabular}{|c|c|c|c|c|c|c|}
\hline Source & $\begin{array}{l}\text { Sum of } \\
\text { Squares }\end{array}$ & $\mathrm{df}$ & $\begin{array}{l}\text { Mean } \\
\text { Square }\end{array}$ & $\mathrm{F}$ & Sig. & $\begin{array}{l}\text { Eta } \\
\text { Squared }\end{array}$ \\
\hline GEND & 32.900 & 1 & 32.900 & 4.921 & .029 & .058 \\
\hline GROLE & 6.827 & 1 & 6.827 & 1.021 & .315 & .013 \\
\hline AGEN & .570 & 1 & .570 & .085 & .771 & .001 \\
\hline COMM & 2.734 & 1 & 2.734 & .409 & .524 & .005 \\
\hline GEND * GROLE & $1.042 \mathrm{E}-02$ & 1 & $1.042 \mathrm{E}-02$ & .002 & .969 & .000 \\
\hline GEND * AGEN & $6.667 \mathrm{E}-03$ & 1 & $6.667 \mathrm{E}-03$ & .001 & .975 & .000 \\
\hline GROLE * AGEN & 14.570 & 1 & 14.570 & 2.179 & .144 & .027 \\
\hline GEND * GROLE * AGEN & 3.375 & 1 & 3.375 & .505 & .479 & .006 \\
\hline GEND * COMM & .427 & 1 & .427 & .064 & .801 & .001 \\
\hline GROLE * COMM & 17.854 & 1 & 17.854 & 2.671 & .106 & .032 \\
\hline GEND $*$ GROLE $*$ COMM & 14.415 & 1 & 14.415 & 2.156 & .146 & .026 \\
\hline AGEN * COMM & .540 & 1 & .540 & .081 & .777 & .001 \\
\hline GEND * AGEN * COMM & 26.670 & 1 & 26.670 & 3.989 & .049 & .047 \\
\hline GROLE * AGEN * COMM & 22.427 & 1 & 22.427 & 3.355 & .071 & .040 \\
\hline GEND * GROLE * AGEN * & 2.600 & 1 & 2.600 & .389 & .535 & .005 \\
\hline \multicolumn{7}{|l|}{ COMM } \\
\hline Error & 534.827 & 80 & 6.685 & & & \\
\hline Total & 1539.960 & 96 & & & & \\
\hline Corrected Total & 680.753 & 95 & & & & \\
\hline
\end{tabular}


ANOVA table for Perceived Effort to Convince

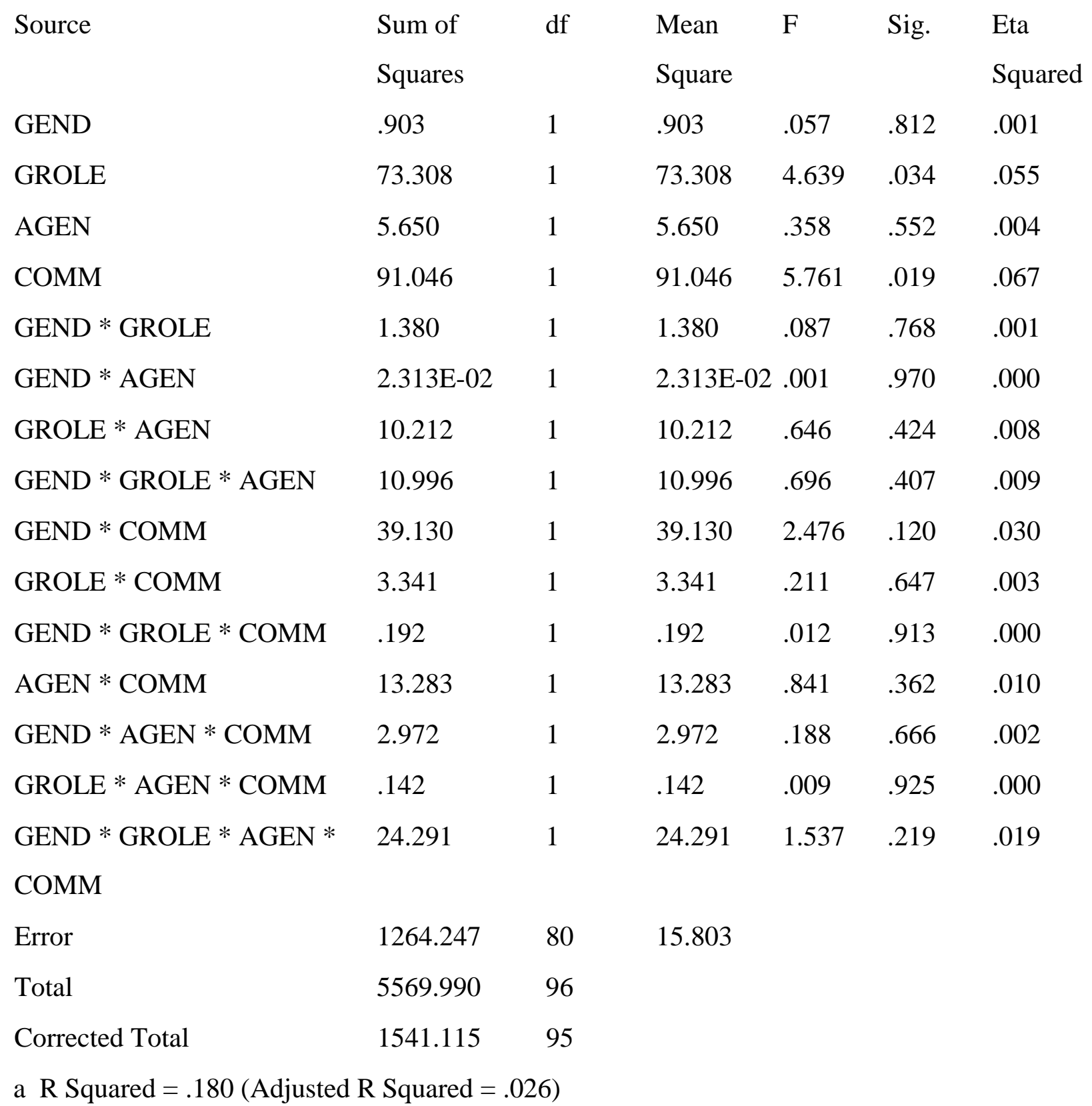


ANOVA table for Perceived Threat

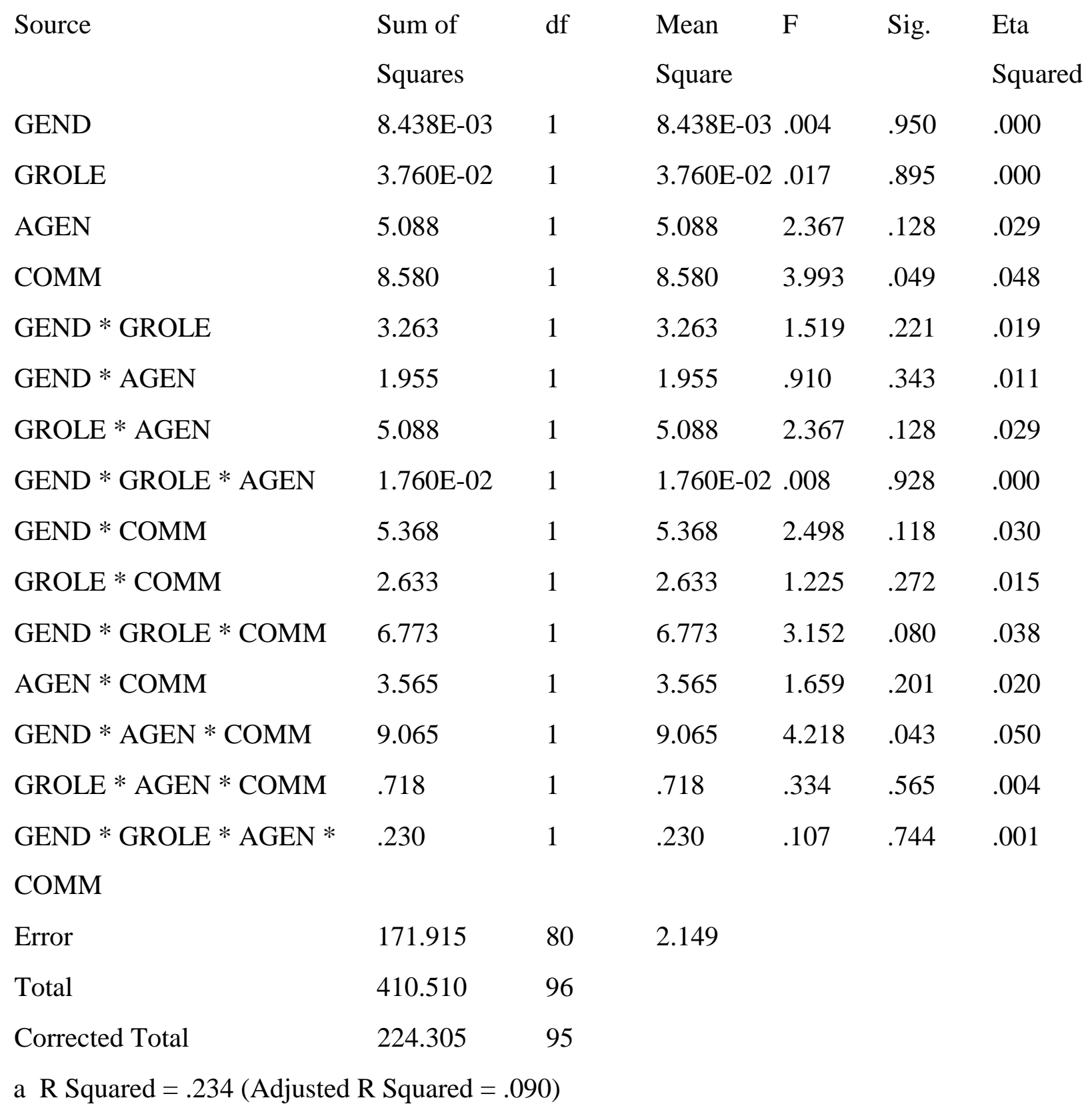


ANOVA table for Perceived Support

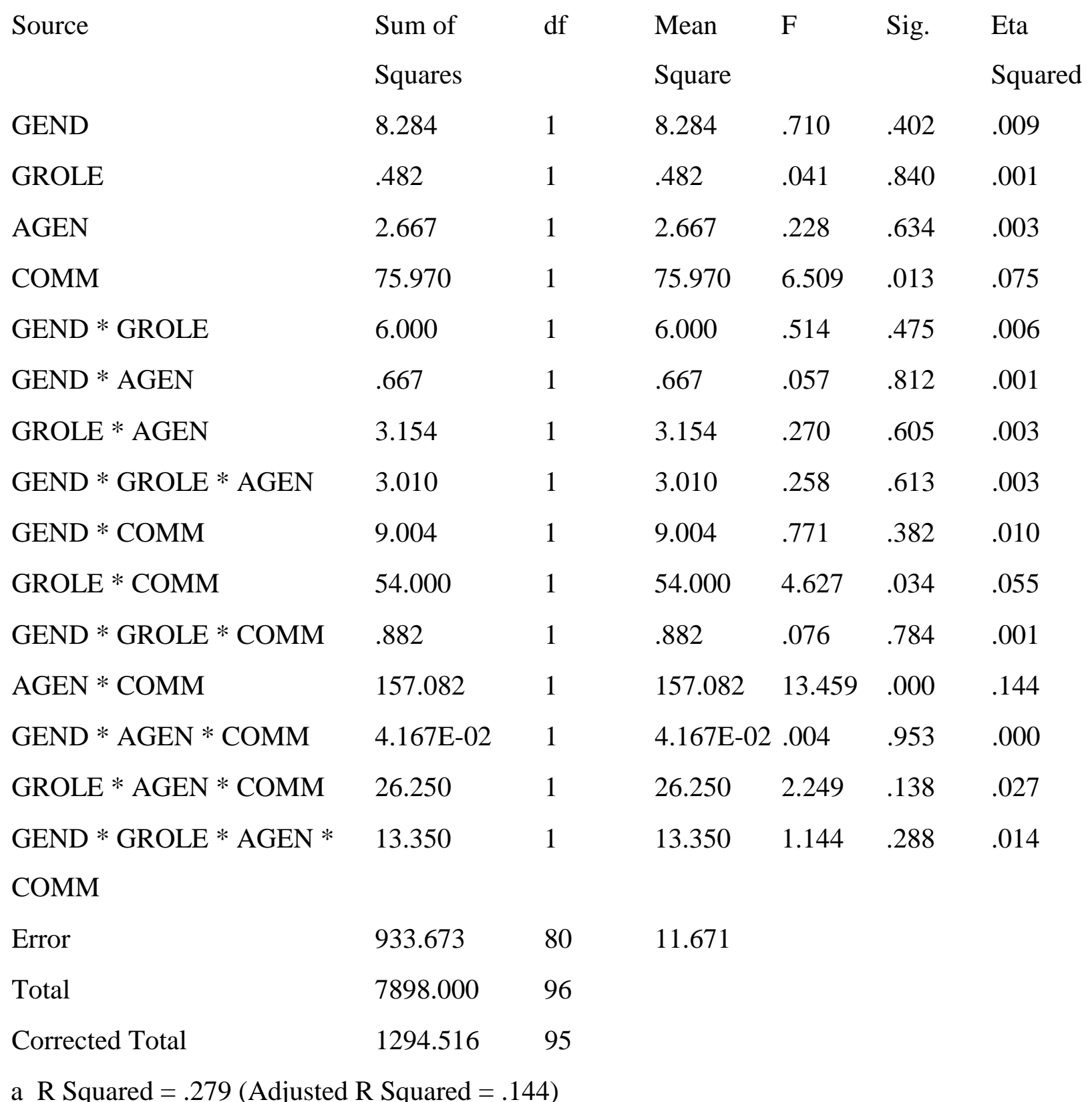




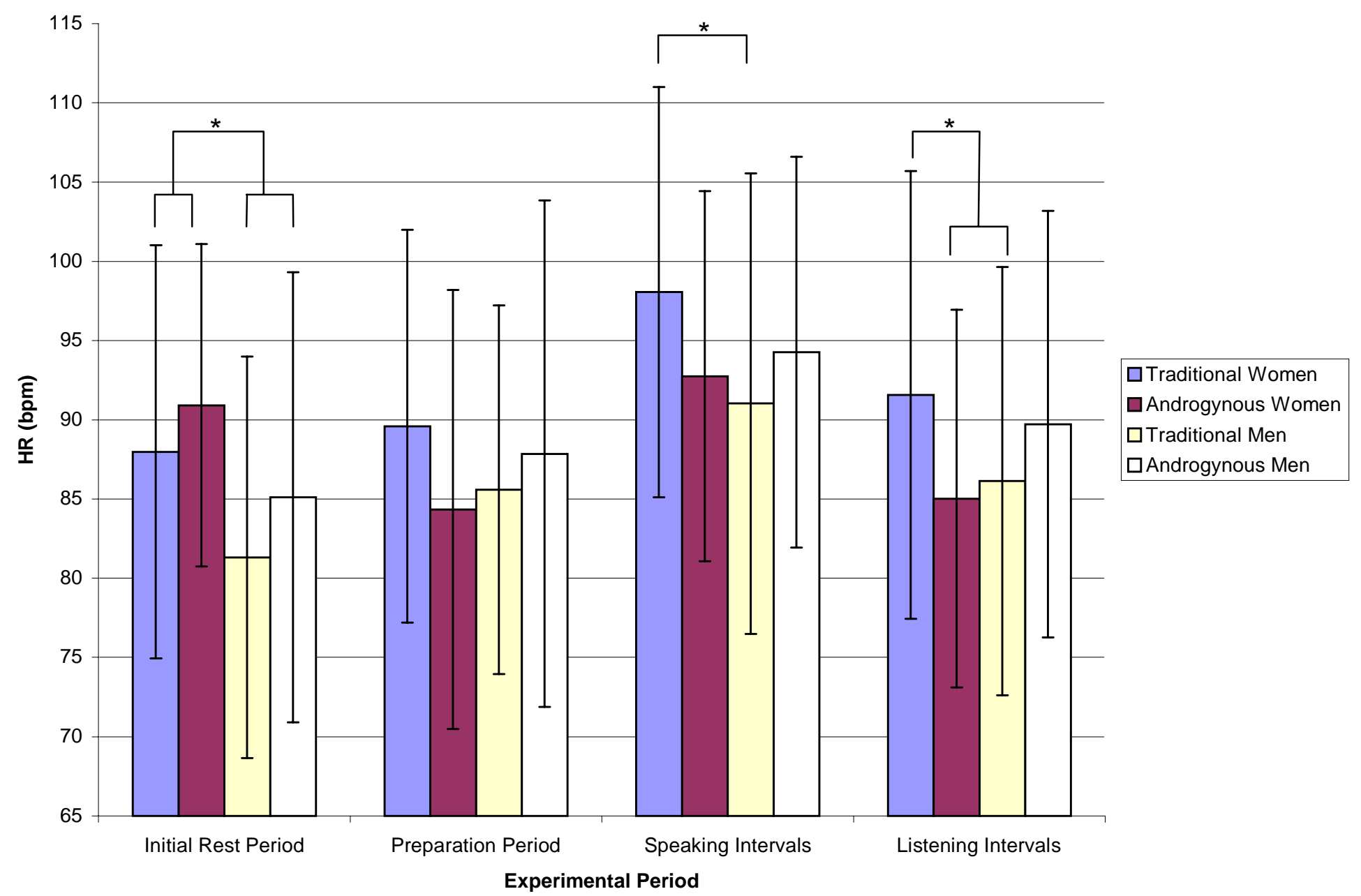

Figure 1. Gender X Gender Role interaction for HR. 


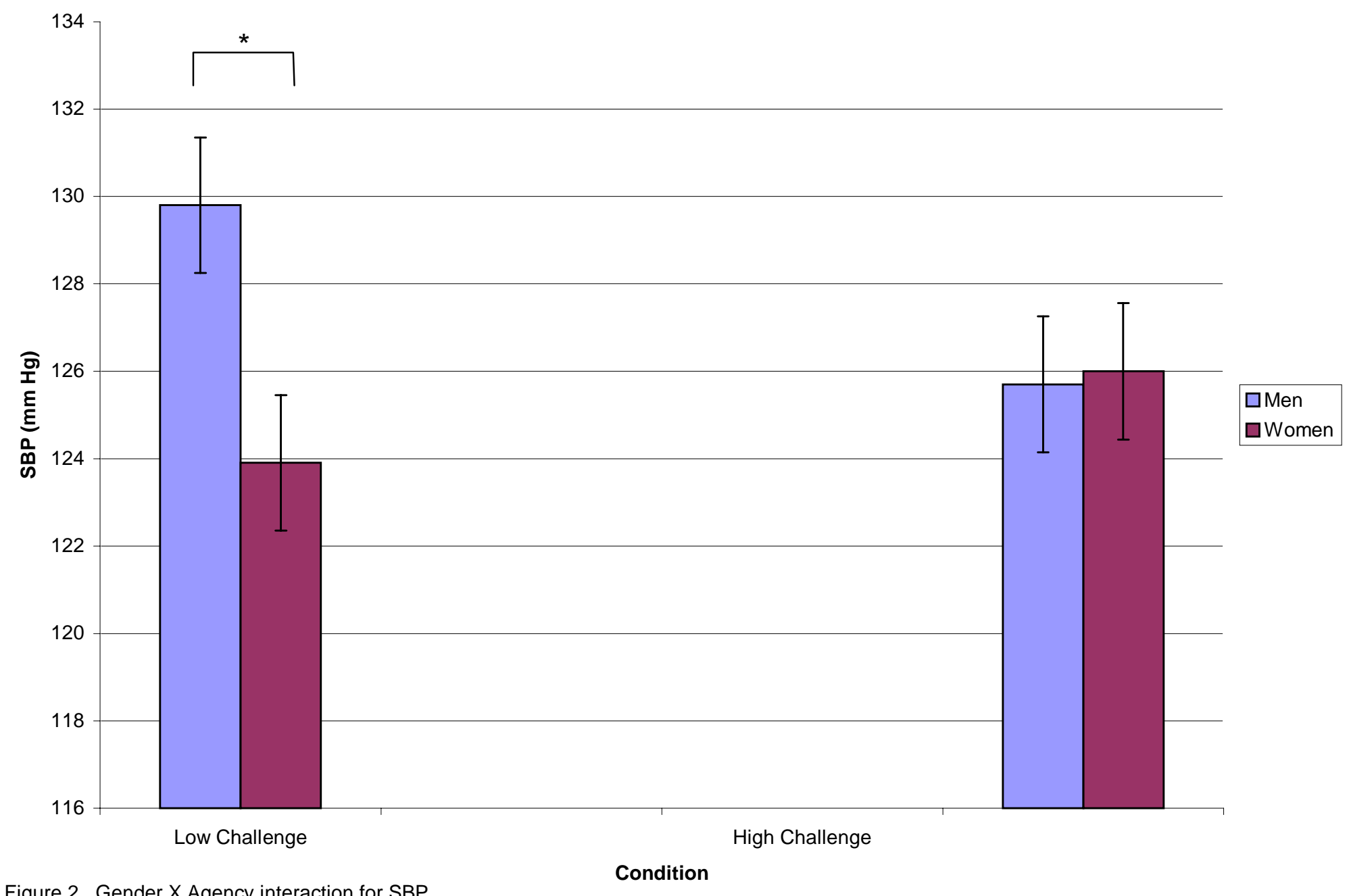

Figure 2. Gender X Agency interaction for SBP. 


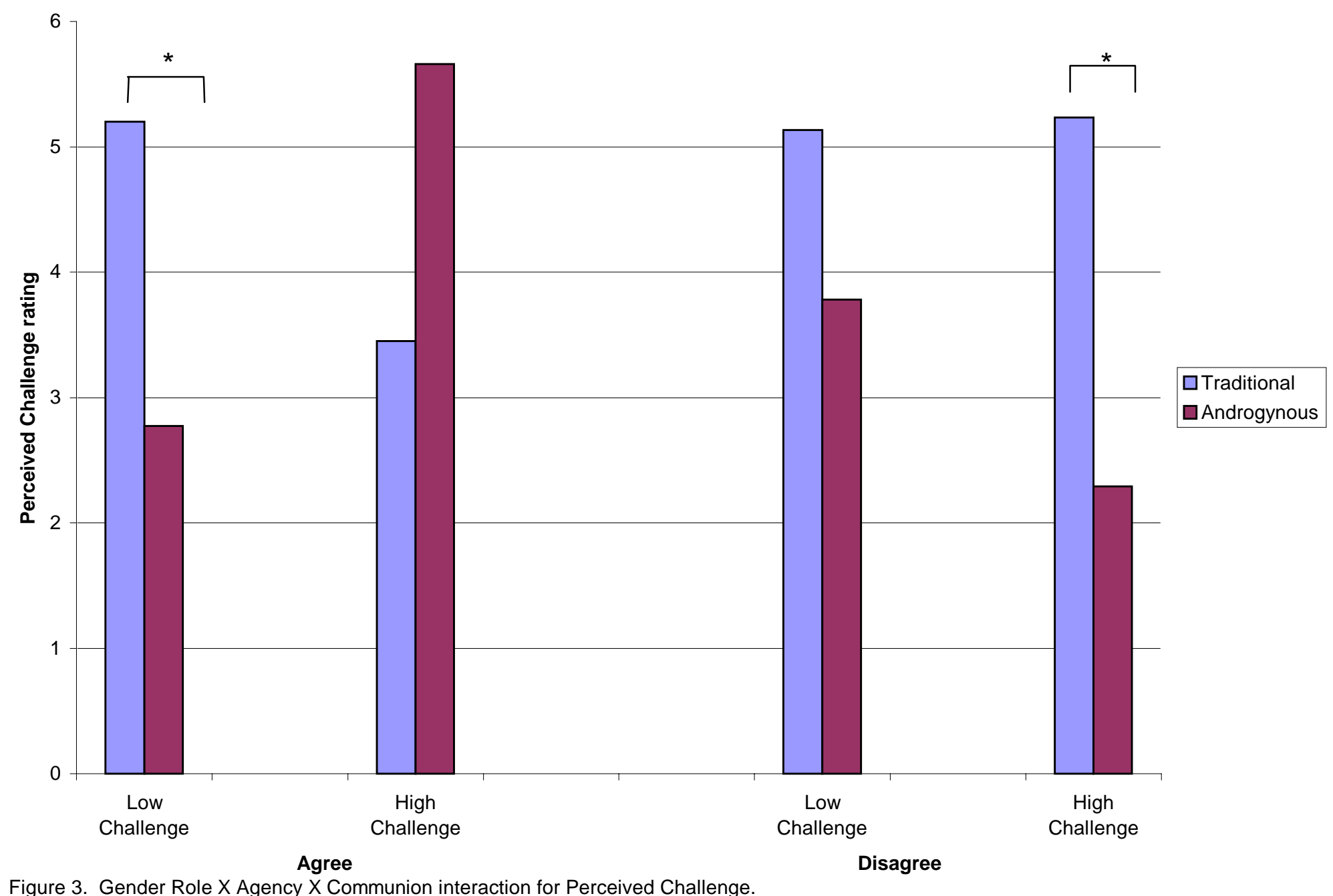

Figure 3. Gender Role X Agency X Communion interaction for Perceived Challenge. 


$$
1111
$$




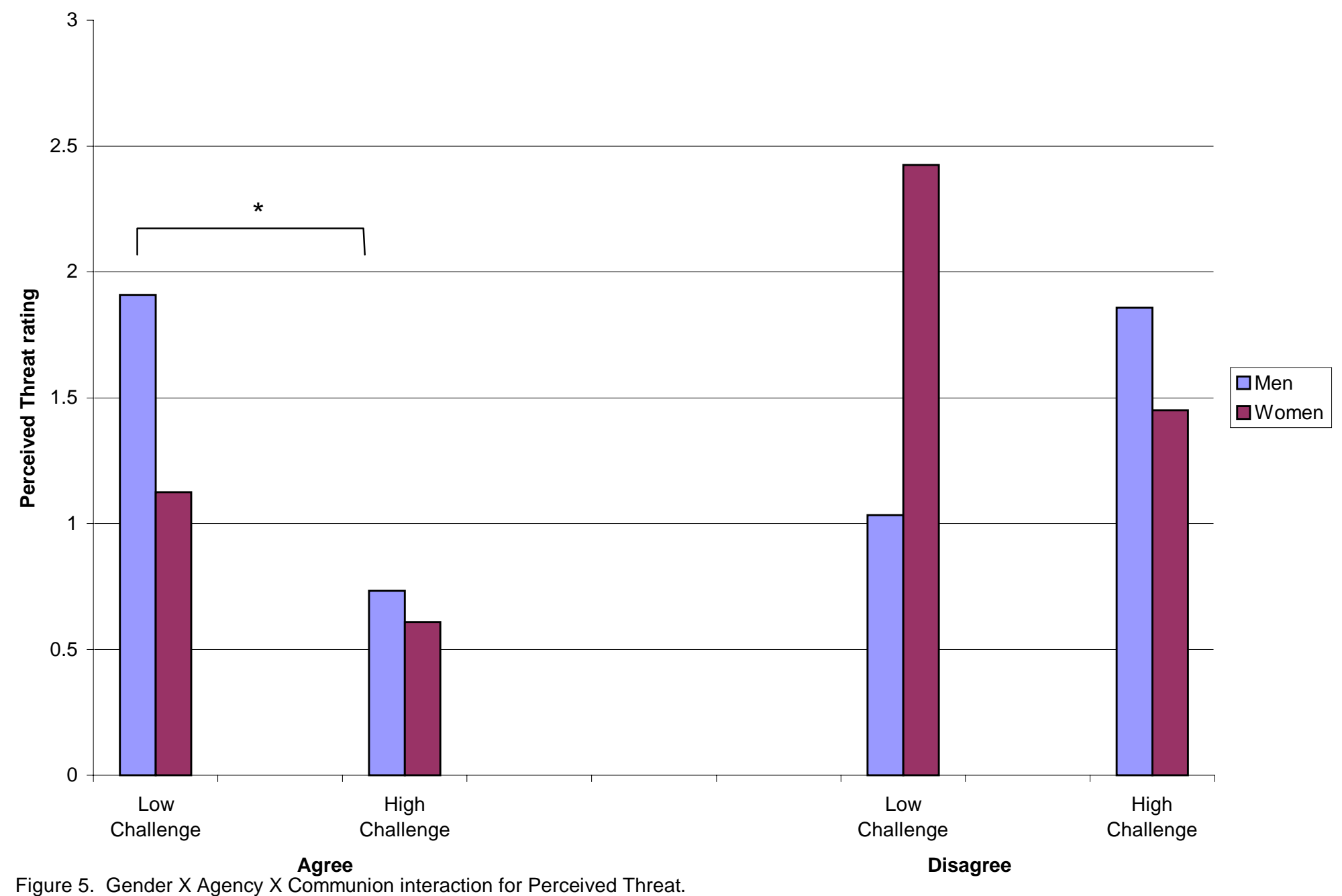




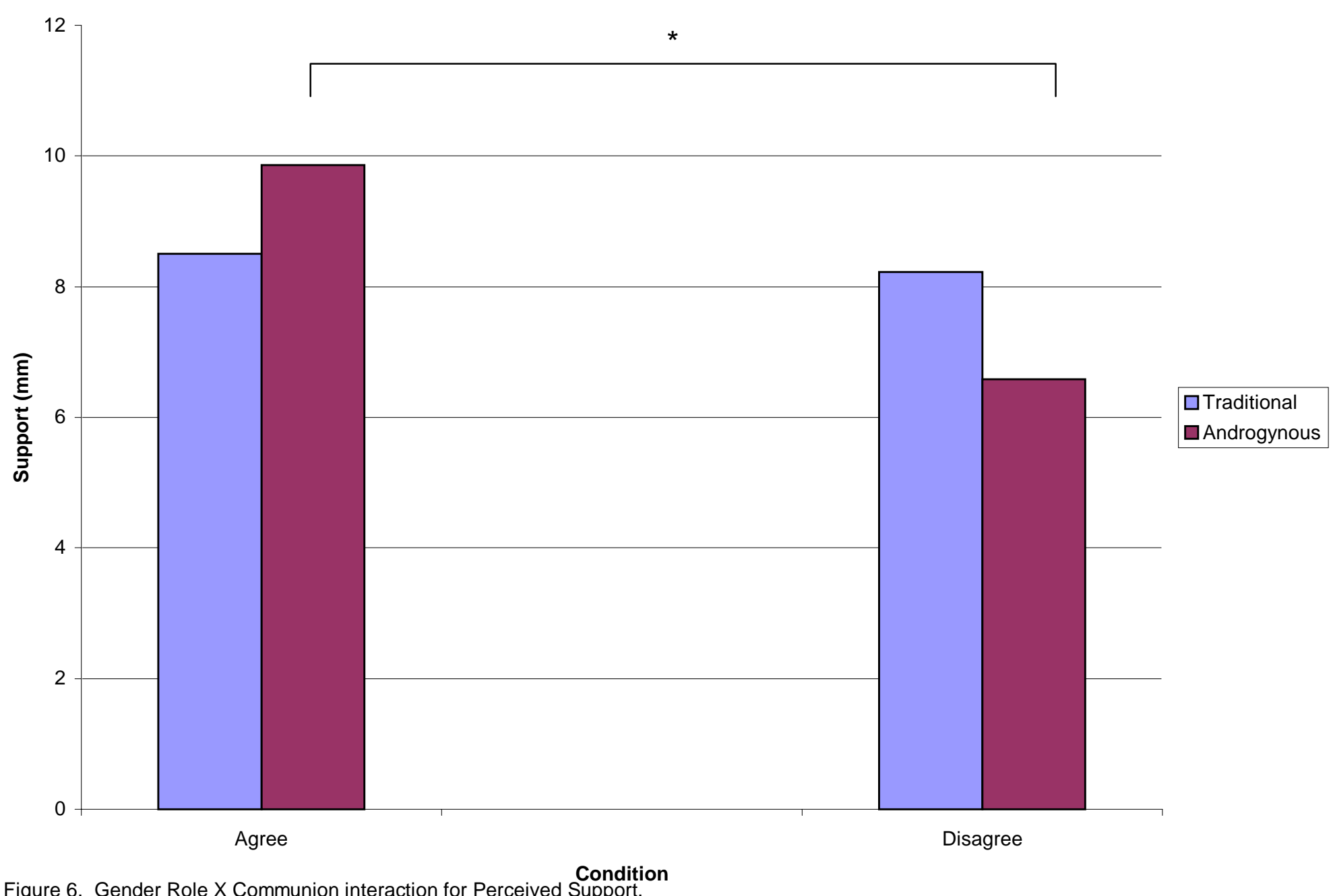




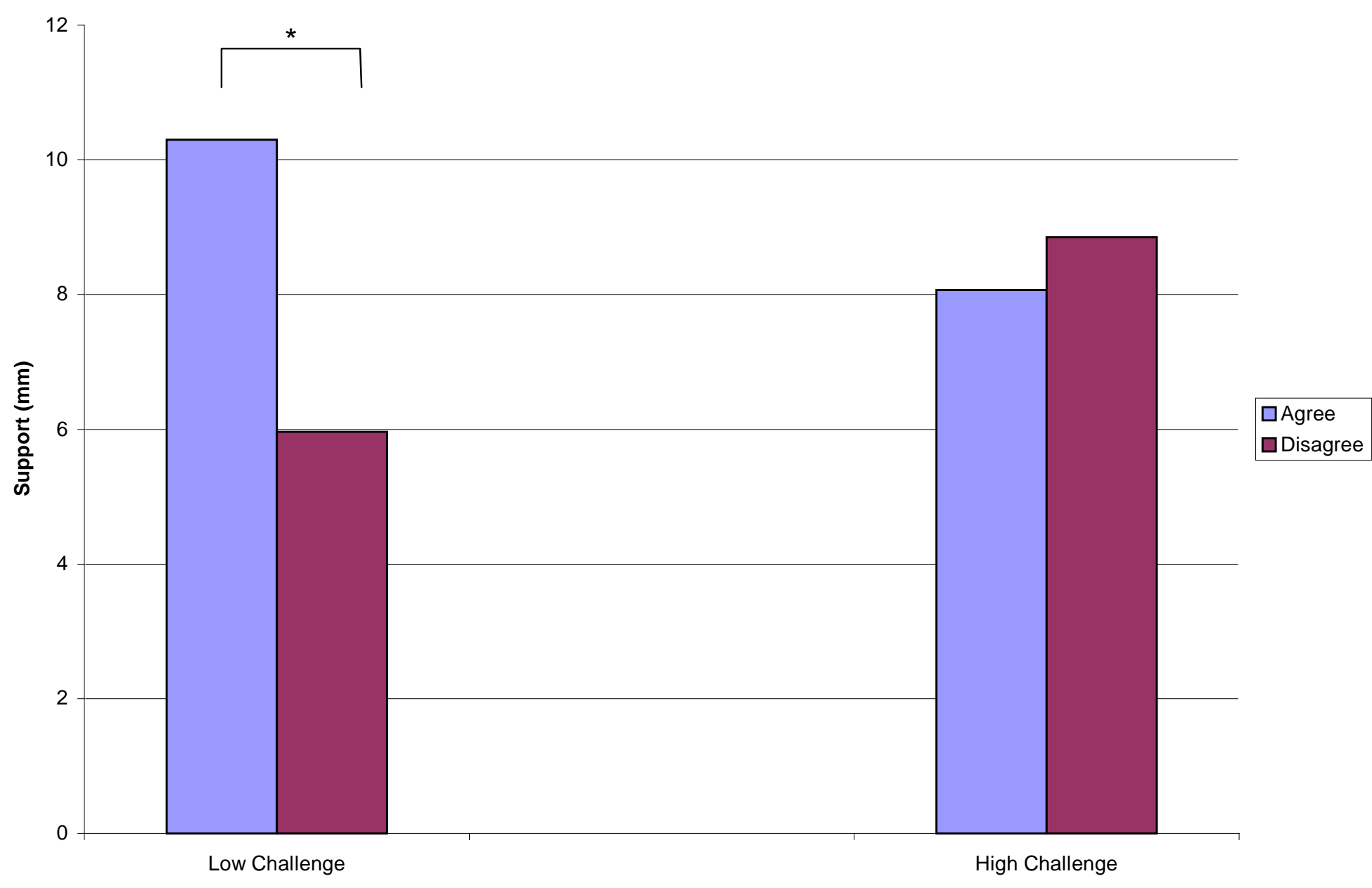

Figure 7. Agency X Communion interaction for Perceived Support. 